\title{
Vitamin D in pediatric age: consensus of the Italian Pediatric Society and the Italian Society of Preventive and Social Pediatrics, jointly with the Italian Federation of Pediatricians
}

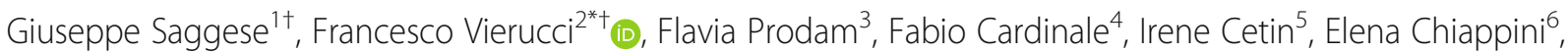 \\ Gian Luigi de' Angelis ${ }^{7}$, Maddalena Massari ${ }^{5}$, Emanuele Miraglia Del Giudice ${ }^{8}$, Michele Miraglia Del Giudice ${ }^{8}$, \\ Diego Peroni ${ }^{1}$, Luigi Terracciano ${ }^{9}$, Rino Agostiniani ${ }^{10}$, Domenico Careddu ${ }^{11}$, Daniele Giovanni Ghiglioni ${ }^{12}$, \\ Gianni Bona ${ }^{13}$, Giuseppe Di Mauro ${ }^{14}$ and Giovanni Corsello ${ }^{15}$
}

\begin{abstract}
Vitamin D plays a pivotal role in the regulation of calcium-phosphorus metabolism, particularly during pediatric age when nutritional rickets and impaired bone mass acquisition may occur.

Besides its historical skeletal functions, in the last years it has been demonstrated that vitamin D directly or indirectly regulates up to 1250 genes, playing so-called extraskeletal actions. Indeed, recent data suggest a possible role of vitamin D in the pathogenesis of several pathological conditions, including infectious, allergic and autoimmune diseases. Thus, vitamin D deficiency may affect not only musculoskeletal health but also a potentially wide range of acute and chronic conditions. At present, the prevalence of vitamin D deficiency is high in Italian children and adolescents, and national recommendations on vitamin D supplementation during pediatric age are lacking. An expert panel of the Italian Society of Preventive and Social Pediatrics reviewed available literature focusing on randomized controlled trials of vitamin D supplementation to provide a practical approach to vitamin D supplementation for infants, children and adolescents.
\end{abstract}

Keywords: Vitamin D, Supplementation, Children, Adolescents, Deficiency, Hypovitaminosis D

\section{Background}

Vitamin D plays a fundamental role in regulating calcium and phosphorus homeostasis and, in particular, the pathways involved in bone mineralization and bone mass acquisition. Besides these classic skeletal actions, recent studies have demonstrated that vitamin D exerts other significant extraskeletal actions, with a possible role in the pathogenesis of several pathological conditions, including infectious and autoimmune diseases [1]. The term 'vitamin $D^{\prime}$ is used for two different forms which are found in

\footnotetext{
* Correspondence: vieruf@hotmail.it

${ }^{\dagger}$ Equal contributors

${ }^{2}$ Pediatric Unit, San Luca Hospital, Lucca, Italy

Full list of author information is available at the end of the article
}

nature: vitamin $\mathrm{D}_{3}$ (cholecalciferol) from animal sources and vitamin $\mathrm{D}_{2}$ (ergocalciferol) from plants. Humans synthesize vitamin $D_{3}$ in their skin in response to sunlight exposure and vitamin $D_{2}$ and $D_{3}$ may be supplied from dietary sources, although only a few foods contain significant amounts (Table 1). Thus, with the exclusion of artificially fortified foods, the contribution of dietary intakes may be considered negligible $[2,3]$. Previtamin $D_{3}$ is produced in the skin following ultraviolet B irradiation (at wavelengths between 290 and $315 \mathrm{~nm}$ ) of the 7dehydrocholesterol present in all the layers of human skin, mainly in the epidermis. Previtamin $\mathrm{D}_{3}$ is an unstable molecule, subsequently transformed in vitamin $\mathrm{D}_{3}$ by a process of thermo-conversion. Once previtamin $\mathrm{D}_{3}$ is synthesized

(C) The Author(s). 2018 Open Access This article is distributed under the terms of the Creative Commons Attribution 4.0 International License (http://creativecommons.org/licenses/by/4.0/), which permits unrestricted use, distribution, and 
Table 1 Vitamin D content in some foods

\begin{tabular}{ll}
\hline Food & Vitamin D average content (IU) \\
\hline Milk and dairy products & \\
Cow's milk & $5-40 / 1$ \\
Goat's milk & $5-40 / 1$ \\
Butter & $30 / 100 \mathrm{~g}$ \\
Yogurt & $2.4 / 100 \mathrm{~g}$ \\
Cream & $30 / 100 \mathrm{~g}$ \\
Other Foods & \\
Pork & $40-50 / 100 \mathrm{~g}$ \\
$\begin{array}{l}\text { Beef liver } \\
\text { Snapper (genus Dentex dentex), cod, }\end{array}$ & $40-50 / 100 \mathrm{~g}$ \\
gilthead (Sparus auratus), dogfish & \\
(Mustelus mustelus), sole, trout, salmon, & \\
herring & \\
Cod liver oil & $400 / 5 \mathrm{ml}$ \\
Egg yolk & $20 / 100 \mathrm{~g}$ \\
\hline
\end{tabular}

in the skin, it can undergo also a photoconversion to lumisterol and tachysterol, solar photoproducts inactive on calcium metabolism that are produced at times of prolonged exposure to solar UV-B radiation, to prevent sun-induced vitamin $\mathrm{D}$ intoxication. Vitamin $\mathrm{D}_{2}$ and $\mathrm{D}_{3}$ are transported by vitamin $\mathrm{D}$ binding protein to the liver, where they are 25 hydroxylated by the vitamin D-25-hydroxylase (CYP2R1) to produce 25-hydroxyvitamin D $[25(\mathrm{OH}) \mathrm{D}]$, the major circulating vitamin D metabolite which is used to evaluate individual vitamin D status. Then $25(\mathrm{OH}) \mathrm{D}$ reaches the kidney, where it undergoes a further hydroxylation by $25(\mathrm{OH})$ D-1 $\alpha$-hydroxylase (CYP27B1) into 1,25-dihydroxyvitamin D $\left[1,25(\mathrm{OH})_{2} \mathrm{D}\right.$ or calcitriol], the bioactive hormonal form of vitamin D $[2,4]$. Calcitriol is able to regulate calciumphosphorus balance in various pathways, first stimulating calcium and phosphorus absorption by enterocytes. When dietary calcium intakes are inadequate, calcitriol interacts with the vitamin D receptor (VDR) expressed on osteoblasts, bringing osteoclasts precursors to maturation and promoting calcium and phosphorus absorption by bone tissue. Calcitriol acts synergistically with parathormone $(\mathrm{PTH})$ that acts in bone stimulating calcium absorption by the osteoclasts, and in the kidney where it promotes calcium reuptake in the tubules, phosphorus excretion, and vitamin $\mathrm{D}$ conversion into its active hormone form [2].

\section{Methods}

This document represents a consensus opinion of experts derived from current literature revision and it is intended to be mainly directed to hospital or primary care pediatricians. The main objective is to give recommendations regarding the prevention and treatment of vitamin $\mathrm{D}$ deficiency in Italian children and adolescents (0-18 years), considering both the skeletal and extra-skeletal effects of vitamin D and potential risk factors in specific subgroups of children. The Working Group agreed on a list of relevant clinical topics. Using the Consensus Conference method based on the National Institutes of Health and the Italian National Programme Guidelines [5, 6], relevant publications in English limited to the pediatric age $(<18$ years) were identified by a review of MEDLINE by PubMed, from 1st January 2005 to 1st August 2017, and using appropriate search strategies for each topic. Checklists and predefined tables were used to assess study quality and to extract data in a standard way. Further literature search was performed focusing available international guidelines on vitamin $\mathrm{D}$ supplementation in children. The panel will be taking up the issue again in 2 years, and will promote a new consensus conference if clinically relevant evidence has emerged from new studies. The full text of the guidelines and related documents in Italian are available at the site of the Italian Society of Preventive and Social Pediatrics [7].

\section{Vitamin D deficiency: Ranges, analytic methods, and epidemiology}

The major circulating form of vitamin $\mathrm{D}$ is $25(\mathrm{OH}) \mathrm{D}$, having a half-life of $2-3$ weeks. It is the best marker to monitor for vitamin D status. In literature, several cut-offs have been proposed for vitamin $\mathrm{D}$ deficiency with respect to serum 25(OH)D levels measured with a reliable assay. These cut-offs derive from PTH feedback threshold, calcium intestinal absorption and bone health (presence of rickets/osteomalacia, low bone mass and/or mineral content, fracture risk) [8-30] (Table 2). On the other hand, the majority of the studies have been realized in adults.

Severe vitamin D deficiency is defined as $25(\mathrm{OH}) \mathrm{D}$ levels $<10 \mathrm{ng} / \mathrm{ml}$ by several Authors and Societies because the risk of rickets is high below this cut-off also in presence of an adequate calcium intake [31-33] (see chapter "Nutritional rickets"). The prevalence of rickets is also significant with $25(\mathrm{OH}) \mathrm{D}$ levels of $10-15 \mathrm{ng} / \mathrm{ml}$ in case of a low calcium intake [31, 33]. In the majority of studies in adults, $25(\mathrm{OH}) \mathrm{D}$ levels of at least $20 \mathrm{ng} / \mathrm{ml}$ meet the needs of at least $97.5 \%$ of the population with regards to bone health $[10,11]$, while serum $25(\mathrm{OH}) \mathrm{D}$ levels $\geq 30 \mathrm{ng} / \mathrm{ml}$ are sufficient in about $100 \%$ of the adults $[10,11]$. Secondary hyperparathyroidism generally develops with 25(OH)D levels $<20 \mathrm{ng} / \mathrm{ml}$, and PTH levels reach a plateau at 25(OH)D levels of 30-40 ng/ $\mathrm{ml}$ [34-37]. However, some Authors showed that the relationship between PTH and 25(OH)D levels may be influenced by many factors as age, gender, ethnicity, and weight [38, 39]. Few studies evaluated the relationship between 25(OH)D and $\mathrm{PTH}$ in pediatrics, thus defining a threshold is even more complex [40-48]. A study on 1370 Canadian infants (1-6 years) observed the PTH plateau at 25(OH)D levels $>42.8 \mathrm{ng} / \mathrm{ml}$ [49], whereas an Italian study on children and adolescents reported a lower prevalence of secondary hyperparathyroidism at 25(OH)D levels of 20-29 ng/ml, but 
Table 2 Definition of vitamin D status according to several Societies and Organizations in the last 10 years

\begin{tabular}{|c|c|c|c|c|c|}
\hline Society/Organization & Year & Severe deficiency & Deficiency & Insufficiency & Sufficiency/Adequacy \\
\hline Canadian Pediatric Society [8] & 2007 & - & $<10 \mathrm{ng} / \mathrm{ml}$ & $10-29 \mathrm{ng} / \mathrm{ml}$ & $\geq 30 \mathrm{ng} / \mathrm{ml}$ \\
\hline Lawson Wilkins Pediatric Endocrine Society [9] & 2008 & $<5 \mathrm{ng} / \mathrm{ml}$ & $5-14 \mathrm{ng} / \mathrm{ml}$ & $15-19 \mathrm{ng} / \mathrm{ml}$ & $\geq 20 \mathrm{ng} / \mathrm{ml}$ \\
\hline Institute of Medicine [10] & 2011 & - & $<12 \mathrm{ng} / \mathrm{ml}$ & $12-20 \mathrm{ng} / \mathrm{ml}^{\mathrm{a}}$ & $\geq 20 \mathrm{ng} / \mathrm{ml}$ \\
\hline The Endocrine Society [11] & 2011 & - & $<20 \mathrm{ng} / \mathrm{ml}$ & $21-29 \mathrm{ng} / \mathrm{ml}$ & $\geq 30 \mathrm{ng} / \mathrm{ml}$ \\
\hline British Paediatric and Adolescent Bone Group [12] & 2012 & - & $<10 \mathrm{ng} / \mathrm{ml}$ & $10-19 \mathrm{ng} / \mathrm{ml}$ & $\geq 20 \mathrm{ng} / \mathrm{ml}$ \\
\hline French Society of Paediatrics [13] & 2012 & - & $<20 \mathrm{ng} / \mathrm{ml}$ & - & $\geq 20 \mathrm{ng} / \mathrm{ml}$ \\
\hline Asociación Espanola de Pediatría (Spain) [14] & 2012 & - & $<20 \mathrm{ng} / \mathrm{ml}$ & - & $\geq 20 \mathrm{ng} / \mathrm{ml}$ \\
\hline Federal Commission for Nutrition (Switzerland) [15] & 2012 & $<10 \mathrm{ng} / \mathrm{ml}$ & $<20 \mathrm{ng} / \mathrm{ml}$ & - & $\geq 20 \mathrm{ng} / \mathrm{ml}$ \\
\hline Nordic Nutrition Recommendations [16] & 2012 & - & $<12 \mathrm{ng} / \mathrm{ml}$ & $12-20 \mathrm{ng} / \mathrm{ml}$ & $\geq 20 \mathrm{ng} / \mathrm{ml}$ \\
\hline German Nutrition Society [17] & 2012 & - & - & - & $\geq 20 \mathrm{ng} / \mathrm{ml}$ \\
\hline Health council of the Netherlands [18] & 2012 & - & - & - & $\geq 12 \mathrm{ng} / \mathrm{ml}$ \\
\hline $\begin{array}{l}\text { European Society for Paediatric Gastroenterology } \\
\text { Hepatology and Nutrition [19] }\end{array}$ & 2013 & $<10 \mathrm{ng} / \mathrm{ml}$ & $<20 \mathrm{ng} / \mathrm{ml}$ & - & $\geq 20 \mathrm{ng} / \mathrm{ml}$ \\
\hline Central Europe [20] & 2013 & - & $<20 \mathrm{ng} / \mathrm{ml}$ & $20-29 \mathrm{ng} / \mathrm{ml}$ & $\geq 30 \mathrm{ng} / \mathrm{ml}$ \\
\hline Society for Adolescent Health and Medicine [21] & 2013 & - & $<20 \mathrm{ng} / \mathrm{ml}$ & $20-29 \mathrm{ng} / \mathrm{ml}$ & $\geq 30 \mathrm{ng} / \mathrm{ml}$ \\
\hline Australia/New Zealand [22] & 2013 & $<5 \mathrm{ng} / \mathrm{ml}$ & $5-11 \mathrm{ng} / \mathrm{ml}$ & $12-19 \mathrm{ng} / \mathrm{ml}$ & $\geq 20 \mathrm{ng} / \mathrm{ml}$ \\
\hline American Academy of Pediatrics [23] & 2014 & - & $<20 \mathrm{ng} / \mathrm{ml}$ & - & $\geq 20 \mathrm{ng} / \mathrm{ml}$ \\
\hline $\begin{array}{l}\text { Japanese Society for Bone and Mineral Research, } \\
\text { Japan Endocrine Society }{ }^{b}[24]\end{array}$ & 2015 & - & $<20 \mathrm{ng} / \mathrm{ml}$ & - & - \\
\hline Scientific Advisory Committee on Nutrition [25] & 2016 & - & - & - & $\geq 10 \mathrm{ng} / \mathrm{ml}$ \\
\hline European Food Safety Authority [26] & 2016 & - & - & - & $\geq 20 \mathrm{ng} / \mathrm{ml}$ \\
\hline United Arab Emirates [27] & 2016 & - & $<20 \mathrm{ng} / \mathrm{ml}$ & $20-29 \mathrm{ng} / \mathrm{ml}$ & $\geq 30 \mathrm{ng} / \mathrm{ml}$ \\
\hline Global Consensus for rickets [28] & 2016 & - & $<12 \mathrm{ng} / \mathrm{ml}$ & $12-19 \mathrm{ng} / \mathrm{ml}$ & $\geq 20 \mathrm{ng} / \mathrm{ml}$ \\
\hline $\begin{array}{l}\text { Japanese Society for Bone and Mineral Research, } \\
\text { Japan Endocrine Society }{ }^{C}[29]\end{array}$ & 2017 & - & $<20 \mathrm{ng} / \mathrm{ml}$ & $20-29 \mathrm{ng} / \mathrm{ml}$ & $\geq 30 \mathrm{ng} / \mathrm{ml}$ \\
\hline European Academy of Pediatrics [30] & 2017 & \multicolumn{4}{|c|}{ Definition of vitamin $D$ status is unclear due to a lack of consensus } \\
\hline
\end{tabular}

aitamin D inadequacy

bDiagnostic criteria for rickets

${ }^{c}$ Assessment criteria for vitamin D deficiency/insufficiency (authors reported that different criteria may be needed for children)

no cases were detected above $30 \mathrm{ng} / \mathrm{ml}$ [50]. Moreover, no clear evidence of a threshold for calcium absorption was found with several $25(\mathrm{OH}) \mathrm{D}$ ranges in pediatrics. This could be due by an age-dependent more efficient calcium absorption, a compensatory absorption vitamin $\mathrm{D}$-independent and a higher conversion to calcitriol $[44,51,52]$. Also when bone health is considered, the studies are relatively small (see chapter "Bone health"). A positive association between 25( $\mathrm{OH}) \mathrm{D}$ levels, bone mineral content (BMC), and bone mineral density (BMD) has been reported in children and adolescents, in particular from the peripuberty, without a specific threshold [53]. Moreover, a recent study in Chinese infants (0-7 years) showed that when serum 25(OH)D levels were above $30 \mathrm{ng} / \mathrm{ml}$, the prevalence of low tibial BMD (assessed by quantitative ultrasound) reached a plateau [54]. Based on the above considerations, we suggest to define vitamin D status as reported in Table 3.

Vitamin D status is defined by the measurement of 25(OH)D concentrations. This term refers to both its circulating forms, the $25(\mathrm{OH}) \mathrm{D}_{3}$ and $25(\mathrm{OH}) \mathrm{D}_{2}$, the last from plant dietary sources. $1,25(\mathrm{OH})_{2} \mathrm{D}$ measurement does not reflect vitamin D status, owing to the short half-life (4$6 \mathrm{~h}$ ) and the lower concentration ( $\mathrm{pg} / \mathrm{ml}$ vs. $\mathrm{ng} / \mathrm{ml}$ ). $1,25(\mathrm{OH})_{2} \mathrm{D}$ levels are reduced only when $25(\mathrm{OH}) \mathrm{D}$ levels are below $4 \mathrm{ng} / \mathrm{ml}$. The measurement of $25(\mathrm{OH}) \mathrm{D}$ is difficult due to its lipophilic nature, the binding to vitamin $\mathrm{D}$ binding protein, the different circulating forms that also include epimers and isobars, and the standardization. In particular, the 24,25-dihydroxyvitamin D may represent up to $10-15 \%$ of the total quantity of $25(\mathrm{OH}) \mathrm{D}$ [55]. Various

Table 3 Cut-off points for the definition of vitamin D status based on circulating levels of $25(\mathrm{OH}) \mathrm{D}$

\begin{tabular}{cllll}
\hline $\begin{array}{l}\text { Severe } \\
\text { deficiency }\end{array}$ & Deficiency & Insufficiency & Sufficiency \\
\hline $25(\mathrm{OH}) \mathrm{D}$ & $<10 \mathrm{ng} / \mathrm{ml}$ & $<20 \mathrm{ng} / \mathrm{ml}$ & $20-29 \mathrm{ng} / \mathrm{ml}$ & $\geq 30 \mathrm{ng} / \mathrm{ml}$ \\
& $(<25 \mathrm{nmol} / \mathrm{l})$ & $(<50 \mathrm{nmol} / \mathrm{l})$ & $(50-74 \mathrm{nmol} / \mathrm{l})$ & $(\geq 75 \mathrm{nmol} / \mathrm{l})$ \\
\hline
\end{tabular}

Conversion factor: $\mathrm{ng} / \mathrm{ml}=\mathrm{nmol} / \mathrm{I}^{*} 0.401 ; \mathrm{nmol} / \mathrm{l}=\mathrm{ng} / \mathrm{ml}{ }^{*} 2.496$ 
methods are available for determining 25(OH)D concentration, from the low-throughput radioimmunoassay techniques to the new automated immunoassays with high capacity, which in some cases still present poor accuracy and precision [56, 57].The National Institute of Standards and Technology has developed the stock standards for the measurements of $25(\mathrm{OH}) \mathrm{D}_{3} / \mathrm{D}_{2}$ levels through isotopedilution liquid chromatography-tandem mass spectrometry (LC-MS/MS) methods [58]. The issue of international standardization of serum $25(\mathrm{OH}) \mathrm{D}$ measurement is also being progressed by the Vitamin D Standardization Program. The standardization, also retrospectively, should help to develop future vitamin D guidelines $[59,60]$. The isotope-dilution LC-MS/MS is the standard method to always use in the neonates, because it is able to detect the serum $\mathrm{C} 3$ epimer of $25(\mathrm{OH}) \mathrm{D}_{3}$, that may represent up to the $40 \%$ of the total quantity of $25(\mathrm{OH}) \mathrm{D}$ [61-63]. When a patient is under treatment with ergocalciferol, measurements able to detect $25(\mathrm{OH}) \mathrm{D}_{2}$ are needed to avoid the risk of hypervitaminosis D [64]. Because LC-MS/MS methods are not so frequently used in clinical practice, at the moment other reliable assays could be used and certified laboratories are suggested. The measurement of free $25(\mathrm{OH})$ $\mathrm{D}$ has not been standardized. Moreover, current algorithms to calculate free $25(\mathrm{OH}) \mathrm{D}$ may not be accurate [65].

Hypovitaminosis D and vitamin D deficiency, independently from cut-off definitions, have a higher prevalence worldwide in any age. In pediatrics, US data derived by the National Health and Nutrition Examination Survey cohort indicate a prevalence ranging 9-18\%, and $51-61 \%$ of vitamin D deficiency and hypovitaminosis D, respectively [66, 67]. A recent meta-analysis was conducted on all the cohort studies of the European population, basing also on a pediatric population of 14971 subjects (1-18 years) [68]. The Authors applied the Vitamin D standardization Program and developed protocols for standardizing existing 25(OH)D values from national health/nutrition surveys. The prevalence according to age (1-6 years, 7-14 years, and 15-18 years) ranged $4-7 \%, 1-$ $8 \%$, and $12-40 \%$, respectively, suggesting that particular attention should be kept not only in infants but also in adolescents. Non-white subjects and those living at relatively mild-latitude countries $\left(47-60^{\circ} \mathrm{N}\right)$ had a higher prevalence range (5-20\%) than southern countries. Limitations of the study include the fact that some of the studies mainly included children aged 7-11 years, and that vitamin D supplements, food fortification or sun awareness campaigns could have influenced the estimates. Data from Italian pediatrics are only limited being represented by the Roma cohort (12.5-17.5 years) included in the HELENA study [68].

Other Italian data are present in literature, although they show some limitations, regarding small populations, analytic methods for $25(\mathrm{OH}) \mathrm{D}$, the season of recruitment, the prevalence of overweight/obesity, vitamin D supplements, sunscreens, ethnicity, and uncovered areas of latitude. Despite these points, Italian data are in line with those reported above, with higher prevalence in neonates, in particular in those not Caucasian, in adolescents and in overweight/obese subjects [50, 69-84]. Interestingly, also the more limited estimates in southern Italy parallel those of northern areas. Table 4 summarizes published studies in Italian populations.

\section{Sources of vitamin D and dietary reference values}

Most of the vitamin D we synthesize (90\%) starts with skin exposure to ultraviolet B radiation from the sun. Cutaneous vitamin $\mathrm{D}_{3}$ production is influenced by several factors, such as skin pigmentation, latitude, altitude, seasonality, daily timing of sun exposure, atmospheric pollution, percentage of skin area exposed, type of clothing, and sunscreen use. Children require less sunlight exposure than adults to produce sufficient quantities of vitamin $\mathrm{D}$, both because of their higher body surface-area-to-volume ratio and of their increased capacity to produce vitamin D [85]. In Italy children are unable to synthesize vitamin D in the skin during late fall, winter months and early spring, even if sufficiently exposed to sunlight [50]. Thus, during this period an adequate vitamin $\mathrm{D}$ status can be maintained only from endogenous stores accumulated during previous summer or by exogenous supplementation.

Breast milk represents the best food to satisfy children's nutritional needs, although it contains insufficient amount of vitamin D (<50 IU/l) [86]. Vitamin D intake of formula fed infants varies according to the vitamin content (about $400 \mathrm{IU} / \mathrm{l}$ ) and daily formula intakes. Considering water requirements, formula fed infants may receive $400 \mathrm{IU} /$ day of vitamin $\mathrm{D}$, which is adequate for the first year of life [10], only when they come to weigh 5 to $6 \mathrm{Kg}$. However, children are weaned by the time they reach this weight and this further reduces their daily milk consumption [1].

Most foods contain little amounts of vitamin D, with the exception of some fatty fish (Table 1), rarely eaten by children $[9,87]$. Thus, dietary sources of vitamin D should not be considered significant for humans except some populations living at higher latitudes where fish, fish oil and fish eggs are frequently consumed [88]. In Italy, few commercial milks or yoghurts are supplemented with vitamin D and/or calcium. Nonetheless, despite the presence of this vitamin in fortified milk, amounts can be insufficient in respect of recommended intakes and needs. These foods, therefore, fail to represent an optimal solution for the prevention of vitamin-D deficiency among children and adolescents [50].

In the last years various Organizations and Societies $[10,11,16-18,25,26,89]$ revised dietary reference values of vitamin $\mathrm{D}$ in infants, children, and adolescents, as reported in Table 5. In 2016 the United Kingdom 


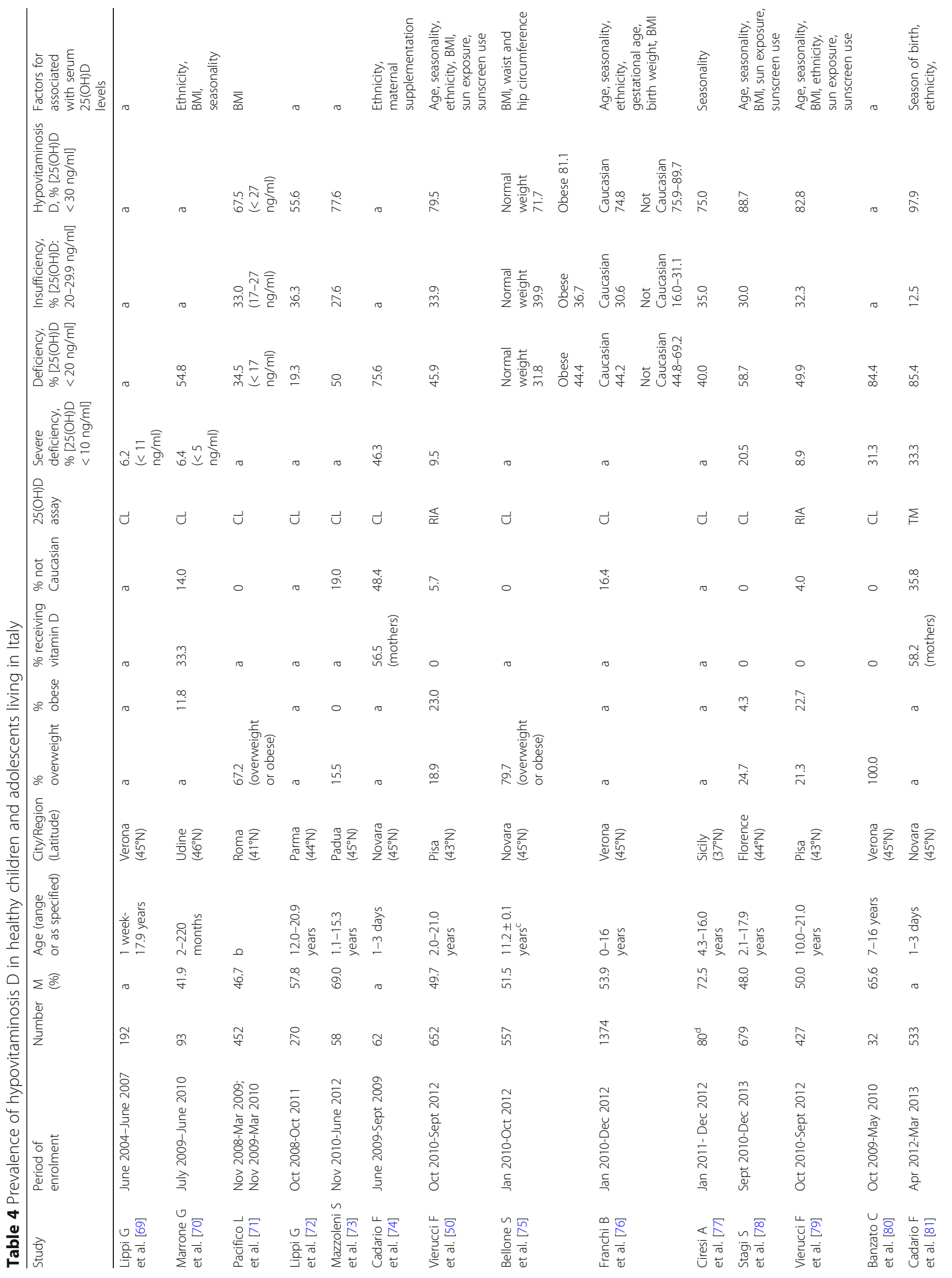




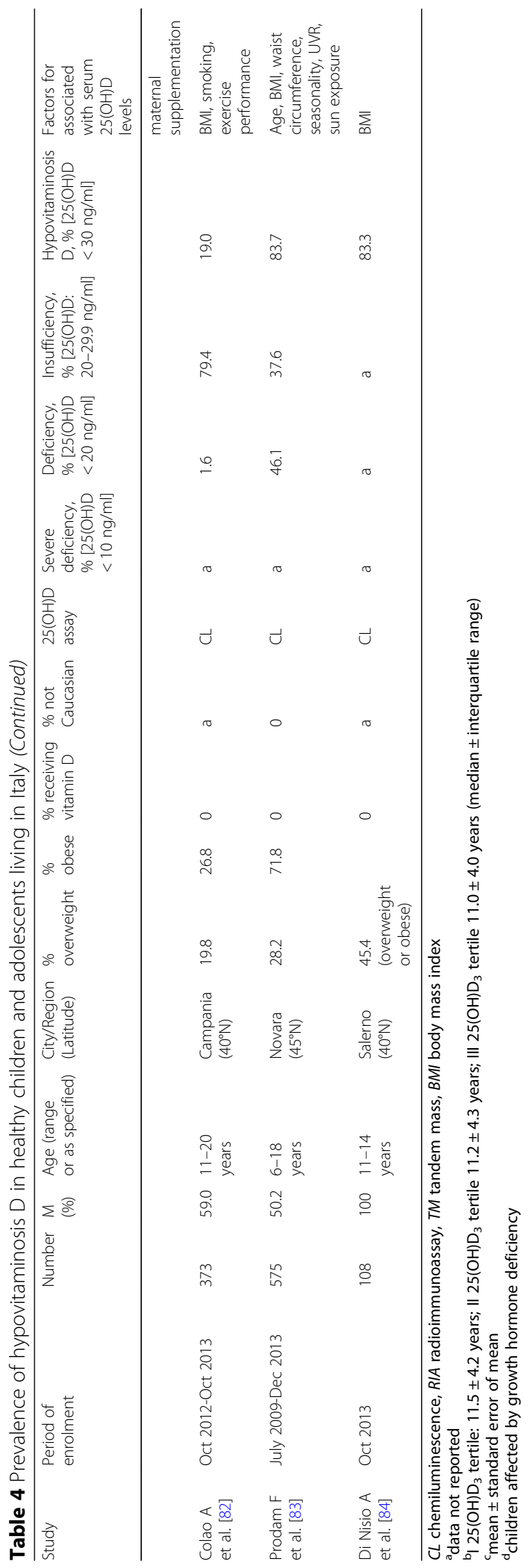


Table 5 Dietary reference values of vitamin D in infants, children, and adolescents as proposed by various Organizations and Societies

\begin{tabular}{|c|c|c|c|c|c|}
\hline Organization/Society & Year & Country/Countries & $\begin{array}{l}\text { Dietary reference } \\
\text { value for vitamin } D\end{array}$ & $\begin{array}{l}0-12 \text { months, } \\
\text { IU/day }\end{array}$ & $\begin{array}{l}1-18 \text { years, } \\
\text { IU/day }\end{array}$ \\
\hline $\begin{array}{l}\text { European Food Safety } \\
\text { Authority [26] }\end{array}$ & 2016 & Europe & $\mathrm{Al}$ & 400 (7-11 months) & 600 (1-17 years) \\
\hline \multirow{2}{*}{$\begin{array}{l}\text { Scientific Advisory Committee } \\
\text { on Nutrition [25] }\end{array}$} & \multirow[t]{2}{*}{2016} & \multirow[t]{2}{*}{ United Kingdom } & Safe Intake (< 4 years) & \multirow[t]{2}{*}{$340-400$} & \multirow[t]{2}{*}{400} \\
\hline & & & RNI (4-18 years) & & \\
\hline $\begin{array}{l}\text { Nordic Nutrition } \\
\text { Recommendations [16] }\end{array}$ & 2012 & $\begin{array}{l}\text { Denmark, Finland, Iceland, Norway, Sweden, } \\
\text { Faroe Islands, Greenland, Åland Islands }\end{array}$ & $\mathrm{Rl}$ & 400 & 400 \\
\hline German Nutrition Society [17] & 2012 & Germany, Austria, Switzerland & Al & 400 (infants) & $800^{\mathrm{a}}$ (children) \\
\hline $\begin{array}{l}\text { Health Council of the } \\
\text { Netherlands [18] }\end{array}$ & 2012 & The Netherlands & $\mathrm{Al}$ & 400 & 400 \\
\hline \multirow[t]{2}{*}{ Italian Society of Nutrition [89] } & \multirow[t]{2}{*}{2012} & \multirow[t]{2}{*}{ Italy } & Al (< 12 months) & \multirow[t]{2}{*}{400 (6-12 months) } & \multirow[t]{2}{*}{600} \\
\hline & & & PRI (1-18 years) & & \\
\hline \multirow[t]{2}{*}{ Institute of Medicine [10] } & \multirow[t]{2}{*}{2011} & \multirow[t]{2}{*}{ North America, Canada } & Al (< 12 months) & \multirow[t]{2}{*}{400} & \multirow[t]{2}{*}{600} \\
\hline & & & RDA (1-18 years) & & \\
\hline The Endocrine Society [11] & 2011 & Worldwide & Daily requirement ${ }^{\mathrm{b}}$ & $400-1000$ & $600-1000$ \\
\hline
\end{tabular}

Al Adequate Intake, the average observed daily level of intake by a population group of apparently healthy people that is assumed to be adequate

Safe Intake, a level or range of intakes considered to pose no risk of deficiency and below a level where there is a risk of undesirable effects

RNI Reference Nutrient Intake, the amount of a nutrient that is likely to meet the needs of $97.5 \%$ of the population

RI Recommended Intake, the amount of a nutrient that meets the known requirement and maintains good nutritional status among practically all (97-98\%)

healthy individuals in a particular life stage or gender group

PRI Population Reference Intake, the level of nutrient intake sufficient to satisfy the needs of almost all (97.5\%) healthy subjects in one specific population group

RDA Recommended Dietary Allowance, the estimated intake capable of satisfying the needs of $97.5 \%$ of the population

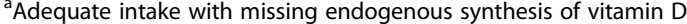

${ }^{\mathrm{b}}$ Recommended requirements for subjects at risk of vitamin D deficiency

Scientific Advisory Committee on Nutrition (SACN) reviewed the evidence on vitamin $\mathrm{D}$ and health and recommended that serum $25(\mathrm{OH}) \mathrm{D}$ levels of all children and adolescents in the United Kingdom should not fall below $10 \mathrm{ng} / \mathrm{ml}$ (a so-called "population protective level") at any time of the year to protect musculoskeletal health. Assuming minimal sunshine exposure, SACN recommended a safe intake of 340-400 IU/day of vitamin D for infants under 1 year of life, a safe intake of $400 \mathrm{IU} /$ day for age 1 up to 4 years, and a reference nutrient intake of $400 \mathrm{IU} /$ day for the United Kingdom population aged 4 years and above [25]. In 2016 also the European Food Safety Authority (EFSA) revised dietary reference values for vitamin $\mathrm{D}$. Considering a serum $25(\mathrm{OH}) \mathrm{D}$ levels of $20 \mathrm{ng} / \mathrm{ml}$ as a suitable target value, under conditions of minimal cutaneous vitamin D synthesis EFSA recommended an adequate intake of $400 \mathrm{IU} /$ day for infants aged 7-11 months and of $600 \mathrm{IU} /$ day for children aged 1-17 years [26]. While there is sufficient global agreement in considering $400 \mathrm{IU} /$ day as dietary reference value for vitamin $\mathrm{D}$ during the first year of life, recommended reference values for children and adolescents (1-18 years) slightly differ between Organizations and Societies, reflecting different approaches and methods applied to calculate them. However, various dietary reference values for vitamin D are useful to guide local strategies for vitamin D supplementation, but are not directly comparable. Particularly, the Endocrine Society guidelines focused on patients at risk for vitamin $\mathrm{D}$ deficiency, recommending a vitamin D daily requirement of 400-1000 IU in the first years of life and of 600-1000 IU from 1 up to 18 years [11].

In accordance with the European Society for Paediatric Gastroenterology Hepatology and Nutrition [ESPGHAN] [19] and the European Academy of Pediatrics [30], we endorsed Tolerable Upper Intake Levels of vitamin D proposed by EFSA in 2012 (1000 IU/day for infants: $2000 \mathrm{IU} /$ day for children ages 1 to 10 years; $4000 \mathrm{IU} /$ day for children and adolescents ages 11 to 17 years) [90].

\section{Vitamin D supplementation}

\section{$0-12$ months}

Vitamin D supplementation in the first year of life is essential to ensure an adequate vitamin D status and to prevent nutritional rickets. Indeed, newborns and infants are poorly exposed to sunlight, as the Section on Dermatology of the American Academy of Pediatrics (AAP) recommended that infants younger than 6 months of age should be kept out of direct sunlight and covered with appropriate protective clothing and hats [91]. As previously discussed, breast milk [86] and formula milk [1] contain insufficient amount of vitamin D to prevent its deficiency. Moreover, newborns from deficient mothers are at increased risk for vitamin $\mathrm{D}$ deficiency as cord blood and neonatal 25(OH)D levels highly correlate with maternal vitamin $\mathrm{D}$ status during gestation [92, 93]. The importance of vitamin D supplementation 
during the first year of life has been confirmed by the finding that children not receiving supplementation have reduced serum 25(OH)D levels, particularly if exclusively breastfed and during winter season [94-96].

Some studies evaluated the effect of daily vitamin D supplementation at variable dosages (ranging from 200 to $1600 \mathrm{IU} /$ day) on vitamin D status in children during the first year of life [52, 62, 97-107]. The administration of $400 \mathrm{IU} /$ day starting from birth was effective in maintaining serum 25(OH)D levels $\geq 30 \mathrm{ng} / \mathrm{ml}$ [52, 62, 97-99, 103-107]. On the contrary, vitamin D supplementation at higher dosages seemed to be associated with increased risk of hypervitaminosis D with hypercalciuria and hypercalcemia [62]. Daily vitamin $\mathrm{D}_{2}$ or $\mathrm{D}_{3}$ administration was equally effective in increasing serum 25(OH)D levels [108]. Only few studies evaluated the efficacy and safety of intermittent vitamin D supplementation during the first year of life, particularly in cases with low compliance [109-111], thus at present daily supplementation remains preferred.

Various international Scientific Societies agree to recommend vitamin $\mathrm{D}$ supplementation during the first year of life $[9,12-15,19,20,22,23,27,28,30,112-116]$. Particularly, the Global Consensus on prevention of nutritional rickets recommended the administration of $400 \mathrm{IU} /$ day of vitamin $\mathrm{D}$ for all infants from birth to 12 months of age, independently of their mode of feeding [28]. The same recommendation has been worldwide proposed also by an Expert Position Statement on vitamin D in childhood [1], the Department of Nutrition for Health and Development of the World Health Organization [116], the ESPGHAN [19], the European Academy of Pediatrics [30], and the vitamin D guidelines for United Arab Emirates [27] and Central Europe [20]. These Societies also agree that the administration of $400 \mathrm{IU} /$ day is safe and effective to prevent rickets and ensure an adequate vitamin D status. The Endocrine Society recommended a daily intake of 400-1000 IU of vitamin D in children under 1 year of age at risk for vitamin D deficiency [11]. Regarding the preferred form of vitamin D for supplementation, the National Institute for Health and Care Excellence guideline recommended vitamin D drops in infants and young children [114], while other international Scientific Societies did not make any specific recommendation.

Despite this global agreement on vitamin D supplementation in the first year of life, several barriers to adherence still exist, such as reluctance of mothers to give their children daily supplementation, lack of knowledge about vitamin $\mathrm{D}$ actions and the risk of nutritional rickets, lack of awareness by health care professionals, assumption that both breast milk and formula milk provide sufficient vitamin D intake [116, 117].

In the present Consensus we recommend vitamin D supplementation in all newborns independently of the type of feeding, starting from birth and continuing throughout the first year of life. Infants born at term without risk factors for vitamin D deficiency should receive 400 IU/day of vitamin $\mathrm{D}$, while in the presence of risk factors for vitamin $\mathrm{D}$ deficiency (Table 6) up to $1000 \mathrm{IU} /$ day of vitamin D can be administered. We recommend against using vitamin D metabolites and their analogs (calcifediol, alfacalcidol, calcitriol, and dihydrotachysterol) for the routine vitamin D supplementation, as the administration of these compounds increases the risk of hypercalcemia and is not able to maintain and/or restore vitamin D stores $[118,119]$.

\section{Preterm}

Preterm infants are at risk for calcium-phosphorus metabolism alterations, with possible development of osteopenia of prematurity [120]. As the majority of calcium and phosphate accretion and fetal bone mineralization occur during the third trimester of pregnancy, preterm infants are deprived of the physiological mineral intrauterine supply, with consequent impaired bone mineralization and increased fracture risk. Very low birth weight (VLBW) infants (birth weight $<1500 \mathrm{~g}$ ) are at significant risk of osteopenia due to the frequent administration of drugs that adversely affect bone mineralization (steroids, methylxanthines and diuretics) and prolonged period of immobilization and total parenteral nutrition [121]. At present, the exact timing and proportion of vitamin D-dependent absorption of calcium and phosphorus in preterm infants is unknown [122]. However, after 24 weeks gestation maternal $25(\mathrm{OH}) \mathrm{D}$ crosses the placenta and is metabolized to $1,25(\mathrm{OH})_{2} \mathrm{D}$ for endocrine and paracrine actions [123]. In addition to optimize bone mineralization during fetal life, vitamin $\mathrm{D}$ status has been associated with acute respiratory morbidity in preterm infants born $<32$ weeks gestation [124].

Relatively few international Scientific Societies gave recommendations on vitamin D supplementation in preterm infants. In 2013 the AAP recommended a daily vitamin D intake of 200-400 IU for VLBW infants, as their smaller size may lead to a lower need for vitamin $D$ to ensure adequate serum 25(OH)D levels. Vitamin D intake should be increased to $400 \mathrm{IU} /$ day (up to a maximum of $1000 \mathrm{IU} /$

Table 6 Risk factors for vitamin D deficiency in the first year of life - Non-Caucasian ethnicity with dark skin pigmentation

- Inadequate diets (i.e. vegan diet)

- Chronic kidney disease

- Hepatic failure and/or cholestasis

- Malabsorption syndromes (i.e. cystic fibrosis, inflammatory bowel diseases, celiac disease at diagnosis, etc.)

- Chronic therapies: anticonvulsants, systemic glucocorticoids, antiretroviral therapy, systemic antifungals (i.e. ketoconazole)

- Infants born from mothers with multiple risk factors for vitamin $D$ deficiency, particularly in absence of vitamin D supplementation during pregnancy 
day) when weight exceeds $1500 \mathrm{~g}$ and the infant tolerates full enteral nutrition [122]. Differently, considering the high prevalence of vitamin D deficiency during pregnancy, the ESPGHAN recommended for preterm infants a vitamin D intake of 800-1000 IU/day during the first months of life to rapidly correct fetal low serum $25(\mathrm{OH}) \mathrm{D}$ levels [125]. Other authors and guidelines for Central Europe recommended vitamin D supplementation in preterm infants at higher dosages (400-1000 IU/day) than those suggested for healthy term newborns [1, 9, 20, 126], but such an intake should not be prolonged over the theoretical term (40 weeks of post-conceptional age) due to the potential risk of vitamin D intoxication [126].

Preterm infants may receive vitamin $\mathrm{D}$ from various sources, such as parenteral nutrition, fortified human milk or preterm infant formula, but it has been calculated that without supplementation they do not receive $400 \mathrm{IU} /$ day of vitamin D until reaching a weight of $2-2.5 \mathrm{Kg}$ [123] or only 4 weeks after birth [127]. However, total vitamin D intake from supplementation and feeding should be assessed to avoid excess, particularly in VLBW infants.

Some studies evaluated the effect of vitamin D supplementation at different doses in preterm infants of various gestational age and birth weight [124, 128-146]. Vitamin D supplementation at $400 \mathrm{IU} /$ day has been generally retained safe and effective in maintaining adequate serum 25(OH)D levels in preterm infants [131, 132, 135, 139-141]. Studies that evaluated vitamin D supplementation at $200 \mathrm{IU} /$ day gave conflicting results $[128,129,134]$. Finally, some studies evaluated the effect of supplementation at higher doses (800-1000 IU/day) [133, 135-137, 140-146]. Cho et al. recently recommended vitamin D supplementation at $800 \mathrm{IU} /$ day to enhance vitamin D status during early hospitalization in VLBW infants with serum 25(OH)D levels $<10 \mathrm{ng} / \mathrm{ml}$ at birth [142]. Mathur et al. found that supplementation at $1000 \mathrm{IU} /$ day for 6 weeks was more effective than $400 \mathrm{IU} /$ day in maintaining serum $25(\mathrm{OH}) \mathrm{D}$ levels with a lower incidence of skeletal hypomineralization and better growth [144]. However, other authors did not find any difference in clinical outcome or in bone accrual in preterm infants receiving supplementation at higher doses [135-137, 143] and advised to avoid prolonged supplementation at $1000 \mathrm{IU} /$ day for the risk of hypervitaminosis D [143, 145, 146]. Particularly, Fort et al. suggested for extremely low gestational age newborns an initial vitamin D supplementation at $800 \mathrm{IU} /$ day for 1-2 weeks to restore serum 25(OH)D levels followed by a lower dosage (200 IU/day) [143].

In the present Consensus we recommend a total daily vitamin D intake of 200-400 IU (including the amount administered through parenteral nutrition, fortified breast milk, and preterm formula) for preterm infants with a birth weight $<1500 \mathrm{~g}$. Vitamin D supplementation at 400$800 \mathrm{IU} /$ day is recommended for VLBW infants when they reach a weight $\geq 1500 \mathrm{~g}$ and full enteral nutrition, and for preterm infants with a birth weight $\geq 1500 \mathrm{~g}$. After a postconceptional age of 40 weeks, recommendations for vitamin $\mathrm{D}$ supplementation are equal to those for healthy term infants.

\section{1-18 years}

The promotion of an adequate vitamin D status is important for older children and adolescents, as nutritional rickets may develop during the entire pediatric age [28] and vitamin D deficiency may negatively affect bone health $[25,26]$. Various studies evaluated different regimens of vitamin $\mathrm{D}$ supplementation, but comparison of results is complex due to heterogeneity in vitamin $\mathrm{D}$ administration (dose, interval, and length of supplementation) and population enrolled (age, gender, ethnicity, body mass index, latitude of the country of residence, season of enrolment, and basal vitamin D status).

Most of the studies evaluated daily vitamin D supplementation at doses ranging from 200 to $1000 \mathrm{IU} /$ day [78, 147-164]. Supplementation at 400 IU/day for variable length (up to 12 months) was usually insufficient in raising serum 25(OH)D levels > $30 \mathrm{ng} / \mathrm{ml}$ [78, 147-149, 151-153, 160-162], particularly in subjects with vitamin D deficiency. A recent RCT performed during winter showed that a vitamin D intake up to $800 \mathrm{IU} /$ day was required by white Danish children (4-8 years) to maintain serum $25(\mathrm{OH}) \mathrm{D}>20 \mathrm{ng} / \mathrm{ml}$. Particularly, subjects receiving $800 \mathrm{IU} /$ day for 20 weeks increased their 25(OH)D levels from $23.2 \mathrm{ng} / \mathrm{ml}$ to $30.3 \mathrm{ng} / \mathrm{ml}$ [161]. Another RCT demonstrated that white UK adolescents (14-18 years) required higher intake of vitamin D (up to $1200 \mathrm{IU} /$ day) during winter to achieve $25(\mathrm{OH}) \mathrm{D}$ concentration $>20 \mathrm{ng} /$ $\mathrm{ml}$ in $97.5 \%$ of cases. Indeed, children and adolescents supplemented with 800 or $1000 \mathrm{IU} /$ day for 20 weeks increased their 25(OH)D levels but frequently remained insufficient [156-158, 162-164], while supplementation at $300 \mathrm{IU} /$ day for 7 weeks did not result efficacious in younger children [163]. A few studies evaluated intermittent regimens of supplementation (weekly, monthly, every 26 months) in older children and adolescents, with conflicting results [165-175]. Intermittent vitamin D administration may be considered in case of reduced compliance with daily supplementation, but actual evidence is insufficient to recommend a preferred doses and interval.

Several international Societies recommended vitamin D supplementation in children older than 1 year and adolescents with risk factors for vitamin $\mathrm{D}$, such as reduced sun exposure or dark skin pigmentation $[8,9,11,18,19,23,28$, $30,114]$. Particularly, the ESPGHAN reinforced that first of all a healthy lifestyle associated with a normal body mass index and including a healthy diet with vitamin Dcontaining foods and adequate outdoor activities should be promoted in healthy children and adolescents [19]. Moreover, pediatricians should periodically evaluate vitamin D 
intake from diet and supplements [23, 28]. Considering the Italian Child Health Care System organization, family pediatricians may anamnestically evaluate vitamin $\mathrm{D}$ intake of children and possible risk factors for deficiency during periodic health check-ups [176].

On the contrary, other Societies systematically recommended vitamin D supplementation in children and adolescents during winter months $[13,20,115]$ or throughout the whole year if reduced sun exposure during summer $[20,115]$. Following the publication of SACN review of the evidence on vitamin D and health [25], Public Health England advised that UK children aged 1 to 4 years should receive vitamin D supplementation at $400 \mathrm{IU} /$ day, and older children and adolescents should take a daily supplement containing 400 IU of vitamin $\mathrm{D}$ in autumn and winter to protect bone and muscle health because it is difficult to meet this intake from dietary sources. Public Health England also recommended that individuals with darker skin and people with reduced sun exposure should receive vitamin D supplementation throughout the year [115].

Adolescents are at increased risk for vitamin D deficiency [79], thus the Society for Adolescent Health and Medicine recommended continuous vitamin D supplementation (600 IU daily for healthy adolescents, and at least $1000 \mathrm{IU}$ daily for adolescents at risk for vitamin $\mathrm{D}$ deficiency or insufficiency) in addition to vitamin $\mathrm{D}$ received through the diet or via sun exposure [21].

Variation of sunlight efficacy in promoting skin vitamin D synthesis (depending on season and latitude) and local factors related to sunlight exposure (i.e. cultural habits) should be taken into account when considering supplementation [30, 177, 178]. For example, Arab Emirates guidelines recommended vitamin D supplementation between May and October because Arabian people avoid sun exposure during summer due to excessive heat [27]. Regarding Italy (latitude $35^{\circ} 29^{\prime} 24^{\prime \prime}-47^{\circ} 5^{\prime} 31^{\prime \prime}$ ), an in vitro study showed that no vitamin D is produced as a result of sun exposure at the latitude of Pisa $\left(43^{\circ} 43^{\prime} \mathrm{N}\right)$ from November to February [179], confirming that sunlight-derived vitamin D production is ineffective for at least 1 month during the year in countries placed between $23.5^{\circ}$ and $66.5^{\circ}$ of latitude [180]. Subsequent Italian cross sectional studies enrolling children and adolescents living in the north-western area of Tuscany, Central Italy (latitude between $43^{\circ} \mathrm{N}$ and $44^{\circ} \mathrm{N}$ ) not receiving vitamin $\mathrm{D}$ supplementation confirmed seasonal variability in serum $25(\mathrm{OH}) \mathrm{D}$ levels, with lower concentrations during late winter-early spring months (February-April), with negligible amount of vitamin D obtained from diet [50, 79], according to other Italian pediatric studies [70, 76-78, 83]. These data suggest that wintry vitamin D status depends on the amount of vitamin D produced and stored during the previous summer [181]. Finally, a recent cross sectional study showed high prevalence of vitamin D deficiency and insufficiency (40.3\% and $33.5 \%$, respectively) among internationally adopted children at their first clinical evaluation in Italy [182].

In the present Consensus we recommend vitamin D supplementation in children and adolescents with risk factors for vitamin D deficiency (Table 7), at doses ranging from $600 \mathrm{IU} /$ day (i.e. in presence of reduced sun exposure) up to $1000 \mathrm{IU} /$ day (i.e. in presence of multiple risk factors for vitamin D deficiency). In cases of poor compliance, supplementation with intermittent dosing (weekly or monthly doses for a cumulative monthly dose of 18000-30000 IU of vitamin D) can be considered, starting from children aged 5-6 years and particularly during adolescence. Considering the results of Italian studies, we suggest vitamin D supplementation from the end of fall to the beginning of spring (November-April) in children and adolescents with reduced sun exposure during summer. Continuous supplementation should be reserved to children with permanent risk factors for vitamin D deficiency. Individuals on anticonvulsants, oral corticosteroids, antimicotics and antiretroviral drugs should receive at least 2-3 times more vitamin D than the daily requirement recommended for age, in agreement with the Endocrine Society [11] and the AAP [23]. As reported for infants in the first years of life, we recommend against using vitamin $\mathrm{D}$ metabolites and their analogs (calcifediol, alfacalcidol, calcitriol, and dihydrotachysterol) for the routine vitamin D supplementation.

At present, population screening for vitamin D deficiency in healthy individuals is not recommended. Indeed, serum $25(\mathrm{OH}) \mathrm{D}$ evaluation should be reserved to subjects at risk for vitamin D deficiency, but indications for $25(\mathrm{OH}) \mathrm{D}$ measurement significantly vary among different societies (Table 8) $[9,11,13,15,20-23$, $27,30]$. We recommend against routine $25(\mathrm{OH}) \mathrm{D}$ testing in children and adolescents, suggesting to limit

Table 7 Risk factors for vitamin D deficiency between 1 and 18 years of age

- Non-Caucasian ethnicity with dark skin pigmentation
- Reduced sunlight exposure (due to lifestyle factors, chronic illness
or hospitalization, complex disability, institutionalization, covering
clothing for religious or cultural reasons) and/or constant use of
sunscreens
- International adoption
- Obesity
- Inadequate diets (i.e. vegan diet)
- Chronic kidney disease
- Hepatic failure and/or cholestasis
- Malabsorption syndromes (i.e. cystic fibrosis, inflammatory bowel
diseases, celiac disease at diagnosis, etc.)
- Chronic therapies: anticonvulsants, systemic glucocorticoids,
antiretroviral therapy, systemic antifungals (i.e. ketoconazole)


Table 8 Indications for 25(OH)D evaluation (besides rickets) in children and adolescents as proposed by various Organizations and Societies

\begin{tabular}{|c|c|c|c|c|c|c|c|c|c|c|}
\hline $\begin{array}{l}\text { Organization/Society, } \\
\text { year of publication }\end{array}$ & $\begin{array}{l}\text { PES, } \\
2008 \\
{[9]} \\
\end{array}$ & $\begin{array}{l}\text { ES, } \\
2011 \\
{[11]} \\
\end{array}$ & $\begin{array}{l}\text { FCN, } \\
2012 \\
{[15]} \\
\end{array}$ & $\begin{array}{l}\text { French Soc. } \\
\text { of Pediatrics, } \\
2012^{a}[13]\end{array}$ & $\begin{array}{l}\text { Australia - } \\
\text { New Zealand, } \\
2013 \text { [22] }\end{array}$ & $\begin{array}{l}\text { Central } \\
\text { Europe, } \\
2013 \text { [20] }\end{array}$ & $\begin{array}{l}\text { SAHM, } \\
2013 \\
{[21]} \\
\end{array}$ & $\begin{array}{l}\text { AAP, } \\
2014 \\
{[23]} \\
\end{array}$ & $\begin{array}{l}\text { Arab } \\
\text { Emirates, } \\
2016 \text { [27] }\end{array}$ & $\begin{array}{l}\text { EAP, } \\
2017 \\
{[30]} \\
\end{array}$ \\
\hline Frequent/low trauma fractures and/or low BMD & $x$ & $x$ & $x$ & & & $x$ & $x$ & $x^{b}$ & $x$ & \\
\hline Calcium/phosphate metabolism abnormalities & & & & & & $x$ & & & $x$ & \\
\hline Immobilization/disabilities & & & & & $x$ & & $x$ & $x$ & $x$ & \\
\hline Dark skin pigmentation & $x^{c}$ & $x^{d}$ & $x$ & $x$ & $x$ & & $x$ & & & $x$ \\
\hline Reduced sun exposure & $x$ & & & $x$ & $x$ & & $x$ & & & $x$ \\
\hline Athletes (indoor sports) & & & $x$ & & & & & & & \\
\hline Children institutionalized & & & & & & & & & $x$ & $x$ \\
\hline Constant use of sunscreens & & & & & & & $x$ & & & \\
\hline Obesity & & $x$ & $x^{e}$ & $x$ & $x$ & & $x$ & & $x$ & \\
\hline Inadequate diets (e.g. vegan) & & & & $x$ & & & $x$ & & & $x$ \\
\hline $\begin{array}{l}\text { Elimination diets (e.g. cow/s milk allergy), eating } \\
\text { disorders }\end{array}$ & & & & & & $x$ & & $x$ & $x$ & \\
\hline On anticonvulsants & $x$ & $x$ & $x$ & $x$ & $x$ & $x$ & $x$ & $x$ & $x$ & $x$ \\
\hline On chronic glucocorticoids & $x$ & $x$ & $x$ & & & $x$ & $x$ & $x$ & $x$ & \\
\hline On HIV medications & & $x$ & $x$ & & & $x$ & $x$ & & $x$ & \\
\hline On antifungals (e.g. ketoconazole) & & $x$ & $x$ & & & $x$ & & & $x$ & \\
\hline On rifampicin & & & & $x$ & $x$ & & & & & \\
\hline Malabsorption syndromes & $x$ & $x$ & $x$ & $x$ & $x$ & $x$ & $x$ & $x$ & $x$ & $x$ \\
\hline Chronic kidney disease & & $x$ & $x$ & $x$ & $x$ & $x$ & $x$ & $x$ & $x$ & $x$ \\
\hline Nephrotic syndrome & & & & $x$ & & & & & & \\
\hline Hepatic failure and/or cholestasis & & $x$ & $x$ & $x$ & $x$ & $x$ & $x$ & & $x$ & $x$ \\
\hline Granulomatous disorders (e.g. tuberculosis) & & $x$ & $x$ & & & $x$ & & & $x$ & \\
\hline Amenorrhea & & & & & & & $x$ & & & \\
\hline Cancer (different types) & & $x^{f}$ & & & & $x$ & & $x$ & $x$ & \\
\hline Hepatitis $C^{g}$ & & & & & & $x$ & & & $x$ & \\
\hline Recurrent acute lower respiratory tract infections ${ }^{9}$ & & & & & & $x$ & & & $x$ & \\
\hline Atopic dermatitis ${ }^{9}$ & & & & & & $x$ & & & $x$ & \\
\hline Atopic Asthma ${ }^{9}$ & & & & & & $x$ & & & $x$ & \\
\hline Autoimmune diseases ${ }^{h}$ & & & & & & $x$ & & $x^{i}$ & $x$ & \\
\hline Cardiovascular diseases (especially hypertension) & & & & & & $x$ & & & $x$ & \\
\hline Metabolic syndrome, type 2 diabetes & & & & & & & & & $x$ & \\
\hline
\end{tabular}

PES Pediatric Endocrine Society, ES Endocrine Society, FCN Federal Commission for Nutrition (Switzerland), SAHM Society for adolescent health and medicine, AAP American Academy of Pediatrics, EAP European Academy of Pediatrics

${ }^{a}$ suggested to guide vitamin $D$ prescription in individuals with underlying risks requiring continuing supplementation all year long, if necessary

${ }^{b}$ genetic conditions (osteogenesis imperfecta, idiopathic juvenile osteoporosis, Turner syndrome), endocrine conditions (Cushing syndrome, hypogonadism,

hyperthyroidism, hyperparathyroidism, growth hormone deficiency, diabetes mellitus) associated with reduced bone mass

cliving at higher latitudes in the winter and spring months

${ }^{\mathrm{d}}$ African-American and Hispanic children

eobese children with additional risk factors/symptoms for vitamin D deficiency

f some lymphomas

${ }^{g}$ patients admitted to hospital

${ }^{h}$ multiple sclerosis, psoriasis, rheumatoid arthritis, dermatomyositis, systemic lupus erythematosus

i systemic lupus erythematosus, juvenile idiopathic arthritis, juvenile dermatomyositis as associated with reduced bone mass

serum 25(OH)D levels evaluation in children and adolescents with multiple risk factors for vitamin D deficiency. Particularly, vitamin D status should be monitored at least yearly in subjects that require supplementation during the whole year because affected from pathological conditions or receiving drugs affecting vitamin D metabolism (Table 7) (see "Extraskeletal actions of vitamin D" for specific recommendations). 


\section{Skeletal actions of vitamin D Nutritional rickets}

Rickets is characterized by defective mineralization of developing bone tissue and reduced or absent endochondral ossification of the growth plate, with subsequent deformation [183, 184]. Nutritional rickets is caused by vitamin D deficiency and/or low calcium intake in children. Despite a significant decrease in the incidence and prevalence of nutritional rickets during the twentieth century, new cases are still reported worldwide, both in developing and industrialized countries $[185,186]$.

Children of immigrants living in industrialized countries are at increased risk of rickets because they usually present several risk factors for vitamin D deficiency such as prolonged breastfeeding without vitamin D supplementation, increased skin pigmentation, reduced sun exposure due to cultural habits (i.e. veiling), and reduced intestinal calcium uptake due to an excessive intake of high-phytates foods [187]. At present, no exact serum 25(OH)D threshold has been defined below which nutritional rickets may develops [33]. A recent global consensus recommendations on prevention and management of nutritional rickets defined vitamin $\mathrm{D}$ deficiency as serum $25(\mathrm{OH}) \mathrm{D}<12 \mathrm{ng} / \mathrm{ml}$, considering the increased incidence of rickets with serum 25(OH)D levels under this threshold [28]. Similarly, in 2016 the SACN reported that the risk of nutritional rickets increased for serum 25(OH)D levels $<10 \mathrm{ng} / \mathrm{ml}$ [25].

Nutritional rickets diagnosis is based on the evaluation of clinical, radiological and biochemical findings, as reviewed elsewhere [9, 183, 188]. Rickets typically develops towards the end of the first year of life and in the course of the second year of life. Subsequently, the clinical signs of vitamin $\mathrm{D}$ deficiency (i.e. rickety wrists and ankles, rachitic rosary, Harrison's sulci, lower limb deformities) become more subtle. Particularly, adolescents may develop non-specific symptoms, such as lower limb pain or difficulties in climbing stairs, because of proximal myopathy secondary to vitamin D deficiency [189]. Nutritional rickets may be associated also with extraskeletal manifestations, such as muscular hypotonia, delayed motor development, and increased risk of respiratory infections. Moreover, vitamin D deficiency may determine hypocalcaemia that may be asymptomatic, latent or symptomatic possibly with acute onset (seizures, syncope, laryngospasm, bronchospasm, tetanus, paresthesia, tremors, muscular cramps, dilated cardiomyopathy) [188]. At X-rays osteopenia of the long bones may be the earliest radiological sign of rickets. Subsequently, a fraying and cupping deformity of metaphyses following the proliferation of uncalcified cartilage and osteoid tissue is usually observed [190]. If nutritional rickets is suspected, biochemical investigations [serum $25(\mathrm{OH}) \mathrm{D}, \mathrm{PTH}$, alkaline phosphatase, calcium, and phosphorus levels] and X-rays evaluation of metaphyseal sites (wrists and ankles) are recommended [188]. On the contrary, the evaluation of serum $1,25(\mathrm{OH})_{2} \mathrm{D}$ and bone turnover markers is not useful to pose diagnosis.

Vitamin D administration represents the main treatment of nutritional rickets [183, 188], and some age-dependent regimens have been proposed [9, 28, 183]. Oral treatment is preferred as it more rapidly restores serum $25(\mathrm{OH}) \mathrm{D}$ levels than intramuscular treatment [28]. The global consensus on nutritional rickets recommended the administration of $2000 \mathrm{IU} /$ day of vitamin D in patients aged less than 1 year, 3000-6000 IU/day in patients aged 1 to 12 years and $6000 \mathrm{IU} /$ day in patients older than 12 years for a minimum of 3 months, even if some children may require a longer treatment duration [28]. Intermittent administration of vitamin $\mathrm{D}$ may be a reliable alternative to daily administration, particularly in cases with low compliance. Indeed, Munns et al. recommended a single dose of $50000 \mathrm{IU}$ in children age 3 to 12 months, 150000 IU in children aged 1 to 12 years, and $300000 \mathrm{IU}$ in adolescents $>12$ years of age. When single large doses are used, vitamin $D_{3}$ is preferable compared to vitamin $\mathrm{D}_{2}$ because the former has a longer half-life [28]. Monthly oral administration of $100000 \mathrm{IU}$ for three consecutive months was demonstrated to be safe and effective to treat nutritional rickets in immigrant children and adolescents living in Italy [187]. The administration of a single large dose of vitamin D > 300000 IU is not recommended, because may cause high risk of vitamin D intoxication with hypercalciuria and hypercalcemia, as confirmed by recent studies [191-195]. After rickets healing, vitamin D supplementation should continue according to age (at least $400 \mathrm{IU} /$ day in the first year of life and $600 \mathrm{IU} /$ day from 1 to 18 years) [11, 23, 28, 183, 188]. Besides vitamin $\mathrm{D}$, calcium is also important to treat nutritional rickets, even in absence of hypocalcemia. Munns et al. recommended oral calcium administration of $500 \mathrm{mg} /$ day in conjunction with vitamin D regardless of age or weight [28], while Misra et al. recommended 30-75 mg/ $\mathrm{kg} /$ day of elemental calcium in 3 divided doses, starting at a higher dose and weaning down to the lower end of the range over $2-$ 4 weeks [9]. Calcium should be administered intravenously in presence of acute, symptomatic hypocalcaemia. Calcium supplementation is important to prevent "hungry-bone" syndrome (hypocalcemia secondary to an increase in bone mineralization as PTH levels normalize during vitamin D treatment) [9]. Vitamin D metabolites and their analogs (calcifediol, alfacalcidol, calcitriol, and dihydrotachysterol) are not recommended for treatment of nutritional rickets. Particularly, the use of $1 \alpha$-hydroxylated metabolites of vitamin $\mathrm{D}$ does not restore vitamin $\mathrm{D}$ levels, and may determine supraphysiological levels of $1,25(\mathrm{OH})_{2} \mathrm{D}$ with increased risk of hypercalcemia $[183,188]$. The administration of $1 \alpha$-hydroxylated metabolites of vitamin $\mathrm{D}$ may be considered in nutritional rickets associated with acute hypocalcemia or hypocalcemic cardiomyopathy $[9,183]$. 


\section{Bone health}

Bone mass acquisition is influenced by both genetics and lifestyle-related factors, such as vitamin D status, physical activity and calcium intake $[23,53]$. Vitamin D contributes significantly to bone mineralization by promoting intestinal calcium and phosphorus reabsorption. Moreover, vitamin D stimulates skeletal calcium and phosphorus and renal calcium reabsorption. Besides the direct regulation of calcium-phosphorus metabolism, vitamin D also indirectly promotes bone mass accrual stimulating the development of muscle tissue [196-198]. Bone mass acquisition starts during fetal life and continues throughout the entire pediatric age until young adulthood with the achievement of peak bone mass (PBM), that is the total amount of bone mass acquired when accrual plateaus after completion of growth and development [199]. As bone mass tracks during childhood and adolescence, bone status during pediatric age is a strong predictor of bone status in young adulthood [200].

As discussed before, vitamin D supplementation during the first year of life is essential to prevent nutritional rickets occurrence. A few studies evaluated the relationship between vitamin $\mathrm{D}$ status and bone mass during this period of life [52, 62, 97, 104, 201-203]. Among these, three Italian studies assessed bone mineral status in infants using quantitative ultrasound [201-203], suggesting that vitamin D supplementation is important to provide an adequate bone development, particularly in exclusively breastfed infants. On the contrary, studies using dualenergy X-ray absorptiometry (DXA) or peripheral quantitative computed tomography (pQCT) failed to demonstrate an association between serum 25(OH)D levels and bone mass parameters in the first year of life [52, 104]. Moreover, studies comparing supplementation with placebo or different regimens of vitamin D supplementation (up to $1600 \mathrm{IU} /$ day) did not find any difference in infant bone mass at 3 months [104], 6 months [97], 1 year [62] or 3 years of life [204]. Interestingly, higher vitamin D status from infancy through to 3 years of age was associated with leaner body composition [205]. Thus, vitamin D supplementation during infancy is important to optimize bone mass acquisition and body composition, but high doses are not recommended.

Several studies evaluated the association between vitamin D status and bone mass in children and adolescents, usually searching for a correlation between actual serum $25(\mathrm{OH}) \mathrm{D}$ levels and bone mass. Results of these studies are heterogeneous, because some demonstrated that vitamin D status was significantly related to bone mass [41, 42, 54, 206-208] while others did not find any association [44, 209-211]. Vitamin D status seems particularly important for bone health during adolescence. Indeed, duodenal expression of 25-hydroxyvitamin $\mathrm{D}_{3}-1 \alpha$-hydroxylase is higher in adolescents than in children and adults, representing a metabolic adaptation to promote dietary calcium absorption for the growing bone [212]. A recent study confirmed that serum $25(\mathrm{OH}) \mathrm{D}$ levels correlated with bone density and bone quality pQCT parameters in adolescents [213]. Moreover, vitamin D status was demonstrated to be a significant determinant of PBM in young adults $[214,215]$.

In 2010 a Cochrane meta-analysis of 6 randomized controlled trials (RCTs) [148, 153, 166, 216-218] evaluated the effect of vitamin D supplementation on BMD in healthy children and adolescents (age 8-17 years, 541 subjects receiving vitamin $\mathrm{D}$ and 343 receiving placebo) [219]. Overall, meta-analysis showed a non-significant effect of vitamin D supplementation on BMD at any site. However, the effect of supplementation became significant on total body BMC and lumbar spine BMD by dividing the sample into two groups, depending on vitamin $\mathrm{D}$ status $[25(\mathrm{OH}) \mathrm{D}$ levels $<14 \mathrm{ng} / \mathrm{ml}$ vs. $\geq 14 \mathrm{ng} / \mathrm{ml}]$, suggesting that vitamin $\mathrm{D}$ supplementation may result in a clinically significant increase in bone mass in subjects with vitamin D deficiency. In 2016 the National Osteoporosis Foundation applied an evidence based grading system to describe the strength of available evidence on modifiable lifestyle factors that may influence the acquisition of PBM, reporting moderate evidence (grade B) for vitamin D [220]. This systematic review selected 1 prospective study [221], 3 cross-sectional studies [42, 222, 223], and 8 RCTs of vitamin D supplementation. Five RCTs were already evaluated by the Cochrane meta-analysis [148, 153, 166, $216,217]$, while the remaining 3 studies were published in 2010 [147, 224, 225]. Particularly, 4 RCTs provide evidence for a beneficial effect of vitamin $D$ supplementation on bone mineral accrual [148, 166, 216, 224], mainly in subjects with vitamin D deficiency. In 2016, SACN and EFSA revised dietary reference values for vitamin D reporting an increased risk of adverse musculoskeletal health outcomes at serum 25(OH)D levels in the range of deficiency, but with different thresholds $(<10 \mathrm{ng} / \mathrm{ml}$ and $<20 \mathrm{ng} / \mathrm{ml}$, respectively) [25, 26]. Interestingly, a recent study showed that the beneficial effect of vitamin $D$ on hip bone mass in Lebanese adolescent girls persisted 1 year after discontinuation of supplementation [226]. At present, some unanswered questions remain [critical times during which supplementation may be most effective, regimen and length of supplementation (continuous or intermittent), gender difference] [227], thus vitamin D supplementation to optimize bone mass acquisition should be reserved for children at risk for deficiency.

Maternal vitamin D status during pregnancy may significantly influence fetal and neonatal bone mass, as recently confirmed by the SACN [25]. Particularly, fetal bone growth was associated with maternal serum $25(\mathrm{OH})$ $\mathrm{D}$ at 26 weeks [228] and 34 weeks of gestation [229]. Newborns from mothers with serum $25(\mathrm{OH}) \mathrm{D}$ levels $<17 \mathrm{ng} /$ 
$\mathrm{ml}$ (median value of the individual means for maternal blood samples collected during the first trimester and 2 days postpartum) had higher tibia BMC and larger cross-sectional area, as assessed by pQCT at 10 days postpartum. These results confirmed that maternal vitamin $\mathrm{D}$ status may affect bone mineral accrual during the intrauterine period and influence bone size [230]. Moreover, postnatal vitamin D supplementation (follow-up 14 months) may only partly eliminate the differences in bone variables induced by maternal vitamin $\mathrm{D}$ status during the fetal period [231]. Recently an English RCT (MAVIDOS) failed to demonstrate an effect of maternal vitamin D supplementation (1000 IU/day from 14 week of gestation until delivery) on offspring bone mass assessed within 2 weeks of birth by DXA. However, secondary analysis showed a benefit for neonatal whole-body BMC (increased by almost $10 \%$ vs. placebo) with supplementation for deliveries during winter [232]. Women who gave birth in winter had a mean $25(\mathrm{OH}) \mathrm{D}$ concentration of $12 \mathrm{ng} / \mathrm{ml}$ at 34 weeks of gestation, suggesting a threshold at which supplementation may significantly affect neonatal bone mass [233]. Another smaller RCT on 50 newborns failed to demonstrate an effect of vitamin D supplementation during pregnancy (2000 IU/day from 26 to 28 weeks until childbirth) on infant bone mass measured at $23 \pm 10$ days by DXA [234].

Uncertain evidence exists on the relationship between maternal gestational 25(OH)D levels and offspring bone mass later in life (from 12 months to 10 years) [235239]. Several variables may justify this discrepancy, such as different enrolled populations, various regimens of vitamin $\mathrm{D}$ supplementation, and age at bone mass assessment. However, the most recent study suggested that vitamin $\mathrm{D}$ status during childhood might be more relevant for bone health that maternal 25(OH)D levels during fetal life [237].

\section{Extraskeletal actions of vitamin D Respiratory infections}

Vitamin D has complex immunoregolatory properties, exerted by modulating both innate and adaptive immunity and regulating the inflammatory response. A relationship between vitamin $\mathrm{D}$ status and the incidence or the severity of respiratory infections in children has been found in many observational studies, most with a case-control or cross sectional design, both in developing and in westernized countries. Some systematic reviews have addressed this topic as well [240-242]. The link between severe vitamin D deficiency and susceptibility to respiratory infections is prototypically represented by the high respiratory morbidity in children with rickets [243, 244]. Children with rickets are more likely to develop pneumonia or poor outcomes after lower respiratory infections [244, 245]. Other than pneumonia, some data also indicate that vitamin D deficiency might be a risk factor also for undifferentiated viral infections [246], recurrent pharyngotonsillitis [247], otitis media [248], bronchiolitis [249] and viral wheezing [250]. Some authors also postulated that the lower vitamin D production in winter might contribute to the marked seasonality of epidemic influenza [251]. Obviously, the more robust evidences on the association between vitamin $\mathrm{D}$ deficiency and respiratory infections stem from prospective studies. Camargo et al., after adjusting for season of birth, found that newborns with vitamin D cord blood levels $<10 \mathrm{ng} / \mathrm{ml}$ had a two-fold (odds ratio: 2.16 ; 95\% CI 1.35-3.46) increased risk of respiratory infections by 3 months of age as compared to newborns with 25(OH)D concentrations $>30 \mathrm{ng} / \mathrm{ml}$ [252]. Belderbos et al. also demonstrated that cord blood vitamin D levels < $20 \mathrm{ng} / \mathrm{ml}$ were associated with a sixfold (95\% CI: 1.6-24.9) increased risk of respiratory syncytial virus lower respiratory tract infections in the first year of life as compared with concentrations $\geq 30 \mathrm{ng} / \mathrm{ml}$ [249]. Science et al. in a cohort of 743 Canadian children aged 3-15 years prospectively followed for 6 months found that 25(OH)D D levels $<20 \mathrm{ng} / \mathrm{ml}$ increased the risk of laboratory confirmed viral infections by $70 \%$ [246]. Other studies have found an inverse association between vitamin D concentrations in pregnancy and the risk of respiratory infections in newborns or children during the first 3 years of life [253, 254]. However, not all studies have confirmed these associations $[255,256]$. For example, no relationship has been found in children and adults between baseline vitamin D concentrations and influenza virus infection [256].

Taken together, all these data indicate that vitamin D status might have some influence on conditioning the incidence and severity of some but not all type of respiratory infections and that more information are required before drawing any firm conclusion on this topic. A recent literature review supports a role for vitamin D deficiency only for tuberculosis, recurrent acute otitis media and severe bronchiolitis [242]. Furthermore, some role from VDR polymorphisms or other genetic factors might play a role in determining the influence of vitamin D status on respiratory morbidity $[257,258]$.

Several studies, mostly in adults, have also addressed the question whether vitamin D supplementation can prevent or reduce the severity of upper or lower respiratory infections. Systematic reviews with or without meta-analysis [241, 259-266] also focused on this topic. Of those, four included only studies in children [241, 263, 264, 266]. All but two $[259,261]$ of the aforementioned reviews concluded that published studies do not indicate a protective effect of vitamin D supplementation on the prevention of acute respiratory infections in healthy individuals. Some authors also indicated a possible publication bias [261, 266]. However, a well conducted study, not included in the above cited metaanalysis, on a selected population of otitis prone children, 
found that vitamin D administration (1000 IU/day) reduces the risk of uncomplicated acute otitis [267].

A recent meta-analysis of 25 RCTs (total 11,321 participants, aged 0-95 years) showed that vitamin D supplementation was safe and protected against acute respiratory tract infections overall (adjusted odds ratio 0 . 88). Subjects with severe deficiency $[25(\mathrm{OH}) \mathrm{D}<10 \mathrm{ng} /$ $\mathrm{ml}$ ] and those receiving daily or weekly doses rather than bolus dose had greater benefits [268], although the indication for this condition is still debated [269, 270]. Indeed, a more recent Canadian RCT showed that daily administration of 2000 IU of vitamin D did not reduce overall wintertime upper respiratory tract infections among healthy children aged 1-5 years compared with supplementation with $400 \mathrm{IU} /$ day. Thus, the results of this study do not support the routine use of high-dose vitamin D supplementation in children for the prevention of viral upper respiratory tract infections [271]. Finally, limited data are available on vitamin D supplementation in pregnancy and the risk of respiratory infections in the offspring [272, 273].

\section{Other infections}

An association between serum 25(OH)D levels and several types of pediatric infections has been reported. In a Turkish study including 82 children with urinary tract infection and 64 healthy controls lower serum $25(\mathrm{OH}) \mathrm{D}$ concentrations were evaluated, observing lower levels in infected children [274]. Moreover, VDR gene polymorphisms can be important for susceptibility to urinary tract infection and renal scar formation [275]. In an USA study a similar association was observed between skin or soft tissue infections by Staphylococcus aureus strains and vitamin D levels $[25(\mathrm{OH}) \mathrm{D}<$ $30 \mathrm{ng} / \mathrm{ml}$ ] in 202 children [276]. Other authors reported similar findings in children with acute diarrhea [277], otitis [277], rotavirus infection [278], malaria [279], leishmaniosis [280], hepatitis C [281], or sepsis [282]. However, it is unclear whether the observed vitamin D deficiency/insufficiency is to be considered a consequence of the infection itself or if it plays a role in determining susceptibility to infections or the severity of the disease. Interpretations of study results should also consider the different settings, the nutritional status of the enrolled children and the prevalence of co-infections.

Few reports exist regarding the benefit of vitamin D supplementation in children with specific infections. In a large randomized study in Afghanistan involving 3000 children with acute diarrhea vitamin $\mathrm{D}$ supplementation has been associated with improvement in clinical parameters [283]. The interpretation of results conducted in human immunodeficiency virus (HIV) infected patient is extremely complex. The vitamin D status can be influenced by the infection itself but also by antiretroviral therapy. Moodley et al. evaluated more than 900 infected children and observed that vitamin D-related host genetic variants may alter the availability and activity of vitamin $\mathrm{D}$ and are associated with risk of HIV disease progression in children [284]. In another study in Tanzania, serum $25(\mathrm{OH}) \mathrm{D}$ levels were evaluated in 884 pregnant women and, subsequently, in their infants. Low maternal $25(\mathrm{OH})$ D levels $(<32 \mathrm{ng} / \mathrm{ml})$ were associated with a $46 \%$ higher risk of mother to child transmission of HIV. Moreover, children born from women with a low 25(OH)D level had a $61 \%$ higher risk of dying during follow-up [285]. In a large French study vitamin D deficiency was more frequent in 113 children with HIV than in 54 healthy controls [286]. Similar results were observed by Rustein et al. in USA [287]. An Italian RCT was performed to test whether vitamin $\mathrm{D}_{3}$ supplementation (oral 100000 IU every 3 months for 4 doses) could improve vitamin D status and affect the T-cell phenotype in HIV-infected patients aged 8 to 26 years with serum $25(\mathrm{OH}) \mathrm{D}<30 \mathrm{ng} /$ $\mathrm{ml}$. Supplementation increased $25(\mathrm{OH}) \mathrm{D}$ and $1,25(\mathrm{OH})_{2} \mathrm{D}$ concentrations and decreased PTH levels but had no effect on CD4+ T-lymphocyte count. However, it was associated with changes in CD4+ T-lymphocyte phenotype [288]. In a pilot study in Botswana, vitamin $\mathrm{D}_{3}$ supplementation (4000-7000 IU/day for 12 weeks) was safe and improved vitamin D status, growth and HIV status [289]. Similarly, Dougherty et al. confirmed that a 7000 IU/day $\mathrm{D}_{3}$ supplementation was safe and effective in HIV infected children and young adults [290].

Tuberculosis is the infection probably more deeply studied at this regard [291-294]. Several studies investigated a possible relationship between vitamin $\mathrm{D}$ deficiency and tuberculosis infection in children [295], but literature results are discordant. Significant association between active tuberculosis and vitamin D deficiency [25(OH)D levels $<20 \mathrm{ng} /$ $\mathrm{ml}$ ] has been evidenced in an Australian study including 91 children with latent or active tuberculosis and 236 controls [296], similarly to one UK study [297]. A more recent large study on 996 children serum 25(OH)D levels $<20 \mathrm{ng} / \mathrm{ml}$ were more frequently observed in children with tuberculosis infection than in healthy controls [298]. Conversely, such association was not confirmed in a smaller Indian study [299]. Moreover, a large meta-analysis failed to demonstrate that vitamin D supplementation may be beneficial in children with tubercular infection [300]. Chiappini et al. did not find an association between tubercular infection and vitamin D status in a large population of internationally adopted children, although results demonstrated a high prevalence (about $75 \%$ ) of hypovitaminosis D in this population [182]. In the same study parassitosis was not related to serum $25(\mathrm{OH}) \mathrm{D}$ levels. The same authors had previously demonstrated a relation between tubercular disease and vitamin D status [301]. However, it should be noticed that only two internationally adopted children had active tubercular disease, possibly explaining the discrepancy with respect to previous results. 
These results are in line with those reported by Grobler et al. in a Cochrane review in 2016. According to this review, although blood levels of some vitamins may be low in patients starting treatment for active tuberculosis, there is currently no reliable evidence that routine supplementation at or above recommended daily amounts has clinical benefits [302].

\section{Asthma}

Vitamin D status has also been linked with asthma development and control [303]. Recently, Litonjua showed that vitamin $\mathrm{D}$ has both in utero and post-natal effects on lung development and immune system development and function [304]. Adverse exposures in this critical period, such as low levels of serum $25(\mathrm{OH}) \mathrm{D}$, might lead to developmental changes including reduced lung and airway growth and could therefore be a major importance for the development of asthma. Vitamin D appears to affect innate and adaptive immune system development through lymphocyte activation and proliferation, and T-helper cell differentiation [305]. Several studies showed that vitamin D deficiency in utero and in early life was associated with an increase in Th2 lymphocyte cells and a reduction in T regulatory cells and production of interleukin (IL)-10, which subsequently may activate pro-inflammatory cytokine production through macrophages and dendritic cells [306-308]. Consequently, several studies in vivo and in vitro showed that vitamin D supplementation inhibits the Th2 expression contrasting allergic diseases [309-314]. Furthermore, previous studies focused on the association between serum 25(OH)D levels and the expression of genes involved in the proliferation and cells differentiation, showing an antiproliferative activity of vitamin $\mathrm{D}$ with consequently remodeling inhibition [309-312]. Experimental data suggests that vitamin $D_{3}$ significantly overcame the inhibition of glucocorticoid-receptor expression by dexamethasone while IL-10 upregulated glucocorticoid-receptor expression by CD4+ $\mathrm{T}$ cells, suggesting potential mechanisms whereby these treatments may overcome poor glucocorticoid responsiveness [315]. About the role of vitamin D in the immunopathogenesis of allergic skin diseases, vitamin D induces the production of antimicrobial peptides, as betadefensin and cathelicidin, causing a reduction of the bacterial infections that may exacerbate asthma and atopic dermatitis (AD) [316, 317]. Not yet fully understood is the role of vitamin $\mathrm{D}$ on eosinophilic airway inflammation. In a recent study low $25(\mathrm{OH}) \mathrm{D}$ levels were associated to high levels of fractional exhaled nitric oxide [318]. On the contrary, in a study on 3130 mother child pairs there was no association between $25(\mathrm{OH}) \mathrm{D}$ levels and fractional exhaled nitric oxide in the first month of life [319].

Several studies evaluated the incidence of asthma in children and its relationship with $25(\mathrm{OH}) \mathrm{D}$ levels during pregnancy [320-323] and at delivery [252, 324]. Observational studies on the relationship between vitamin D in pregnancy and wheezing, asthma, and allergies development in early life showed unclear results. Recently, two studies on 581 and 806 children respectively showed that $2800 \mathrm{IU} /$ day or $4400 \mathrm{IU} /$ day of vitamin $\mathrm{D}_{3}$ administered during the third trimester of pregnancy compared to $400 \mathrm{IU} /$ day did not show any statistically significant reduction on the risk of persistent wheezing in the offspring until 3 years of age $[325,326]$. These results were confirmed in other studies that did not find without any correlation between serum $25(\mathrm{OH}) \mathrm{D}$ levels during pregnancy or at delivery and asthma development [252, 320-322, 324]. On the other hand, the study of Bener et al. in 966 children demonstrated that vitamin D deficiency [serum $25(\mathrm{OH}) \mathrm{D}<20 \mathrm{ng} / \mathrm{ml}$ ] was the major predictive factor of asthma risk [327], and Gale et al. showed that gestational 25(OH)D levels $>30 \mathrm{ng} / \mathrm{ml}$ were associated with an increased risk of asthma in children at 9 years of age [323].

Three studies evaluated 25(OH)D levels related to severity of asthma assessed by Asthma Control Test [328-330]. The first two studies showed that 25(OH)D levels were inversely related to asthma severity, while Gergen et al. demonstrated a correlation only for Afro-Americans subjects.

Regarding asthma exacerbations, several studies evaluated the association between 25(OH)D levels and the hospitalization for asthma and/or asthma treatment with oral steroids [330-333]. In most studies, low 25(OH)D levels were associated with a rise in hospital admissions or oral steroids treatment. A meta-analysis showed a significant association between vitamin $\mathrm{D}$ supplementation and reduction of asthma exacerbations ( $17 \%$ vs. $46 \%, p<0.029)$ [334].

Recently, three studies showed a positive correlation between vitamin D supplementation and the improvement of asthma control [335-337], accordingly with two recent meta-analyses. Vitamin D supplementation regimen changed in the studies between 500 and $2000 \mathrm{IU} /$ day $[338,339]$. Only the study of Lewis et al. did not show any correlation between 25(OH)D levels and asthma control [340].

About the effects of vitamin D on lung function, a recent meta-analysis demonstrated a difference of $0.54 \mathrm{l} / \mathrm{s}$ in forced expiratory volume in the 1st second (FEV1) values after the treatment with vitamin D [334]. In another study high doses of vitamin D (100,000 IU as first dose and 50,000 IU/week for 6 months) were administered to 130 patients (children and adults). After 28 weeks the authors showed an increase (20\%) in FEV1 values in the patients treated with vitamin $\mathrm{D}$ and corticosteroids in comparison with an increase of $7 \%$ in the control group [341]. Vitamin D supplementation at $2000 \mathrm{IU} /$ day for 6 weeks in 39 children with mild asthma and serum 25(OH)D levels $<30 \mathrm{ng} /$ $\mathrm{m})$ did not showed significant variations in bronchial reactivity or inflammatory markers (IL-4, IL-5, IL-10, IL-17, and interferon-gamma) [342]. Two studies in vitro showed the importance of vitamin $\mathrm{D}$ supplementation in patients 
affected by corticosteroid-resistant asthma [315, 343] but two other studies demonstrated in vivo that lower $25(\mathrm{OH})$ $D$ levels were associated with an increase in corticosteroids use and an impaired lung function [344, 345].

\section{Atopic dermatitis and allergic diseases}

Atopic dermatitis (AD) is a common chronic disease with symptoms starting from the early childhood. It has been observed in several studies that in moderate-severe AD serum 25(OH)D levels are often reduced [346]. Being vitamin D involved in innate immunity and in skin barrier integrity, and because both factors are dysfunctional in AD, the association is actively debated. The evidences for a pathogenetic role for vitamin $\mathrm{D}$ in $\mathrm{AD}$ are still conflicting even though data in favour of such correlation are increasingly stronger with more studies in favour but others opposing this hypothesis. However, at least two longitudinal studies have correlated the vitamin D cord blood low levels to the development of AD in the offsprings, finding that low levels in the cord blood significantly increased the risk to develop the disease $[347,348]$. The lower intake of vitamin D during early childhood increased the risk for disease persistence during the mild childhood [348].

It is still a matter for full debate whether supplementation with vitamin $\mathrm{D}$ in pediatric $\mathrm{AD}$ is worth, particularly in deficient patients. A recent large study found no evidence that genetically determined reduction in $25(\mathrm{OH}) \mathrm{D}$ levels conferred an increased risk for $\mathrm{AD}$, suggesting that efforts to increase vitamin $\mathrm{D}$ are unlikely to reduce risks of the atopic disease [349]. However, there are also two reviews and meta-analyses, considering $\mathrm{AD}$ patients of all ages, showing that vitamin D supplementation is capable of a higher mean difference in severity of AD symptoms [350, 351]. Particularly, vitamin D supplementation decreased AD severity and improved its symptoms and clinical signs. In pediatric population there is some evidence about a favourable effect of administration of vitamin D on several aspects of $\mathrm{AD}$, but results are still conflicting. For these reasons at present vitamin $\mathrm{D}$ supplementation as adjunctive standard therapy for AD cannot be recommended in all the affected children [351]. There is a need for RCTs conducted on broader populations, with a prolonged follow up. However, it has been suggested that in patients with a more severe $\mathrm{AD}$, unresponsive to common therapy and with low serum $25(\mathrm{OH}) \mathrm{D}$ levels, a trial of vitamin D supplementation can be considered [352]. This could be particularly indicated during the winter season where the sun exposure is limited and ineffective and supplementation not already suggested. Again, we need clinical data showing that restoring normal levels of vitamin D one can obtain significant variation in severity especially if evaluated by standardized methods (symptom score, Scoring Atopic Dermatitis or equivalent).
The so-called ecological studies suggest the relationship between latitude, the consequent level of sun exposure, vitamin $\mathrm{D}$ production and subsequent serum $25(\mathrm{OH}) \mathrm{D}$ levels and the prevalence and severity of allergic diseases. However, data from observational studies even though encouraging, are still controversial [353]. Furthermore, the use of vitamin D supplementation for primary prevention of allergic diseases remains an attractive area of study, but current knowledge and evidence does not allow to recommend it in routine use. Data from ongoing intervention trials are warranted to establish the extent of vitamin $\mathrm{D}$ potentially preventive effect, along with the best timing and dose of an intervention.

Also in food allergies the role of vitamin D remains controversial. There are studies suggesting that both lower and higher levels of vitamin D are associated with elevated IgE concentrations, with a U-shaped relationship [354]. However, evidences are still subtle and conflicting. A recent systematic review failed to demonstrate a significant association between serum 25(OH)D levels and food allergies prevalence [355]. Negative results were obtained in term of primary prevention by vitamin $\mathrm{D}$ supplementation in a recent meta-analysis and conclusions were that the effects of vitamin D supplementation remain uncertain [353]. There is the need for RCTs to validate these hypotheses and to evaluate the possibility of primary prevention and treatment of food allergies with vitamin D [355-357].

\section{Type 1 diabetes mellitus}

Several epidemiological studies suggested that type 1 diabetes mellitus (T1DM) is associated with vitamin D deficiency. A north-south gradient in the incidence of T1DM as well as a seasonal pattern of disease onset have been described. Low serum 25(OH)D levels are associated to T1DM in children and adolescents independently by ethnic origins and environmental living conditions (latitude, altitude) [358], persisting over time [359-366]. Moreover, 25(OH)D levels were lower in some but not all studies on siblings at risk [367, 368]. Some studies suggest a linkage between polymorphisms of the VDR and T1DM with data more convincing in Asians [369-371]. A recent large metaanalysis focused only on pediatric populations revealed that BsmIBB, BsmIBb and TaqItt polymorphisms were associated with an increased risk of T1DM, whereas BsmIbb and TaqITT had protective effect [372]. Data on polymorphisms of other genes involved in vitamin D metabolism are still conflicting or related to small populations [373-376].

A meta-analysis of six case-control studies and two cohort-studies showed a reduction of the risk of T1DM in later life (odds ratio: $0.71 ; 95 \%$ CI $0.51-0.98$ ) in infants who were supplemented with vitamin D compared with controls, although the needed time of supplementation and the dose are still unclear [377-379]. On the other hand, data on supplementation in pregnancy are 
debated, and no evidence of protection has been shown by recent meta-analyses [379, 380].

If data of observational studies in general population in infancy are encouraging, in the DAISY study, conducted in subjects at higher risk, the vitamin D nutritional intake in the first years of life as well as the serum $25(\mathrm{OH}) \mathrm{D}$ levels at 9 months of age were not associated with the development of autoantibodies or with the progression to T1DM [381]. Conversely, neonatal vitamin D status seems to be associated to the risk of T1DM in some [382] but not all the populations [383]. Moreover, $25(\mathrm{OH}) \mathrm{D}$ levels were not associated with a fast progression to T1DM later in life [368].

Until now, few clinical studies using cholecalciferol, calcidiol, calcitriol or its analogs have been conducted in the prevention or T1DM or in children with a recent onset. They are small, short-term and often not randomized. The IMDIAB XI study in which new onset T1DM children were given in the vitamin $\mathrm{D}$ group calcitriol at $0.25 \mu \mathrm{g} / 2$ days or nicotinamide at $25 \mathrm{mg} / \mathrm{kg} /$ day reported a reduction of insulin requirements in the vitamin D group [384]. However, the IMDIAB XIII study in which adolescents and young adults were given calcitriol $0.25 \mu \mathrm{g} /$ day vs. placebo for 2 years failed to demonstrate any improvement in T1DM [385]. Higher doses of cholecalciferol (2000 IU/day, $4000 \mathrm{IU} /$ day, $70 \mathrm{IU} / \mathrm{Kg} /$ day, or $14000 \mathrm{IU} /$ month) improved the immunity status in small populations with T1DM [386-389]. Similar data were obtained with calcidiol for 1 year or calcitriol for 6 months in two pilot studies [390, 391].

Although some suggestive and encouraging data on epidemiological observational studies and pilot clinical studies of intervention, the lack of evidence deriving by RCTs does not allow to encourage treatment with cholecalciferol or other vitamin D metabolites in patients with T1DM or subjects at higher risk. However, vitamin D deficiency should be avoided in these populations.

\section{Inflammatory bowel diseases}

Vitamin D status has been associated with the pathogenesis of several autoimmune diseases, including inflammatory bowel disease (IBD) [392-395]. Interestingly, the incidence of pediatric Crohn's disease increases with higher latitude and greater number of months with low ambient ultraviolet radiation [396], and some studies showed high prevalence of hypovitaminosis D in IBDs children and adolescents [397, 398]. A recent meta-analysis showed that patients with Crohn's disease $(n=129808$, age 11-48 years) had lower serum $25(\mathrm{OH}) \mathrm{D}$ concentrations compared with healthy controls, with an overall prevalence of vitamin D deficiency [25(OH)D $<20 \mathrm{ng} / \mathrm{ml}]$ of $57.7 \%$ and an inverse correlation between serum 25(OH)D levels and the severity of disease [399]. The etiology of vitamin D deficiency in patients with IBD is multifactorial and not entirely known. Besides risk factors common to general population (seasonality, reduced sun exposure, low dietary vitamin D intake, etc.) subjects with IBD had increased risk due to malabsorption, intestinal inflammation, proteinlosing enteropathy, and steroid treatment. Patients at early stage of IBD, with more severe disease, and upper gastrointestinal tract involvement are at higher risk for deficiency [398, 400-402].

Clinical guideline for skeletal health of children and adolescents with IBD in 2011 recommended monitoring vitamin D levels at least yearly, at the end of winter/beginning of spring, especially in dark skinned subjects. The authors suggested particular attention in children with active IBD, low albumin level $(<3 \mathrm{~g} / \mathrm{dl})$, and evidence of nutritional impairment [403]. The North American Society for Pediatric Gastroenterology, Hepatology and Nutrition [404] and other authors [405, 406] also recommended to evaluate serum 25(OH)D levels in IBD children at diagnosis and at least yearly, preferably in the spring. A dietary assessment should also be routinely performed in IBD children, paying close attention to the consumption of vitamin D-containing foods and dairy products [404].

At present the ideal dosing regimen to treat vitamin $\mathrm{D}$ deficiency and to maintain sufficiency in IBD patients is still debated [406]. In IBD pediatric patients, $2000 \mathrm{IU} /$ day of vitamin $D_{3}$ for 6 months was more effective in raising serum $25(\mathrm{OH}) \mathrm{D}$ concentrations $>30 \mathrm{ng} / \mathrm{ml}$ than $400 \mathrm{UI} /$ day or doses up to $2000 \mathrm{IU}$ of vitamin $\mathrm{D}_{2}$ [407, 408]. On the other hand, supplementation with $2000 \mathrm{IU} /$ day of vitamin $\mathrm{D}_{3}$ for 13.8 months improved trabecular BMD, cortical bone cross-sectional area, and maximal muscle power in 55 IBD patients [409].

Regarding dose regimens, both oral doses of $2000 \mathrm{IU} /$ day of vitamin $\mathrm{D}_{3}$ and $50000 \mathrm{IU} /$ week of vitamin $\mathrm{D}_{2}$ for 6 weeks were well-tolerated and superior to $2000 \mathrm{IU} /$ day of vitamin $\mathrm{D}_{2}$ in raising serum $25(\mathrm{OH}) \mathrm{D}$ concentration IBD patients with vitamin D deficiency [410]. Simek et al. found that two regimens of weekly vitamin $\mathrm{D}_{3}$ administration $(5000 \mathrm{IU} / 10 \mathrm{Kg} /$ week, maximum weekly dose of $25000 \mathrm{IU}$ and maximum cumulative dose of $150000 \mathrm{IU}$ vs. $10000 \mathrm{IU} / 10 \mathrm{Kg} /$ week, maximum weekly dose of $50000 \mathrm{IU}$ and maximum cumulative dose of $300000 \mathrm{IU})$ for 6 weeks were safe and effective in normalizing vitamin D status in IBD children and adolescents with hypovitaminosis D [411]. Finally, a single age dependent high-dose oral vitamin $\mathrm{D}_{3}$ (the so-called stoss therapy; < 3 years: 200000 IU; 4-12 years 400000 IU; > 12 years $800000 \mathrm{IU}$ ) was safe and efficacious in achieving and maintaining serum 25(OH)D levels $>20 \mathrm{ng} / \mathrm{ml}$ during a 6-month period in IBD children with vitamin D deficiency [412].

Clinical guideline for skeletal health of children and adolescents with IBD recommend to treat vitamin D 
deficiency and insufficiency administering a cumulative dose of at least $400000 \mathrm{IU}$, and $250000 \mathrm{IU}$ of vitamin D, respectively. Vitamin D supplementation at 800$1000 \mathrm{IU} /$ day is suggested to maintain optimal vitamin D status [403]. The Endocrine Society recommends to treat vitamin $\mathrm{D}$ deficiency in patients with malabsorption with vitamin $\mathrm{D}$ at doses 2-3 times higher than those recommended for otherwise healthy pediatric population for at least 6 weeks, followed by vitamin D supplementation at doses 2-3 times higher than those recommended for age [11]. Recently, Ahlawat et al. suggested to treat pediatric IBD subjects with hypovitaminosis $D$ at least with $2000 \mathrm{IU} /$ day of vitamin $\mathrm{D}_{3}$, adjusting every 3 months depending on serum 25(OH)D levels [406].

The role of vitamin D as a therapeutic agent in IBD is still under investigation. Particularly, large RCTs are needed to better investigate the role of vitamin $\mathrm{D}$ in disease remission and control.

\section{Celiac disease}

Celiac disease (CD) is caused by dysregulated systemic and intestinal mucosal immune responses to dietary gluten proteins in genetically predisposed individuals. It has been suggested that early-life vitamin $\mathrm{D}$ deficiency may contribute to the pathogenesis of childhood-onset $\mathrm{CD}$ by determining inappropriate immune responses, abnormal intestinal mucosal integrity and impaired local defence against microbial agents [413]. A relationship between sun exposure and $C D$ pathogenesis has been suggested demonstrating that $\mathrm{CD}$ was more common in US individuals living at northern latitudes than at southern latitudes (odds ratio $35^{\circ}-39^{\circ} \mathrm{N}$ : 3.2 ; odds ratio $\geq 40^{\circ} \mathrm{N}$ : 5.4 vs. $<35^{\circ} \mathrm{N}$ ) [414]. On the contrary, maternal vitamin D supplementation, maternal and neonatal vitamin D status were not related to the risk of childhood CD $[415,416]$.

Vitamin D deficiency is common (up to 52\%) in children with $C D$ at diagnosis [417-421]. Untreated CD is independently associated with reduced BMD in children and adolescents, as confirmed by US data from the National Health and Nutrition Examination Survey 2009-2010 and 2013-2014 [422], with increased risk of osteoporosis and fragility fractures in adulthood [423]. Indeed, small intestinal mucosal damage may affect intestinal absorption of calcium and vitamin $\mathrm{D}$, and chronic intestinal inflammation may lead to release of proinflammatory cytokines with subsequent increased bone loss [424]. Strict adherence to gluten free diet results in recovery of BMD in both children and adults $[417,425,426]$, and the promotion of an adequate vitamin D status is important to optimize bone health in CD patients [419].

The American College of Gastroenterology [427] and the British Society of Gastroenterology [428] recommend serum $25(\mathrm{OH}) \mathrm{D}$ evaluation in adults with $\mathrm{CD}$ at the time of initial diagnosis. The North American Society for
Pediatric Gastroenterology, Hepatology and Nutrition in 2016 recommend serum $25(\mathrm{OH}) \mathrm{D}$ evaluation also in $\mathrm{CD}$ children at diagnosis and annually after symptoms resolution and normalization of CD serology [429]. Recent evidence-informed expert recommendations for the management of $\mathrm{CD}$ in children suggest to evaluate serum $25(\mathrm{OH}) \mathrm{D}$ levels at diagnosis, while follow-up evaluation is needed only if previously abnormal (grade of evidence low, strength of statement weak) [430]. Other authors gave similar recommendations in a recent review [406].

Spontaneous recovery of vitamin D status following gluten free diet has been suggested [417], but it is still debated. Strict adherence to gluten free diet itself may represents a determinant of vitamin D status, because it has been demonstrated that Sweden CD children on gluten free diet had low vitamin D intake compared with Nordic Nutrition Recommendation and lower nutrient density of vitamin D than healthy children [431].

As vitamin $\mathrm{D}$ is an important key determinant of bone mass acquisition, some authors recommended vitamin $\mathrm{D}$ supplementation during winter and spring in all $C D$ children and adolescents to optimize bone recovery [432]. NICE guidelines advice that people with CD may need to receive calcium and vitamin $\mathrm{D}$ supplementation if their dietary intake is insufficient [433]. Other authors reinforce that vitamin D supplementation should be offered to CD patients at least during the first years of gluten free diet [423]. Expert recommendations for the management of $\mathrm{CD}$ in children recommended to provide counselling on age-appropriate intake of calcium and vitamin $\mathrm{D}$ supplementation by a dietitian to $\mathrm{CD}$ children both at diagnosis and follow-up (grade of evidence high, strength of statement strong) [430]. Future research will clarify the ideal vitamin $\mathrm{D}$ dosing regimen to treat vitamin D deficiency and to maintain serum 25(OH)D levels $\geq 30 \mathrm{ng} / \mathrm{ml}$ in CD children and adolescents [406].

\section{Obesity and metabolic syndrome}

Vitamin $\mathrm{D}$ status is influenced by adiposity because adipose tissue represents a site of storage for lipophilic substances [434, 435]. In fact, obese children frequently show reduced serum 25(OH)D levels [66, 436]. Particularly, obese Italian children and adolescents have high prevalence of vitamin D deficiency and insufficiency [50,71, 75, 78-80, 83, 84, 437, 438]. Two meta-analyses confirmed that vitamin D deficiency was associated with obesity in children, adolescents and adults irrespective of age, latitude, and cut-offs used to define deficiency $[439,440]$.

Conversely, vitamin D deficiency does not lead to obesity [441]. A recent meta-analysis of 4 RCTs and 11 non-RCTs, only 1 enrolling children [442], showed that weight loss marginally improved vitamin $\mathrm{D}$ in comparison with weight maintenance under similar vitamin $D$ intake [443], confirming that increased adiposity causes 
suboptimal serum $25(\mathrm{OH}) \mathrm{D}$ concentrations. On the contrary, two meta-analyses enrolling mainly adults showed that vitamin D supplementation did not decrease adiposity [444, 445]. Animal models and in vitro studies report that vitamin D may influence both pancreatic insulin secretion and insulin sensitivity in skeletal muscle [446, 447]. Thus, several authors have suggested that vitamin $D$ deficiency could play a role in worsening the comorbidities of pediatric obesity. In 2009, Reis et al. reported that obese children with lower serum $25(\mathrm{OH}) \mathrm{D}$ levels had a higher risk for low high density lipoprotein cholesterol, high blood pressure, and elevated fasting glucose [448]. Few years later, Roth et al. showed an inverse relationship between serum 25(OH)D levels and insulin resistance [449]. In 2007, Reinehr et al. reported no correlation between insulin sensitivity and vitamin D levels, even after weight loss [442]. Moreover, Erdönmez et al. showed no difference in vitamin D status between obese with or without impaired glucose homeostasis [450]. Further, contrasting results came from the studies investigating the association between vitamin $\mathrm{D}$ deficiency and non-alcoholic fatty liver disease [451-453].

Several RCTs have been conducted to evaluate the efficacy of vitamin D supplementation as a potential therapy for each component of metabolic syndrome. In a 16-week RCT with $2000 \mathrm{IU} /$ day of vitamin D authors reported that therapy was able to reduce arterial stiffness in black obese adolescents [151]. Other papers describe a significant reduction of insulin resistance index after vitamin D supplementation $[454,455]$. A prospective study showed that high dose vitamin $\mathrm{D}_{2}$ treatment (20000 IU/day for 28 days) increased insulin sensitivity and improved abnormal glucose metabolism in obese children [456]. More recent findings have reported no influence of different vitamin D supplementation schedules on serum lipid levels, glucose homeostasis, glycated hemoglobin and pancreatic insulin secretion [457-459]. A recent Italian RCT showed that supplementation with vitamin D (800 IU/day) plus docosahexanoic acid improved insulin-resistance, lipid profile, aminotransferases levels, and activity score in obese children with non alcoholic fatty liver disease and vitamin $\mathrm{D}$ deficiency [460]. Finally, two recent meta-analyses showed that vitamin D supplementation had no significant effect on glucose and insulin metabolism [461] and on changes in the concentrations of inflammatory biomarkers (C-reactive protein, tumor necrosis factor alpha, IL-6) in obese and overweight adolescents and adults [462].

At present the need for evaluate serum 25(OH)D levels in obese children is still debated. The Endocrine Society [11], United Arab Emirates guidelines [27] and The Society for Adolescent Health and Medicine [21] recommended to screen all obese children and adolescents as they are at increased risk for vitamin D deficiency. On the contrary, the AAP suggested that more evidence is needed before recommendations can be made regarding screening of obese subjects [23].

Different vitamin D dose regimens have been proposed in obese children and adolescents for both vitamin D supplementation and treatment of deficiency [463-467]. The Endocrine Society Clinical Practice Guideline suggested in obese children vitamin D supplementation at doses 2-3 times higher than those recommended for age to satisfy their body's vitamin D requirement. Similarly, obese children with vitamin $\mathrm{D}$ deficiency should be treated with vitamin D at doses 2-3 times higher than those recommended for non-obese pediatric population for at least 6 weeks [11]. Similarly, Guidelines for Central Europe recommended in obese children vitamin D supplementation (1200-2000 IU/day depending on severity of obesity) between September and April, or throughout the whole year if sufficient skin synthesis of vitamin D is not ensured in the summer [20]. Regarding adolescence, the Society for Adolescent Health and Medicine recommended that obese adolescent without a $25(\mathrm{OH}) \mathrm{D}$ measurement empirically receive vitamin D supplementation at $1000 \mathrm{IU} /$ day [21]. More recently, United Arab Emirates guidelines also recommended vitamin $\mathrm{D}$ supplementation in obese children and adolescents (1200-2000 IU/day depending on severity of obesity, season and sun exposure) throughout the year if sufficient skin synthesis if vitamin D is not ensured during winter [27]. Differently, SACN confirmed that obese people are at risk of low serum 25(OH)D concentrations, but highlighted that currently evidence is insufficient to recommend for obese individuals different reference nutrient intake of vitamin D from that proposed for the general UK population [25]. Recently, a doubleblind RCT analyzing the effects of vitamin $\mathrm{D}_{3}$ supplementation (1200 IU/day for 26 weeks vs. placebo) in overweight or obese children with hypovitaminosis D has been proposed [468].

In conclusion, obese children have higher risk of vitamin D deficiency and insufficiency. It is still unknown the role of this nutrient in the natural history of obesity and its comorbidities. More RCTs are needed to evaluate the influence of vitamin D supplementation on controlling metabolic syndrome. Standardization of study design and supplementation dose should improve the evaluation of the efficacy of supplementation. At present, considering that obese Italian children have higher prevalence of vitamin D deficiency and insufficiency then normal weight individuals, we suggest in obese children and adolescents vitamin D supplementation at higher doses than those recommended for age (1000$1500 \mathrm{IU} /$ day) from the end of fall to the beginning of spring (November-April) to ensure an adequate vitamin D status. Obese subjects with reduced sun exposure during summer should receive vitamin D supplementation 
throughout the year. Finally, sensible sunlight exposure and outdoor physical exercise should be encouraged in obese children and adolescents.

\section{Autism and depression}

Autism is a complex disease that compromises nonverbal communication. Several observational studies have linked autism spectrum disorders and low serum 25(OH)D levels during pregnancy because of vitamin $\mathrm{D}$ pleiotropic activity [469-476]. Moreover, autism spectrum disorders affect dietary habits leading to food selectivity, thus patients could develop multiple nutritional deficiencies [477-479]. Particularly, a recent meta-analysis showed that serum $25(\mathrm{OH}) \mathrm{D}$ levels in children and adolescents (age 2-16 years) with autism spectrum disorders were significantly lower than controls, suggesting that lower vitamin $\mathrm{D}$ levels might be a risk factor for autism [480]. Few studies or case reports suggested that vitamin D supplementation can improve autism symptoms [481-484]. Nevertheless, a recent RCT enrolled 42 children with autism spectrum disorders showing that vitamin D supplementation (2000 IU/day of vitamin $\mathrm{D}_{3}$ for 20 weeks) had no effect on the primary outcome (the stereotypic behaviour subscale from the Aberrant Behaviour Checklist) in comparison with placebo [485]. Therefore, further RCTs are needed before recommending routine vitamin D supplementation in children with autism.

Depression affects about 1-6\% of children [486]. Vitamin $\mathrm{D}$ deficiency has been proposed as a possible cause of depression. In fact, VDR is expressed in different brain's areas involved in the pathogenesis of the disease [487, 488]. Moreover, the severity of symptoms is higher in winter when sun exposure is low [489]. Many studies report an association between inadequate serum 25(OH)D levels and a higher rate of depression or severity of symptoms both in adults and children [490-492]. In contrast, Fazeli et al. found no differences in vitamin D status and bone density among adolescents affected by major depression and healthy controls [493]. In agreement, Tolppanen and coworkers reported no association between serum 25(OH)D levels and any mood disorders [494]. A small Swedish study showed that depressed adolescents with serum 25(OH)D levels $<24 \mathrm{ng} / \mathrm{ml}$ supplemented with vitamin D3 (4000 IU/ day for 1 month followed by 2000 IU/day for 2 months) improved symptoms related to depression [491]. Metaanalyses assessing the effect of vitamin D supplementation in depressed adults founded conflicting results [495-497]. As literature shows contrasting results because of different methods and study designs, more studies are needed to define the role of vitamin D in pathogenesis and severity of depression, particularly in the pediatric age.

\section{Pregnancy and breastfeeding}

The high prevalence of vitamin D deficiency in pregnant women is a worldwide health problem regardless of latitude, food intake or socio-economic status [93]. Data about vitamin $\mathrm{D}$ intake and status in pregnant women are relatively scarce but confirm this scenario. A recent Italian study [81] evaluated serum 25(OH)D levels at term of pregnancy in Italian and immigrant women and in cord blood: $18 \%$ and $43.6 \%$ of Italian, $48.8 \%$ and $41 \%$ of immigrant women had severe $(<10 \mathrm{ng} / \mathrm{ml})$ or mild $(<20 \mathrm{ng} / \mathrm{ml}) 25(\mathrm{OH}) \mathrm{D}$ deficiency, respectively. Likewise, severe $25(\mathrm{OH}) \mathrm{D}$ deficiency was found in $38 \%$ of Italian and in $76.2 \%$ of foreign newborns. Semi-quantitative food questionnaires showed that the average dietary vitamin D intake is $136 \pm 68 \mathrm{IU}$, significantly lower than the Institute of Medicine recommended amount (600 IU) [10]. Another Italian study [498] examined 24 women (light and dark skinned) at full-term pregnancy: 23 out of 24 women had vitamin D deficiency. Similarly, both light and dark skinned babies showed vitamin D deficiency at birth.

During pregnancy vitamin $\mathrm{D}$ metabolism changes so that maternal serum $1,25(\mathrm{OH})_{2} \mathrm{D}$ levels significantly rise to meet increased calcium requirements for fetal skeleton mineralization, whereas fetal vitamin D stores are exclusively dependent on maternal vitamin $\mathrm{D}$ status. The increase of $1,25(\mathrm{OH})_{2} \mathrm{D}$ in the mother plays a key role in modulating calcium homeostasis in both mother and fetus, first of all doubling maternal intestinal calcium absorption [499]. Moreover, maternal bone turnover is reduced in the first half of pregnancy, followed by the progressive increase of bone resorption, reaching the maximum in the 3rd trimester of pregnancy, to ensure fetal supply of calcium for fetal bone development. In addition, vitamin D plays a key role in the immunological adaptation needed for the onset and maintenance of a normal pregnancy [500].

Increasing scientific evidence suggests that hypovitaminosis $\mathrm{D}$ in the mother may have an impact on both maternal and child health. Reduced 25(OH)D levels during pregnancy and breastfeeding may affect maternal bone turnover [501]. Moreover, maternal vitamin D deficiency has been associated with increased risk of several obstetrics diseases (spontaneous pregnancy loss, preterm and/or small-for-gestational age birth, gestational diabetes pre-eclampsia) [502-506]. In addition, vitamin D deficiency during pregnancy may negatively affect longterm offspring extraskeletal health outcomes, with increased risk of infant respiratory tract infections, asthma, wheeze, and eczema [273, 380, 507, 508].

Vitamin D supplementation during pregnancy can improve maternal and cord blood 25(OH)D concentrations in women with low 25(OH)D levels [509]. Supplementing pregnant women with vitamin $\mathrm{D}$ in a single or continued dose increases serum $25(\mathrm{OH}) \mathrm{D}$ at term and may reduce the risk of preeclampsia, low birth weight and preterm birth. However, larger and better-designed controlled randomized trials are required to confirm these effects [510]. 
The Royal College of Obstetricians \& Gynaecoloists recommended vitamin D supplementation with $400 \mathrm{IU} /$ day for all pregnant women. Higher doses (at least $1000 \mathrm{IU} /$ day) may be required in high-risk women (women with increased skin pigmentation, reduced exposure to sunlight, or those who are socially excluded or obese) [511]. Indeed, vitamin D supplementation with $400 \mathrm{IU} /$ day has been reported insufficient in pregnancy, particularly for women at higher risk of vitamin D deficiency [512, 513]. More recently, Wagner et al. suggested that a vitamin D intake of at least $4000 \mathrm{IU} /$ day should be considered in all pregnant women to maintain serum 25(OH)D levels $\geq 40 \mathrm{ng} / \mathrm{ml}[513,514]$.

Screening for vitamin D deficiency during pregnancy is still debated. For example, the Endocrine Society considered gestation as a period at significant risk for deficiency and thus recommended serum $25(\mathrm{OH}) \mathrm{D}$ evaluation in all pregnant women [11]. More recently, the Royal College of Obstetricians \& Gynaecoloists suggested to evaluate 25(OH)D concentrations during pregnancy in selected case (Table 9) [511]. Moreover, the Society for Adolescent Health Medicine recommended routine $25(\mathrm{OH}) \mathrm{D}$ testing in pregnant adolescents [21].

In the present Consensus we recommend vitamin $\mathrm{D}$ supplementation in all pregnant and breastfeeding women since the beginning of pregnancy at a dose of $600 \mathrm{IU} /$ day. Women with risk factors for vitamin D deficiency should receive higher dosages (1000-2000 IU/ day). We do not recommend routine screening of serum $25(\mathrm{OH}) \mathrm{D}$ levels in all pregnant and breastfeeding women, but we suggest to consider vitamin D testing in women with multiple risk factors for vitamin D deficiency, particularly if not receiving vitamin $\mathrm{D}$ supplementation.

Table 9 Indications for serum 25(OH)D evaluation during pregnancy (modified from [511])

- Non-Caucasian ethnicity with dark skin pigmentation
- Reduced sunlight exposure (i.e. veiled women) and/or constant
use of sunscreens
- Malabsorption syndromes
- Chronic therapies affecting vitamin D metabolism
- Obesity
- Risk of pre-eclampsia
- Alcohol abuse
- Bone pain
- Hypocalcemia
- A previous child with rickets
- Pregnant adolescents

\section{Appendix. Management of asymptomatic vitamin $D$ deficiency and insufficiency}

In recent years some international Societies and Committees proposed various regimens to treat of vitamin $\mathrm{D}$ deficiency [9, 11, 20-23]. The AAP recommended to treat vitamin D deficiency administering $2000 \mathrm{IU} /$ day or $50,000 \mathrm{IU} /$ week of vitamin $\mathrm{D}_{2}$ or $\mathrm{D}_{3}$ (independent of weight) for 6 week in infants (0-12 months) and for 68 weeks in children and adolescents (1-18 years), suggesting that vitamin $\mathrm{D}_{3}$ may be more potent than vitamin $D_{2}$ [23]. After completion of treatment, serum $25(\mathrm{OH}) \mathrm{D}$ concentrations should be revaluated, as it is not unusual for a second course of treatment to be necessary to achieve adequate vitamin D status [23]. Particularly, maintenance therapy with standard doses or with doses two or three times higher than those recommended for healthy children is recommended after treatment $[9,11,20-23]$.

Relatively few studies evaluated the efficacy of different regimens with vitamin $D_{2}$ or vitamin $D_{3}$ for the treatment of vitamin $\mathrm{D}$ deficiency in otherwise healthy children.

\section{Studies with daily or weekly regimens}

In vitamin $\mathrm{D}$ deficient infants younger than 2 years, either $2000 \mathrm{IU}$ of vitamin $\mathrm{D}_{2}$ or vitamin $\mathrm{D}_{3}$ daily or $50000 \mathrm{IU}$ of vitamin $\mathrm{D}_{2}$ weekly for 6 weeks equally increased serum 25(OH)D levels [515]. A recent RCT in children (25 years) with vitamin D deficiency showed that treatment with oral $4000 \mathrm{IU} /$ day or $30000 \mathrm{IU} /$ week for 12 weeks or a single intramuscular dose of $300000 \mathrm{IU}$ of vitamin $\mathrm{D}_{3}$ followed by a maintenance dose of $400 \mathrm{IU} /$ day increased and maintained serum 25(OH)D concentration $>30 \mathrm{ng} /$ $\mathrm{ml}$ after 1 year [516]. Daily administration of $2000 \mathrm{IU}$ of vitamin $\mathrm{D}_{3}$ for 16 weeks was effective in increasing serum $25(\mathrm{OH}) \mathrm{D}$ levels $>30 \mathrm{ng} / \mathrm{ml}$ also in black adolescents (1418 years) with vitamin D deficiency [151]. Another RCT showed that adult-size adolescents require high-dose vitamin $\mathrm{D}_{3}$ (at least $5000 \mathrm{IU} /$ day for 8 week) to correct deficiency [517]. Particularly, as discussed before, the administration of $50000 \mathrm{IU} /$ week for 6-8 weeks may be insufficient to increase $25(\mathrm{OH}) \mathrm{D}$ concentration $>30 \mathrm{ng} / \mathrm{ml}$ in obese children and adolescents $[466,517]$. The administration of $60000 \mathrm{IU}$ of vitamin $\mathrm{D}_{3}$ weekly for 4-8 weeks followed by 600 IU daily for 12 weeks in Indian adolescents [518] or a regimen of $60000 \mathrm{IU} /$ week of vitamin $\mathrm{D}_{3}$ for 8 weeks followed by $60000 \mathrm{IU} /$ fortnight in young Indian females [519] were both effective in increasing and maintaining 25(OH)D levels in deficient individuals. Adolescents treated with $14000 \mathrm{IU}$ of vitamin $\mathrm{D}_{3}$ weekly (equivalent to 2000 IU daily) for 1 year normalized their 25(OH)D levels $[166,167,520]$. A recent 1-year-RCT compared three different regimens for asymptomatic children and adolescents with vitamin D deficiency and insufficiency (400 IU/day, 45000 IU weekly for 2 months then 400 IU daily, 2000 IU/ 
day for 3 months then $1000 \mathrm{IU} /$ day), suggesting that low loading dose with high maintenance dose is preferred to achieve steady increase in serum 25(OH)D levels avoiding hypercalcemic side effects [521]. Lower doses as 200 IU/day, $400 \mathrm{IU} /$ day, $800 \mathrm{IU} /$ day $[147,153]$ or $1400 \mathrm{IU} /$ week for 1 year [166], $1000 \mathrm{IU} /$ day for 6 months [159], or $5000 \mathrm{IU} /$ week for 8 weeks [165] were not able to normalize $25(\mathrm{OH}) \mathrm{D}$ levels in several pediatric populations, including Italian children and adolescents supplemented with $400 \mathrm{IU} /$ day for 1 year [78].

\section{Studies with monthly or other regimens}

The majority of these studies have been conducted in small populations of adolescents. Several schedules have been used, with conflicting results.

The administration of $60000 \mathrm{IU} /$ month of vitamin $\mathrm{D}_{3}$ for 12 months in Indian children was effective in raising $25(\mathrm{OH}) \mathrm{D}$ concentrations $>30 \mathrm{ng} / \mathrm{ml}$ [171], while another study showed that 60000 IU of vitamin $D_{3}$ monthly or every 2 months for 12 months in Indian females (6-17 years) increased 25(OH)D levels in the range of insufficiency [172]. Similarly, a RCT in Iranian adolescents showed that $50000 \mathrm{IU} /$ months of vitamin $\mathrm{D}_{3}$ for 5 months increased serum 25(OH)D levels but remained insufficient [170]. Two studies evaluated the efficacy of administering a bolus dose of vitamin $\mathrm{D}_{2}$, 150000 IU [225] or 300000 IU [224], every 3 months for 12 months in adolescent females with severe vitamin D deficiency, with conflicting results. Indeed, only in the study of Khadilkar et al. serum 25(OH)D concentrations increased $>30 \mathrm{ng} / \mathrm{ml}$. Adolescents with severe vitamin D deficiency treated with an intramuscular injection of a megadose of vitamin $\mathrm{D}_{3}(10000 \mathrm{IU} / \mathrm{Kg}$, maximum $600000 \mathrm{IU})$ had insufficient serum 25(OH)D after 3 months [522]. Both 300000 and 600000 IU single oral vitamin-D bolus were effecting in treating vitamin $\mathrm{D}$ deficiency in young children (3 months-3 years) but a significant percentage developed hypercalcemia and/or hypercalciuria [195]. On the contrary a stoss therapy (oral single-dose of $10000 \mathrm{IU} / \mathrm{Kg}$ or $300000 \mathrm{IU}$ of vitamin $D_{3}$ ) has been demonstrated effective and safe in the treatment of vitamin $\mathrm{D}$ deficiency in older children (mean age 10.6 \pm 4.4 years) without rickets [523]. However, at present safety data in both the short- and the long-term of monthly or other vitamin D regimens lack due to the nature of the studies, especially in young children.

Different dose regimens have been proposed in conditions and diseases known to be a risk for vitamin D deficiency. However, all the studies have been conducted in small populations.

Regarding children receiving anti-retroviral drugs, Kakalia et al. found that in children infected with HIV and vitamin D insufficiency a daily intake $\geq 1600 \mathrm{IU} /$ day of vitamin $\mathrm{D}_{3}$ vitamin $\mathrm{D}$ may be required to achieve serum 25(OH)D levels $>30 \mathrm{ng} / \mathrm{ml}$ [524]. Higher doses of 4000 or $7000 \mathrm{IU} /$ day of vitamin $\mathrm{D}_{3}$ for $6-12$ weeks or 1 year increased $25(\mathrm{OH}) \mathrm{D}$ levels in the range of sufficiency in the majority of the patients with a variable prevalence of hypercalcemia which required no clinical intervention [289, 525-527]. Differently, regimens with 50,000 IU monthly [528] or 100000 IU of vitamin $D_{3}$ every 2-3 months normalized $25(\mathrm{OH}) \mathrm{D}$ levels only in a half of the patients $[288,529,530]$. In children on longterm antiepileptic drugs (valproate, lamotrigine, topiramate, clonazepam, gabapentin, carbamazepine, phenytoin, phenobarbital), the administration of $2000 \mathrm{IU} /$ day of vitamin $\mathrm{D}_{2}$ for 1 year slightly increased mean $25(\mathrm{OH})$ D level from $18.0 \pm 9.1$ to $22.9 \pm 8.4 \mathrm{ng} / \mathrm{ml}$ [531]. No trials with different vitamin $D_{2}$ or vitamin $D_{3}$ regimens have been conducted in children under chronic corticosteroid treatments. For treatment of vitamin D deficiency in obese or IBD children see specific chapters.

At present there is no strong evidence about whether to treat asymptomatic children with vitamin D insufficiency [23]. The Society for Adolescent Health and Medicine recommended to supplement vitamin D insufficient with vitamin D $1000 \mathrm{IU} /$ day for at least 3 months [21]. In the case of vitamin D insufficiency, particularly in subjects at risk for vitamin D deficiency, we recommended starting vitamin $\mathrm{D}$ supplementation according to the modalities and requirements recommended for age.

\section{Conclusions}

Vitamin D status is a key determinant of bone health during childhood and adolescence. Nutritional rickets cases are still reported in Italy, thus adequate national strategies to prevent vitamin D deficiency are needed. Moreover, the recently suggested role of vitamin $\mathrm{D}$ in the development of other non-skeletal diseases reinforced the interest in the promotion of an adequate vitamin D status during pediatric age. The present Consensus paper aims to give practical approach to vitamin D supplementation for Italian infants, children and adolescents. Particularly, vitamin D supplementation should be recommended in all infants in the first year of life, independently of the type of feeding. Supplementation should be subsequently individualized in terms of regimen and duration on the basis of the presence of risk factors for vitamin D deficiency. More studies, particularly RCTs, are needed to confirm the promising role of vitamin $\mathrm{D}$ in the promotion of the global health of children.

\section{Summary of recommendations \\ Definition of vitamin D status}

- Individual vitamin D status can be assessed evaluating serum circulating 25(OH)D levels. 
- Depending on 25(OH)D levels, vitamin D status can be defined as follows:

Sufficiency $\geq 30 \mathrm{ng} / \mathrm{ml}$

Insufficiency $20-29 \mathrm{ng} / \mathrm{ml}$

Deficiency $<20 \mathrm{ng} / \mathrm{ml}$

Severe deficiency $<10 \mathrm{ng} / \mathrm{ml}$

- The term hypovitaminosis $\mathrm{D}$ refers to serum $25(\mathrm{OH}) \mathrm{D}$ levels $<30 \mathrm{ng} / \mathrm{ml}$.

\section{Evaluation of vitamin D status}

- The isotope dilution- LC-MS/MS is considered the preferred method for measuring serum $25(\mathrm{OH}) \mathrm{D}$ levels, especially in the neonatal period. However, considering the reduced availability on the Italian territory of this method, other reliable immunoassay methods can be used if performed in certified laboratories, with the exclusion of neonates.

\section{Prevalence of hypovitaminosis D in Italy in pediatric age}

- Available epidemiological studies show a high prevalence of hypovitaminosis D (above 50\%) throughout Italy. Adolescents are particularly at risk of hypovitaminosis D.

- Vitamin D status of newborns is influenced by ethnicity, season of birth, and maternal vitamin D status during pregnancy.

- Vitamin D status of children and adolescents is influenced by sun exposure, seasonality, ethnicity, and body mass index.

\section{Vitamin D supplementation \\ 0-12 months}

- We recommend vitamin D supplementation in the first year of life to ensure an adequate vitamin D status and to prevent nutritional rickets.

- We recommend vitamin D supplementation in all newborns independently of the type of feeding.

- Vitamin D supplementation should be started within the first days of life and continued throughout the first year.

- Infants born at term without risk factors for vitamin D deficiency should receive $400 \mathrm{IU} /$ day of vitamin D.

- In the presence of risk factors for vitamin $\mathrm{D}$ deficiency (Table 6) up to 1000 IU/day of vitamin D can be given.

- In the first year of life we recommend daily administration of vitamin D.

- We recommend against using vitamin D metabolites and their analogs (calcifediol, alfacalcidol, calcitriol, and dihydrotachysterol) for the routine vitamin D supplementation. The administration of these compounds increases the risk of hypercalcemia and is not able to maintain and/or restore vitamin D stores.

- We recommend against routine $25(\mathrm{OH}) \mathrm{D}$ testing in infants in the first year of life. We suggest to measure serum 25(OH)D levels in infants with multiple risk factors for vitamin D deficiency (Table 6).

\section{Preterm infants}

- We suggest for VLBW infants a vitamin D intake of 200-400 IU/day (including the amount administered through parenteral nutrition, fortified breast milk, or preterm infant formula).

- When VLBW infants reach a weight $\geq 1500 \mathrm{~g}$ and full enteral nutrition we suggest vitamin $D$ supplementation at 400-800 IU/day.

- We recommend vitamin D supplementation at 400-800 IU/day for preterm infants with birth weight $\geq 1500 \mathrm{~g}$.

- After a post-conceptional age of 40 weeks, recommendations for vitamin D supplementation are equal to those for healthy term infants.

- We recommend against routine $25(\mathrm{OH}) \mathrm{D}$ testing in preterm newborns.

\section{1-18 years}

- We recommend vitamin D supplementation in children and adolescents with risk factors for vitamin D deficiency (Table 7). Moreover, we recommend to evaluate modifiable life-style risk factors for deficiency, particularly a reduced sun exposure. Ensuring an adequate vitamin D intake is particularly important during adolescence.

- We recommend daily vitamin D supplementation ranging from $600 \mathrm{IU} /$ day (i.e. in presence of reduced sun exposure) up to $1000 \mathrm{IU} /$ day (i.e. in presence of multiple risk factors for vitamin $\mathrm{D}$ deficiency).

- In cases of poor compliance, supplementation with intermittent dosing (weekly or monthly doses for a cumulative monthly dose of 18000-30000 IU of vitamin $\mathrm{D}$ ) can be considered, starting from children aged 5-6 years and particularly during adolescence.

- We suggest vitamin D supplementation from the end of fall to the beginning of spring (NovemberApril) in children and adolescents with reduced sun exposure during summer. We suggest continuous vitamin D supplementation in cases of permanent risk factors for vitamin $\mathrm{D}$ deficiency.

- Individuals on anticonvulsants, oral corticosteroids, antimicotics and antiretroviral drugs should receive at least 2-3 times more vitamin $\mathrm{D}$ than the daily requirement recommended for age. 
- We endorsed as Tolerable Upper Intake Levels of vitamin D those proposed by EFSA in 2012 (1000 IU/day for infants; 2000 IU/day for children ages 1 to 10 years; $4000 \mathrm{IU} /$ day for children and adolescents ages 11 to 17 years).

- We recommend against using vitamin D metabolites and their analogs (calcifediol, alfacalcidol, calcitriol, and dihydrotachysterol) for the routine vitamin $\mathrm{D}$ supplementation. The administration of these compounds increases the risk of hypercalcemia and is not able to maintain and/or restore vitamin D stores.

- We recommend against routine $25(\mathrm{OH}) \mathrm{D}$ testing in children and adolescents. We suggest to measure serum 25(OH)D levels in presence of multiple risk factors for vitamin D deficiency. Vitamin D status should be monitored at least yearly in subjects that require supplementation during the whole year because affected from pathological conditions or receiving drugs affecting vitamin $\mathrm{D}$ metabolism (Table 7).

\section{Skeletal actions of vitamin D \\ Nutritional rickets}

- Children of immigrants living in industrialized countries are at increased risk of nutritional rickets because they usually present several risk factors for vitamin $\mathrm{D}$ deficiency such as prolonged breastfeeding without vitamin D supplementation, increased skin pigmentation, reduced sun exposure due to cultural habits (i.e. veiling), and reduced intestinal calcium uptake due to an excessive intake of high-phytates foods.

- In suspicion of nutritional rickets we recommend the assessment of serum $25(\mathrm{OH}) \mathrm{D}$, parathyroid hormone, alkaline phosphatase, calcium, and phosphorus levels and an X-rays evaluation of metaphyseal sites (wrists and ankles) to confirm the diagnosis.

- Treatment of nutritional rickets is based on the administration of vitamin D (2000 IU/day in patients aged less than 1 year, 3000-6000 IU/day in patients aged 1 to 12 years and $6000 \mathrm{IU} /$ day in patients older than 12 years for a minimum of 3 months) and calcium (30-75 mg/kg/day of elemental calcium in 3 divided doses, starting at a higher dose and weaning down to the lower end of the range over 2-4 weeks).

- Vitamin D metabolites and their analogs (calcifediol, alfacalcidol, calcitriol, and dihydrotachysterol) are not recommended for routine treatment of nutritional rickets.

- Daily administration of vitamin D is preferred in infants. Intermittent administration of vitamin D may be considered in children and adolescents with poor compliance with daily treatment (i.e. $50000 \mathrm{IU}$ weekly for 6-8 consecutive weeks or $100000 \mathrm{IU}$ monthly for 3-4 consecutive months).

- We recommend against the administration of a single large dose of vitamin D > 300000 IU.

- After rickets healing, we recommend to continue vitamin D supplementation according to age (400-1000 IU/day in the first year of life and 600-1000 IU/day from 1 to 18 years).

\section{Bone health}

- Vitamin D directly influences bone mass acquisition contributing to the regulation of calcium-phosphorus metabolism, and indirectly stimulating the development of muscle tissue.

- Available evidence suggests a positive effect of vitamin $\mathrm{D}$ supplementation on bone mass acquisition in children and adolescents with vitamin $\mathrm{D}$ deficiency.

- Recent studies suggest a relationship between maternal vitamin D status during pregnancy and bone mass of the fetus and the newborn. Uncertain evidence exists on the relationship with bone mass later in life until the acquisition of bone mass.

\section{Extraskeletal actions of vitamin D \\ Respiratory infections}

- Recent studies suggest an association between vitamin $\mathrm{D}$ deficiency and the severity or the incidence of respiratory infections in children. However, because current evidence is weak, we suggest against vitamin D administration as a therapy for respiratory infections, beyond the correction of a documented vitamin D deficiency.

- No definitive evidence exists to recommend vitamin D supplementation for prevention of respiratory infections (non-associated with wheezing) or recurrent respiratory infections. However, some studies suggested that serum 25(OH)D higher than those needed for the prevention of nutritional rickets may be necessary to exert a regulatory effect on the immune system.

- We recommend against routine $25(\mathrm{OH}) \mathrm{D}$ testing in children with respiratory infections.

- A single RCT suggested that vitamin D supplementation may help in preventing non complicated acute otitis media. However, considering this limited evidence, evaluation of serum 25(OH)D levels may be reasonable before starting supplementation in these children.

\section{Other infections}

- Reduced serum 25(OH)D levels are found in children with different types of infectious diseases (tuberculosis, HIV, viral hepatitis, acute diarrhea). 
However, available evidence does not support a causal relationship between hypovitaminosis $\mathrm{D}$ and infections.

- We suggest the evaluation of vitamin D status only in patients affected by tuberculosis or HIV infection, as they may benefit from vitamin $\mathrm{D}$ supplementation, in particular due to concomitant treatments that influence vitamin D metabolism.

- We recommend against vitamin D supplementation to reduce incidence or severity of non-respiratory infections in children. However, as few studies showed that vitamin D supplementation improves clinical parameters in patients with active tuberculosis or HIV infection, more rigorous and extensive studies are needed to evaluate the role of vitamin D supplementation in infectious diseases, considering also the setting of care, children's age and nutritional status, potential co-infections and compliance with anti-infective therapy.

\section{Asthma}

- Recent meta-analyses did not find an association between 25(OH)D levels in cord blood or during pregnancy and the development of asthma later in life.

- Several studies showed a relationship between latitude, prevalence of hypovitaminosis D and increase in allergic asthma prevalence in the pediatric population.

- Low serum 25(OH)D levels are associated with increased asthma severity and increased risk of asthma exacerbations requiring hospitalization or medical treatment. Recent meta-analyses suggest that supplementation with vitamin D (500-2000 IU/day) may reduce the risk of asthma exacerbation.

- We recommend against routine $25(\mathrm{OH}) \mathrm{D}$ testing in children with asthma.

\section{Atopic dermatitis and allergic diseases}

- Low serum 25(OH)D levels are associated with increased incidence and/or severity of $\mathrm{AD}$ in children in most but not all studies. Indeed, a pathogenetic role of vitamin $\mathrm{D}$ in $\mathrm{AD}$ has yet to be demonstrated.

- We recommend against routine $25(\mathrm{OH}) \mathrm{D}$ testing in children with AD. Serum 25(OH)D evaluation may be considered in children with severe $\mathrm{AD}$ unresponsive to common therapy and multiple risk factors for vitamin D deficiency.

- In pediatric population there is limited evidence regarding a possible favourable effect of vitamin $D$ supplementation on several aspects of AD.

- A short trial of vitamin D supplementation can be considered in patients with severe $\mathrm{AD}$ unresponsive to common therapy, especially in the late winter-early spring period. In presence of documented vitamin D deficiency, we recommended adequate treatment to restore vitamin D status, followed by supplementation at doses recommended for age.

- Vitamin D supplementation for primary prevention of allergic diseases, including food allergies, remains an attractive area of study, but actual evidence does not allow to make any recommendation.

\section{Type 1 diabetes mellitus}

- Children and adolescents with T1DM are at risk for vitamin D deficiency.

- Recommended vitamin D intakes in patients with T1DM are the same as those for the healthy pediatric population.

- Recommendations for vitamin D treatment in subjects with T1DM and vitamin D deficiency are the same as those for the healthy pediatric population.

- At present, there is no evidence that vitamin D supplementation may delay the development of T1DM or may ameliorate its clinical features. However, we recommend to maintain vitamin $\mathrm{D}$ intake for age and to treat vitamin D deficiency if found.

- We recommend against routine $25(\mathrm{OH}) \mathrm{D}$ testing in children with T1DM.

\section{Inflammatory bowel diseases}

- In patients with IBDs (Crohn's disease or ulcerative colitis) we suggest to evaluate serum 25(OH)D levels at diagnosis and at least yearly, preferably in the late winter-early spring period.

- We recommend continuous vitamin D supplementation at higher doses than those recommended for age (at least 1000-1500 IU/day).

- We recommend to treat vitamin D deficiency with daily vitamin $\mathrm{D}$ at higher doses than those recommended for otherwise healthy pediatric population (at least 2000-4000 IU/day), for a minimum of 6-8 weeks.

- Intermittent bolus doses of vitamin D for a cumulative dose of at least 400000 IU should be reserved for IBDs patients with vitamin D deficiency and poor compliance with daily treatment.

- After achieving vitamin D sufficiency, we recommend to continue with vitamin $\mathrm{D}$ supplementation at higher doses than those recommended for age (at least 1000-1500 IU/day).

\section{Celiac disease}

- We recommend to evaluate serum 25(OH)D levels in patients with $\mathrm{CD}$ at diagnosis and 6-12 months after the beginning of gluten-free diet if deficiency 
has been found. We suggest against further $25(\mathrm{OH}) \mathrm{D}$ evaluations in case of sufficient $25(\mathrm{OH}) \mathrm{D}$ levels or documented normalization of vitamin $\mathrm{D}$ status and strict adherence to the gluten-free diet.

- Recommendations for treatment of vitamin D deficiency in patients with newly diagnosed $\mathrm{CD}$ are equivalent to those for IBDs patients, as both these conditions are associated with intestinal malabsorption.

- As gluten-free diet restores normal intestinal absorption, after treatment of deficiency we recommend vitamin D supplementation according to the modalities and requirements for otherwise healthy children and adolescents.

\section{Obesity and metabolic syndrome}

- Epidemiological studies showed that obese children and adolescents are at high risk for vitamin D deficiency.

- Obesity is the cause and not the effect of this association because of the deposition of vitamin $\mathrm{D}$ in adipose tissue with consequent reduction in serum 25(OH)D levels.

- It is uncertain if vitamin D deficiency may worsen metabolic profile of obese children and adolescents.

- We suggest against vitamin D administration to improve obesity-related complications, given inconsistent results and the small number of studies.

- We suggest vitamin D supplementation at higher doses than those recommended for age (1000$1500 \mathrm{IU} /$ day) from the end of fall to the beginning of spring (November-April) in obese children and adolescents to ensure an adequate vitamin D status. Obese subjects with reduced sun exposure during summer should receive vitamin D supplementation throughout the year. Finally, sensible sunlight exposure and outdoor physical exercise should be encouraged in obese children and adolescents.

- We recommend against routine evaluation of 25(OH)D levels in obese subjects. If an obese individual does not receive vitamin $\mathrm{D}$ supplementation and has a sedentary indoor lifestyle with consequent reduced sun exposure, serum 25(OH)D evaluation may be considered to confirm vitamin $\mathrm{D}$ deficiency and start adequate treatment.

- In obese subjects with vitamin D deficiency we recommend vitamin $\mathrm{D}$ treatment at higher doses than those recommended for otherwise healthy pediatric population (at least 2000-4000 IU/day), for a minimum of 6-8 weeks.

\section{Autism}

- Autistic individuals frequently develop nutritional deficiencies, especially in presence of food selectivity; causal relationship with vitamin D deficiency is uncertain.

- We recommend against routine evaluation of 25(OH)D levels in children with autism.

- We recommend against vitamin D treatment to improve patient's performance considering the limited and conflicting available evidence.

\section{Depression}

- Epidemiological studies that evaluated an association between vitamin $\mathrm{D}$ deficiency and depression are lacking at present.

- We recommend against routine evaluation of 25(OH)D levels in children with depression.

- We recommend against vitamin D administration to improve mood.

\section{Pregnancy and breastfeeding}

- We suggest against routine screening of serum 25(OH)D levels in all pregnant and breastfeeding women. We suggest to consider serum 25(OH)D testing in women with multiple risk factors for vitamin D deficiency, particularly if not receiving vitamin $\mathrm{D}$ supplementation, and/or with specific conditions possibly affecting pregnancy course (Table 9).

- We recommend vitamin D supplementation in all pregnant and breastfeeding women at a dose of $600 \mathrm{IU} /$ day. Women with risk factors for vitamin D deficiency should receive higher dosages (1000-2000 IU/day).

- We suggest to start vitamin D supplementation at the beginning of pregnancy and continue for the entire duration of pregnancy and lactation.

\section{Appendix. Management of asymptomatic vitamin D deficiency and insufficiency}

- In children and adolescents with asymptomatic vitamin D deficiency $[25(\mathrm{OH}) \mathrm{D}<20 \mathrm{ng} / \mathrm{ml}]$ we recommend the administration of $2000 \mathrm{IU} /$ day or $50000 \mathrm{IU} /$ week of vitamin $\mathrm{D}_{2}$ or $\mathrm{D}_{3}$ for 6-8 weeks (8 weeks in adolescents) in order to obtain a sufficient vitamin D status $[25(\mathrm{OH}) \mathrm{D} \geq 30 \mathrm{ng} / \mathrm{ml}]$.

- After completion of treatment, serum 25(OH)D concentrations should be revaluated.

- In presence of adequate vitamin D status $[25(\mathrm{OH}) \mathrm{D} \geq 30 \mathrm{ng} / \mathrm{ml}]$, we recommend to continue vitamin D supplementation as recommended for age.

- In subjects with asymptomatic vitamin D deficiency assuming drugs interfering with vitamin D metabolism (anticonvulsants, oral corticosteroids, 
antifungals like ketoconazole, anti-retroviral drugs) we recommend vitamin $\mathrm{D}$ treatment at higher doses than those recommended for otherwise healthy pediatric population (at least 2000-4000 IU/day), for a minimum of 6-8 weeks.

- Considering available evidence, particularly the lack of Italian studies, at present we do not recommend other modalities different from daily or weekly administration of vitamin D to treat asymptomatic vitamin D deficiency.

- In case of detection of asymptomatic vitamin $\mathrm{D}$ insufficiency [25(OH)D between 20 and $29 \mathrm{ng} / \mathrm{ml}$ ], particularly in subjects at risk for vitamin $\mathrm{D}$ deficiency, we recommended to start vitamin D supplementation according to the modalities and requirements recommended for age.

\begin{abstract}
Abbreviations
1,25(OH) $)_{2} \mathrm{D}: 1,25$-dihydroxyvitamin D; 25(OH)D: 25-hydroxyvitamin D; AAP: American Academy of Pediatrics; AD: Atopic dermatitis; BMC: Bone mineral content; BMD: Bone mineral density; CD: Celiac disease; DXA: Dual-energy X-ray absorptiometry; EFSA: European Food Safety Authority; ESPGHAN: European Society for Paediatric Gastroenterology Hepatology and Nutrition; FEV1: Forced expiratory volume in the 1st second; HIV: Human immunodeficiency virus; IBD: Inflammatory bowel disease; IL: Interleukin; LC-MS/MS: Liquid chromatography-tandem mass spectrometry; PBM: Peak bone mass; pQCT: Peripheral quantitative computed tomography; PTH: Parathormone; RCT: Randomized controlled trial; SACN: Scientific Advisory Committee on Nutrition; T1DM: Type 1 diabetes mellitus; VDR: Vitamin D receptor; VLBW: Very low birth weight
\end{abstract}

\section{Acknowledgements}

We thank nurse Tania Minucciani, Dr. Sara Zanetta, Dr. Matteo Castagno, and Dr. Roberta Ricotti for help in preparing the manuscript.

Collaborators: Dora Di Mauro. Gastroenterology and Digestive Endoscopy Unit and Clinical Paediatrics Unit, Department of Paediatrics and Maternal Medicine, University of Parma Hospital Trust, Parma, Italy.

dora.dimauro@hotmail.com. Federica Gaiani. Gastroenterology and Digestive Endoscopy Unit and Clinical Paediatrics Unit, Department of Paediatrics and Maternal Medicine, University of Parma Hospital Trust, Parma, Italy. federica.gaiani@studenti.unipr.it. Cristiana Indolfi. Department of Woman, Child, and General and Specialized Surgery, Second University of Naples, Naples, Italy. Chiara Mandò. Department of Mother and Child, Hospital Luigi Sacco, University of Milano, Milano, Italy. chiara.mando@unimi.it.

\section{Availability of data and materials}

Complete literature research is included in this published article.

\section{Authors' contributions}

GS and FV have made major contributions to conception and design of the consensus and critical revision of the manuscript. All authors contributed to literature research. FV wrote the sections "Sources of vitamin D and dietary reference values", "Vitamin D supplementation", and "Skeletal actions of vitamin D". FP wrote the sections "Vitamin D deficiency: ranges, analytic methods, and epidemiology", "Type 1 diabetes mellitus", and "Management of asymptomatic vitamin D deficiency and insufficiency". FC wrote the section "Respiratory infections"; EC wrote the sections "Methods" and "Other infections"; MMDG wrote the section "Asthma", DP and LT wrote the section "Atopic dermatitis and allergic diseases", GLDA wrote the section "Inflammatory bowel diseases" and "Celiac disease"; EMDG wrote the sections "Obesity and metabolic syndrome" and "Autism and depression"; IC and MM wrote the section "Pregnancy and breastfeeding". All authors read and approved the final manuscript and summary recommendations.

Ethics approval and consent to participate

Not applicable.

\section{Competing interests}

The authors declare that they have no competing interests.

\section{Publisher's Note}

Springer Nature remains neutral with regard to jurisdictional claims in published maps and institutional affiliations.

\section{Author details \\ 'Department of Clinical and Experimental Medicine, Section of Paediatrics, University of Pisa, Pisa, Italy. ${ }^{2}$ Pediatric Unit, San Luca Hospital, Lucca, Italy. ${ }^{3}$ Division of Pediatrics, Department of Health Sciences, Interdisciplinary Research Center of Autoimmune Diseases (IRCAD), University of Piemonte Orientale, Novara, Italy. ${ }^{4}$ Pediatric Unit, Division of Pulmonology, Allergy, and Immunology, AOU Policlinico-Giovanni XXIII, Bari, Italy. ${ }^{5}$ Department of Mother and Child, Hospital Luigi Sacco, University of Milano, Milan, Italy. ${ }^{6}$ Pediatric Infectious Disease Unit, Department of Health Sciences, University of Florence, Anna Meyer Children's University Hospital, Florence, Italy. ${ }^{7}$ Gastroenterology and Digestive Endoscopy Unit and Clinical Paediatrics Unit, Department of Paediatrics and Maternal Medicine, University of Parma Hospital Trust, Parma, Italy. ${ }^{8}$ Department of Woman, Child and General and Specialist Surgery, University of Campania "Luigi Vanvitelli", Naples, Italy. ${ }^{9}$ Pediatric Primary Care, National Pediatric Health Care System, Milan, Italy. ${ }^{10}$ Department of Pediatrics, San Jacopo Hospital, Pistoia, Italy. ${ }^{11}$ Pediatric Primary Care, National Pediatric Health Care System, Novara, Italy. ${ }^{12}$ Pediatric Highly Intensive Care Unit, Department of Pathophysiology and Transplantation, Università degli Studi di Milano, Fondazione IRCCS Ca' Granda Ospedale Maggiore Policlinico, Milan, Italy. ${ }^{13}$ Division of Pediatrics, University of Piemonte Orientale, Novara, Italy. ${ }^{14}$ Pediatric Primary Care, National Pediatric Health Care System, Caserta, Italy. ${ }^{15}$ Department of Sciences for Health Promotion and Mother and Child Care, Neonatal Intensive Care Unit, AOUP, University of Palermo, Palermo, Italy.}

Received: 15 December 2017 Accepted: 16 April 2018 Published online: 08 May 2018

\section{References}

1. Saggese G, Vierucci F, Boot AM, Czech-Kowalska J, Weber G, Camargo CA Jr, et al. Vitamin D in childhood and adolescence: an expert position statement. Eur J Pediatr. 2015;174(5):565-76.

2. Hossein-nezhad A, Holick MF. Vitamin D for health: a global perspective. Mayo Clin Proc. 2013:88(7):720-55.

3. Gröber U, Spitz J, Reichrath J, Kisters K, Holick MF. Vitamin D: update 2013: from rickets prophylaxis to general preventive healthcare. Dermatoendocrinol. 2013;5(3):331-47.

4. Holick MF, Schnoes HK, DeLuca HF. Identification of 1,25dihydroxycholecalciferol, a form of vitamin $\mathrm{D}_{3}$ metabolically active in the intestine. Proc Natl Acad Sci U S A. 1971;68(4):803-4.

5. Programma nazionale per le linee guida (PNLG). Manuale metodologico Come produrre, diffondere e aggiornare raccomandazioni per la pratica clinica. Available at: http://www.iss.it/binary/lgmr2/cont/Manuale_PNLG. 1234439852.pdf. Accessed 01 Sept 2017.

6. Guidelines for the planning and management of $\mathrm{NIH}$ Consensus Development Conferences Online Bethesda (MD): National Institutes of Health, Office of the Director, Office of Medical Applications of Research; 1993. Updated Oct 2001

7. Società Italiana di Pediatria Preventiva e Sociale. Vitamina D in età pediatrica. Pediatr Prev Soc. 2015;3(Suppl):142-258. Available at: http://www sipps.it/pdf/rivista/anno10/2_3ss_2015.pdf. Accessed 01 Sept 2017

8. Canadian Paediatric Society. Vitamin D supplementation: recommendations for Canadian mothers and infants. Paediatr Child Health. 2007;12(7):583-98.

9. Misra M, Pacaud D, Petryk A, Collett-Solberg PF, Kappy M. Drug and therapeutics Committee of the Lawson Wilkins Pediatric Endocrine Society. Vitamin D deficiency in children and its management: review of current knowledge and recommendations. Pediatrics. 2008;122(2):398-417.

10. IOM (Institute of Medicine). Dietary reference intakes for calcium and vitamin D. Committee to review dietary reference intakes for calcium and vitamin D. Washington: National Academies Press; 2011.

11. Holick MF, Binkley NC, Bischoff-Ferrari HA, Gordon CM, Hanley DA, Heaney RP, et al. Evaluation, treatment, and prevention of vitamin D deficiency: an Endocrine Society clinical practice guideline. J Clin Endocrinol Metab. 2011;96(7):1911-30. 
12. Arundel P, Ahmed SF, Allgrove J, Bishop NJ, Burren CP, Jacobs B, et al. British Paediatric and adolescent bone Group's position statement on vitamin D deficiency. BMJ. 2012;345:e8182.

13. Vidailhet $M$, Mallet E, Bocquet $A$, Bresson JL, Briend $A$, Chouraqui JP, et al. Vitamin D: still a topical matter in children and adolescents. A position paper by the committee on nutrition of the French Society of Paediatrics. Arch Pediatr. 2012;19(3):316-28.

14. Martínez Suárez V, Moreno Villares JM, Dalmau Serra J, Comité de Nutrición de la Asociación Española de Pediatría. Recommended intake of calcium and vitamin D: positioning of the nutrition committee of the AEP. An Pediatr (Barc). 2012;77(1):57. e1-8

15. Federal Commission for Nutrition. Vitamin D deficiency: evidence, safety, and recommendations for the Swiss population. Expert report of the FCN Zurich: Federal Office for Public Health; 2012.

16. Nordic Council of Ministers, Nordic Nutrition Recommendations 2012. Integrating nutrition and physical activity, 5th ed., Norden, Copenhagen, Denmark, 2014. Available at: https://www.norden.org/en/theme/formerthemes/themes-2016/nordic-nutrition-recommendation/nordic-nutritionrecommendations-2012. Accessed 01 Sept 2017.

17. German Nutrition Society. New reference values for vitamin D. Ann Nutr Metab. 2012;60(4):241-6.

18. Health Council of the Netherlands, Evaluation of the Dietary Reference Values for Vitamin D, Health Council of the Netherlands, The Hague, 2012 (publication no. 2012/15E). Available at: https:/www.gezondheidsraad.nl/sites/default/files/ 201215EEvaluationDietaryReferenceVitaminD.pdf. Accessed 01 Sept 2017

19. Braegger C, Campoy C, Colomb V, Decsi T, Domellof M, Fewtrell M, et al. Vitamin D in the healthy European paediatric population. J Pediatr Gastroenterol Nutr. 2013;56(6):692-701.

20. Płudowski P, Karczmarewicz E, Bayer M, Carter G, Chlebna-Sokół D, Czech-Kowalska J, et al. Practical guidelines for the supplementation of vitamin D and the treatment of deficits in Central Europe - recommended vitamin $D$ intakes in the general population and groups at risk of vitamin $D$ deficiency. Endokrynol Pol. 2013;64(4):319-27.

21. Society for Adolescent Health and Medicine. Recommended vitamin D intake and management of low vitamin D status in adolescents: a position statement of the society for adolescent health and medicine. J Adolesc Health. 2013;52(6):801-3.

22. Paxton GA, Teale GR, Nowson CA, Mason RS, McGrath JJ, Thompson MJ, et al. Vitamin D and health in pregnancy, infants, children and adolescents in Australia and New Zealand: a position statement. Med J Aust. 2013;198(3):142-3.

23. Golden NH, Abrams SA, Committee on Nutrition. Optimizing bone health in children and adolescents. Pediatrics. 2014;134(4):e1229-43.

24. Fukumoto S, Ozono K, Michigami T, Minagawa M, Okazaki R, Sugimoto T, et al. Pathogenesis and diagnostic criteria for rickets and osteomalaciaproposal by an expert panel supported by the Ministry of Health, Labour and Welfare, Japan, the Japanese Society for Bone and Mineral Research, and the Japan Endocrine Society. J Bone Miner Metab. 2015;33(5):467-73.

25. Scientific Advisory Committee on Nutrition. Vitamin D and health; 2016. p. 1-304. Available at: https://www.gov.uk/government/publications/sacnvitamin-d-and-health-report. Accessed 1 Sept 2017.

26. European Food Safety Authority panel on dietetic products, nutrition, and allergies. Scientific opinion on dietary reference values for vitamin D. EFSA J. 2016;14(10):4547.

27. Haq A, Wimalawansa SJ, Pludowski P, Anouti FA. Clinical practice guidelines for vitamin D in the United Arab Emirates. J Steroid Biochem Mol Biol. 2016;175:4-11.

28. Munns CF, Shaw N, Kiely M, Specker BL, Thacher TD, Ozono K, et al. Global consensus recommendations on prevention and management of nutritional rickets. J Clin Endocrinol Metab. 2016;101(2):394-415.

29. Okazaki R, Ozono K, Fukumoto S, Inoue D, Yamauchi M, Minagawa M, et al. Assessment criteria for vitamin D deficiency/insufficiency in Japan: proposal by an expert panel supported by the research program of intractable diseases, Ministry of Health, Labour and Welfare, Japan, the Japanese Society for Bone and Mineral Research and the Japan Endocrine Society [opinion]. J Bone Miner Metab. 2017;35(1):1-5.

30. Grossman Z, Hadjipanayis A, Stiris T, Del Torso S, Mercier JC, Valiulis A, Shamir R. Vitamin D in European children-statement from the European academy of Paediatrics (EAP). Eur J Pediatr. 2017;176(6):829-31.

31. Thacher TD, Fischer PR, Pettifor JM, Lawson JO, Isichei CO, Chan GM. Case-control study of factors associated with nutritional rickets in Nigerian children. J Pediatr. 2000;137(3):367-73.
32. Atapattu N, Shaw N, Högler W. Relationship between serum 25hydroxyvitamin $\mathrm{D}$ and parathyroid hormone in the search for a biochemical definition of vitamin D deficiency in children. Pediatr Res. 2013;74(5):552-6.

33. Pettifor JM. Nutritional rickets: pathogenesis and prevention. Pediatr Endocrinol Rev. 2013;10(Suppl 2):347-53.

34. Chapuy MC, Schott AM, Garnero P, Hans D, Delmas PD, Meunier PJ. Healthy elderly French women living at home have secondary hyperparathyroidism and high bone turnover in winter. EPIDOS study group. J Clin Endocrinol Metab. 1996;81(3):1129-33.

35. Chapuy MC, Preziosi P, Maamer M, Arnaud S, Galan P, Hercberg S, Meunier PJ. Prevalence of vitamin D insufficiency in an adult normal population. Osteoporos Int. 1997;7(5):439-43.

36. Thomas MK, Lloyd-Jones DM, Thadhani RI, Shaw AC, Deraska DJ, Kitch BT, et al. Hypovitaminosis D in medical inpatients. N Engl J Med. 1998;338(12):777-83.

37. Holick MF, Siris ES, Binkley N, Beard MK, Khan A, Katzer JT, et al. Prevalence of vitamin D inadequacy among postmenopausal north American women receiving osteoporosis therapy. J Clin Endocrinol Metab. 2005;90(6):3215-24.

38. Lips P. Vitamin D deficiency and secondary hyperparathyroidism in the elderly: consequences for bone loss and fractures and therapeutic implications. Endocr Rev. 2001;22(4):477-501.

39. Kuchuk NO, Pluijm SM, van Schoor NM, Looman CW, Smit JH, Lips P. Relationships of serum 25-hydroxyvitamin $D$ to bone mineral density and serum parathyroid hormone and markers of bone turnover in older persons. J Clin Endocrinol Metab. 2009;94(4):1244-50.

40. Guillemant J, Cabrol S, Allemandou A, Peres G, Guillemant S. Vitamin Ddependent seasonal variation of PTH in growing male adolescents. Bone. 1995;17(6):513-6.

41. Outila TA, Kärkkäinen MU, Lamberg-Allardt CJ. Vitamin D status affects serum parathyroid hormone concentrations during winter in female adolescents: associations with forearm bone mineral density. Am J Clin Nutr. 2001;74(2):206-10.

42. Cheng S, Tylavsky F, Kröger H, Kärkkäinen M, Lyytikäinen A, Koistinen A, et al. Association of low 25-hydroxyvitamin D concentrations with elevated parathyroid hormone concentrations and low cortical bone density in early pubertal and prepubertal Finnish girls. Am J Clin Nutr. 2003;78(3):485-92.

43. Gordon CM, DePeter KC, Feldman HA, Grace E, Emans SJ. Prevalence of vitamin D deficiency among healthy adolescents. Arch Pediatr Adolesc Med. 2004;158(6):531-7.

44. Abrams SA, Griffin IJ, Hawthorne KM, Gunn SK, Gundberg CM, Carpenter TO. Relationships among vitamin D levels, parathyroid hormone, and calcium absorption in young adolescents. J Clin Endocrinol Metab. 2005;90(10):5576-81.

45. Harkness L, Cromer B. Low levels of 25-hydroxy vitamin D are associated with elevated parathyroid hormone in healthy adolescent females. Osteoporos Int. 2005;16(1):109-13.

46. Weaver CM, McCabe LD, McCabe GP, Braun M, Martin BR, Dimeglio LA, Peacock M. Vitamin D status and calcium metabolism in adolescent black and white girls on a range of controlled calcium intakes. J Clin Endocrinol Metab. 2008;93(10):3907-14

47. Hill KM, McCabe GP, McCabe LD, Gordon CM, Abrams SA, Weaver CM. An inflection point of serum 25-hydroxyvitamin D for maximal suppression of parathyroid hormone is not evident from multi-site pooled data in children and adolescents. J Nutr. 2010;140(11):1983-8.

48. Hill TR, Cotter AA, Mitchell S, Boreham CA, Dubitzky W, Murray L, et al. Vitamin $D$ status and parathyroid hormone relationship in adolescents and its association with bone health parameters: analysis of the Northern Ireland young Heart's project. Osteoporos Int. 2010;21(4):695-700.

49. Maguire JL, Birken C, Thorpe KE, Sochett EB, Parkin PC. Parathyroid hormone as a functional indicator of vitamin D sufficiency in children. JAMA Pediatr. 2014;168(4):383-5.

50. Vierucci F, Del Pistoia M, Fanos M, Gori M, Carlone G, Erba P, et al. Vitamin D status and predictors of hypovitaminosis D in Italian children and adolescents: a cross-sectional study. Eur J Pediatr. 2013;172(12):1607-17.

51. Abrams SA, Hicks PD, Hawthorne KM. Higher serum 25-hydroxyvitamin D levels in school-age children are inconsistently associated with increased calcium absorption. J Clin Endocrinol Metab. 2009;94(7):2421-7.

52. Abrams SA, Hawthorne KM, Rogers SP, Hicks PD, Carpenter TO. Effects of ethnicity and vitamin D supplementation on vitamin D status and changes in bone mineral content in infants. BMC Pediatr. 2012;12:6.

53. Winzenberg $T$, Jones $G$. Vitamin $D$ and bone health in childhood and adolescence. Calcif Tissue Int. 2013;92(2):140-50. 
54. Fu Y, Hu Y, Qin Z, Zhao Y, Yang Z, Li Y, et al. Association of serum 25hydroxyvitamin D status with bone mineral density in 0-7 year old children. Oncotarget. 2016;7(49):80811-9.

55. Romagnoli E, Pepe J, Piemonte S, Cipriani C, Minisola S. Management of endocrine disease: value and limitations of assessing vitamin D nutritional status and advised levels of vitamin D supplementation. Eur J Endocrinol. 2013;169(4):R59-69.

56. DEQAS (Vitamin D External Quality Assessment Scheme). Available at: http://www.deqas.org/. Accessed 01 Sept 2017.

57. Binkley N, Sempos $C$, Vitamin D Standardization Program (VDSP). Standardizing vitamin D assays: the way forward. J Bone Miner Res. 2014;29(8):1709-14.

58. Gaithersburg. Certificate of analysis, standard reference material 2972: 25Hydroxyvitamin $D_{2}$ and $D_{3}$ calibration solutions. Gaithersburg: Standard Reference Materials Program; National Institute of Standards and Technology; 2009. Available at: https://www.nist.gov/sites/default/files/ documents/srm/March-2010-Spotlight-3.pdf. Accessed 01 Sept 2017

59. Perna L, Haug U, Schöttker B, Müller H, Raum E, Jansen EH, Brenner H. Public health implications of standardized 25-hydroxyvitamin D levels: a decrease in the prevalence of vitamin $D$ deficiency among older women in Germany. Prev Med. 2012;55(3):228-32.

60. Binkley N, Dawson-Hughes B, Durazo-Arvizu R, Thamm M, Tian L, Merkel JM, et al. Vitamin D measurement standardization: the way out of the chaos. J Steroid Biochem Mol Biol. 2016;173:117-21.

61. Singh RJ, Taylor RL, Reddy GS, Grebe SK. C-3 epimers can account for a significant proportion of total circulating 25-hydroxyvitamin D in infants, complicating accurate measurement and interpretation of vitamin D status. J Clin Endocrinol Metab. 2006;91(8):3055-61.

62. Gallo S, Comeau K, Vanstone C, Agellon S, Sharma A, Jones G, et al. Effect of different dosages of oral vitamin $D$ supplementation on vitamin $D$ status in healthy, breastfed infants: a randomized trial. JAMA. 2013;309(17):1785-92.

63. Gallo S, Comeau K, Agellon S, Vanstone C, Sharma A, Jones G, et al. Methodological issues in assessing plasma 25-hydroxyvitamin D concentration in newborn infants. Bone. 2014;61:186-90.

64. Cavalier E, Wallace AM, Knox S, Mistretta VI, Cormier C, Souberbielle JC. Serum vitamin D measurement may not reflect what you give to your patients. J Bone Miner Res. 2008;23(11):1864-5.

65. Schwartz JB, Lai J, Lizaola B, Kane L, Markova S, Weyland P, et al. A comparison of measured and calculated free $25(\mathrm{OH})$ vitamin D levels in clinical populations. J Clin Endocrinol Metab. 2014;99(5):1631-7.

66. Kumar J, Muntner P, Kaskel FJ, Hailpern SM, Melamed ML. Prevalence and associations of 25-hydroxyvitamin D deficiency in US children: NHANES 2001 - 2004. Pediatrics. 2009;124(3):362-70.

67. Mansbach JM, Ginde AA, Camargo CA Jr. Serum 25-hydroxyvitamin D levels among US children aged 1 to 11 years: do children need more vitamin D? Pediatrics. 2009;124(5):1404-10.

68. Cashman KD, Dowling KG, Škrabáková Z, Gonzalez-Gross M, Valtueña J, De Henauw S, et al. Vitamin D deficiency in Europe: pandemic? Am J Clin Nutr. 2016;103(4):1033-44.

69. Lippi G, Montagnana M, Targher G. Vitamin D deficiency among Italian children. CMAJ. 2007;177(12):1529-30.

70. Marrone G, Rosso I, Moretti R, Valent F, Romanello C. Is vitamin D status known among children living in northern Italy? Eur J Nutr. 2011;51(2):143-9.

71. Pacifico L, Anania C, Osborn JF, Ferraro F, Bonci E, Olivero E, Chiesa C. Low $25(\mathrm{OH}) \mathrm{D}_{3}$ levels are associated with total adiposity, metabolic syndrome, and hypertension in Caucasian children and adolescents. Eur J Endocrinol. 2011;165(4):603-11.

72. Lippi G, Montagnana M, Meschi T, Borghi L. Vitamin D concentration and deficiency across different ages and genders. Aging Clin Exp Res. 2012;24(5):548-51.

73. Mazzoleni S, Toderini D, Boscardin C. The vitamin D grey areas in pediatric primary care. Very low serum 25-hydroxyvitamin D levels in asymptomatic children living in northeastern Italy. Int J Pediatr Endocrinol. 2012;2012(1):7

74. Cadario F, Savastio S, Pozzi E, Capelli A, Dondi E, Gatto M, et al. Vitamin D status in cord blood and newborns: ethnic differences. Ital J Pediatr. 2013; 39:35.

75. Bellone S, Esposito S, Giglione E, Genoni G, Fiorito C, Petri A, et al. Vitamin D levels in a paediatric population of normal weight and obese subjects. J Endocrinol Investig. 2014;37(9):805-9.

76. Franchi B, Piazza M, Sandri M, Tenero L, Comberiati P, Boner AL, Capristo C. 25-hydroxyvitamin D serum level in children of different ethnicity living in Italy. Eur J Pediatr. 2015;174(6):749-57.
77. Ciresi A, Cicciò F, Giordano C. High prevalence of hypovitaminosis D in Sicilian children affected by growth hormone deficiency and its improvement after 12 months of replacement treatment. J Endocrinol Investig. 2014;37(7):631-8.

78. Stagi S, Pelosi P, Strano M, Poggi G, Manoni C, de Martino M, Seminara S. Determinants of vitamin $D$ levels in italian children and adolescents: a longitudinal evaluation of cholecalciferol supplementation versus the improvement of factors influencing 25(OD)D status. Int J Endocrinol. 2014;2014:583039.

79. Vierucci F, Del Pistoia M, Fanos M, Erba P, Saggese G. Prevalence of hypovitaminosis D and predictors of vitamin D status in Italian healthy adolescents. Ital J Pediatr. 2014;40:54.

80. Banzato C, Maffeis C, Maines E, Cavarzere P, Gaudino R, Fava C, et al. Hypovitaminosis D and nocturnal hypertension in obese children: an interesting link. J Hum Hypertens. 2014;28(6):360-6.

81. Cadario F, Savastio S, Magnani C, Cena T, Pagliardini V, Bellomo G, et al. High prevalence of vitamin $D$ deficiency in native versus migrant mothers and newborns in the north of Italy: a call to act with a stronger prevention program. PLoS One. 2015;10(6):e0129586.

82. Colao A, Muscogiuri G, Rubino M, Vuolo L, Pivonello C, Sabatino P, et al. Hypovitaminosis D in adolescents living in the land of sun is correlated with incorrect life style: a survey study in Campania region. Endocrine. 2015;49(2):521-7.

83. Prodam F, Zanetta S, Ricotti R, Marolda A, Giglione E, Monzani A, et al. Influence of ultraviolet radiation on the association between 25-hydroxy vitamin $D$ levels and cardiovascular risk factors in obesity. J Pediatr. 2016;171:83-9. e1

84. Di Nisio A, De Toni L, D’Addato E, Pizzo MR, Sabatino P, Foresta C. 25-hydroxyvitamin D insufficiency discriminates cardiovascular risk factors accumulation in peri-pubertal boys undergoing overweight screening. Endocrine. 2016;53(2):530-7.

85. Paller AS, Hawk JL, Honig P, Giam YC, Hoath S, Mack MC, Stamatas GN. New insights about infant and toddler skin: implications for sun protection. Pediatrics. 2011;128(1):92-102.

86. við Streym S, Højskov CS, Møller UK, Heickendorff L, Vestergaard P, Mosekilde L, Rejnmark L. Vitamin D content in human breast milk: a 9-mo follow-up study. Am J Clin Nutr. 2016;103(1):107-14.

87. Holick MF. Vitamin D deficiency. N Engl J Med. 2007;357(3):266-81.

88. Bersamin A, Zidenberg-Cherr S, Stern JS, Luick BR. Nutrient intakes are associated with adherence to a traditional diet among Yup'ik Eskimos living in remote Alaska native communities: the CANHR study. Int J Circumpolar Health. 2007:66(1):62-70.

89. Società di Nutrizione Umana (SINU). LARN-Livelli di Assunzione di Riferimento di Nutrienti ed Energia per la Popolazione Italiana; IV Revisione. Milano: SICS; 2014. p. 1-655.

90. European Food Safety Authority Panel on Dietetic Products NaACA. Scientific opinion on the tolerable upper intake level of vitamin D. EFSA J. 2012;10(7):2813.

91. Council on Environmental Health, Section on Dermatology, Balk SJ. Ultraviolet radiation: a hazard to children and adolescents. Pediatrics. 2011; 127(3):588-97.

92. Kovacs CS. Maternal vitamin D deficiency: Fetal and neonatal implications. Semin Fetal Neonatal Med. 2013:S1744-165X(13)00006-1. Epub ahead of print.

93. Saraf R, Morton SM, Camargo CA Jr, Grant CC. Global summary of maternal and newborn vitamin D status - a systematic review. Matern Child Nutr. 2016;12(4):647-68.

94. Merewood A, Mehta SD, Grossman X, Chen TC, Mathieu J, Holick MF, Bauchner H. Vitamin D status among 4-month-old infants in New England: a prospective cohort study. J Hum Lact. 2012;28(2):159-66.

95. Wall CR, Grant CC, Jones I. Vitamin D status of exclusively breastfed infants aged 2-3 months. Arch Dis Child. 2013;98(3):176-9.

96. Meena P, Dabas A, Shah D, Malhotra RK, Madhu SV, Gupta P. Sunlight exposure and vitamin D status in breastfed infants. Indian Pediatr. 2017:54(2):105-11.

97. Kim MJ, Na B, No SJ, Han HS, Jeong EH, Lee W, et al. Nutritional status of vitamin D and the effect of vitamin D supplementation in Korean breast-fed infants. J Korean Med Sci. 2010;25(1):83-9.

98. Madar AA, Klepp Kl, Meyer HE. Effect of free vitamin D(2) drops on serum 25-hydroxyvitamin $D$ in infants with immigrant origin: a cluster randomized controlled trial. Eur J Clin Nutr. 2009:63(4):478-84.

99. Alonso A, Rodríguez J, Carvajal I, Prieto MA, Rodríguez RM, Pérez AM, et al. Prophylactic vitamin D in healthy infants: assessing the need. Metabolism. 2011;60(12):1719-25. 
100. Saadi HF, Dawodu A, Afandi B, Zayed R, Benedict S, Nagelkerke N, Hollis BW. Effect of combined maternal and infant vitamin $\mathrm{D}$ supplementation on vitamin D status of exclusively breastfed infants. Matern Child Nutr. 2009;5(1):25-32.

101. Siafarikas A, Piazena H, Feister U, Bulsara MK, Meffert H, Hesse V. Randomised controlled trial analysing supplementation with 250 versus 500 units of vitamin $D_{3}$, sun exposure and surrounding factors in breastfed infants. Arch Dis Child. 2011;96(1):91-5.

102. Atas E, Karademır F, Ersen A, Meral C, Aydınoz S, Suleymanoglu S, et al. Comparison between daily supplementation doses of 200 versus $400 \mathrm{IU}$ of vitamin D in infants. Eur J Pediatr. 2013;172(8):1039-42.

103. Grant CC, Stewart AW, Scragg R, Milne T, Rowden J, Ekeroma A, et al. Vitamin D during pregnancy and infancy and infant serum 25hydroxyvitamin D concentration. Pediatrics. 2014;133(1):e143-53.

104. Holmlund-Suila E, Viljakainen $H$, Hytinantti T, Lamberg-Allardt C, Andersson S, Mäkitie O. High-dose vitamin d intervention in infants-effects on vitamin d status, calcium homeostasis, and bone strength. J Clin Endocrinol Metab. 2012;97(11):4139-47.

105. Ziegler EE, Nelson SE, Jeter JM. Vitamin D supplementation of breastfed infants: a randomized dose-response trial. Pediatr Res. 2014;76(2):177-83.

106. Onwuneme C, Diya B, Uduma O, McCarthy RA, Murphy N, Kilbane MT, et al. Correction of vitamin D deficiency in a cohort of newborn infants using daily 200 IU vitamin D supplementation. Ir J Med Sci. 2016;185(3):683-7.

107. Hollis BW, Wagner CL, Howard CR, Ebeling M, Shary JR, Smith PG, et al. Maternal versus infant vitamin D supplementation during lactation: a randomized controlled trial. Pediatrics. 2015;136(4):625-34.

108. Gallo S, Phan A, Vanstone CA, Rodd C, Weiler HA. The change in plasma 25-hydroxyvitamin D did not differ between breast-fed infants that received a daily supplement of ergocalciferol or cholecalciferol for 3 months. J Nutr. 2013;143(2):148-53.

109. Shakiba M, Sadr S, Nefei Z, Mozaffari-Khosravi H, Lotfi MH, Bemanian MH. Combination of bolus dose vitamin D with routine vaccination in infants: a randomised trial. Singap Med J. 2010;51(5):440-5.

110. Shakiba M, Pahloosye A, Mirouliaei M, Islami Z. Comparison of two regimens of vitamin D supplementation for vitamin D-deficient neonates. Singap Med J. 2014;55(5):266-70.

111. Huynh J, Lu T, Liew D, Doery J, Tudball R, Jona M, et al. Vitamin D in newborns. A randomised controlled trial comparing daily and single oral bolus vitamin D in infants. J Paediatr Child Health. 2017;53(2):163-9.

112. Critch JN, Canadian Paediatric Society, Nutrition and Gastroenterology Committee. Nutrition for healthy term infants, birth to six months: an overview. Paediatr Child Health. 2013;18(4):206-7.

113. Critch JN, Canadian Paediatric Society; Nutrition and Gastroenterology Committee Nutrition and Gastroenterology Committee. Nutrition for healthy term infants, six to 24 months: an overview. Paediatr Child Health. 2014;19(10):547-9.

114. Wood CL, Cheetham TD. Vitamin D: increasing supplement use among at-risk groups (NICE guideline PH56). Arch Dis Child Educ Pract Ed. 2016;101(1):43-5.

115. Public Health England. PHE publishes new advice on vitamin D. Available at: https://www.gov.uk/government/news/phe-publishes-new-advice-onvitamin-d. Accessed 01 Sept 2017.

116. Schoenmakers I, Pettifor JM, Peña-Rosas JP, Lamberg-Allardt C, Shaw N, Jones KS, et al. Prevention and consequences of vitamin D deficiency in pregnant and lactating women and children: a symposium to prioritise vitamin D on the global agenda. J Steroid Biochem Mol Biol. 2016;164:156-60.

117. Umaretiya PJ, Oberhelman SS, Cozine EW, Maxson JA, Quigg SM, Thacher TD. Maternal preferences for vitamin D supplementation in breastfed infants. Ann Fam Med. 2017;15(1):68-70.

118. Holick MF, Lim R, Dighe AS. Case records of the Massachusetts General Hospital. case 3-2009. A 9-month-old boy with seizures. N Engl J Med. 2009;360(4):398-407.

119. Vogiatzi MG, Jacobson-Dickman E, MD DB, Drugs, and Therapeutics Committee of The Pediatric Endocrine Society. Vitamin D supplementation and risk of toxicity in pediatrics: a review of current literature. J Clin Endocrinol Metab. 2014;99(4):1132-41.

120. Harrison CM, Gibson AT. Osteopenia in preterm infants. Arch Dis Child Fetal Neonatal Ed. 2013;98(3):F272-5.

121. Bozzetti $\bigvee$, Tagliabue P. Metabolic bone disease in preterm newborn: an update on nutritional issues. Ital J Pediatr. 2009;35(1):20.

122. Abrams SA, Committee on Nutrition. Calcium and vitamin D requirements of enterally fed preterm infants. Pediatrics. 2013;131(5):e1676-83.

123. Taylor SN, Hollis BW, Wagner CL. Vitamin D needs of preterm infants. NeoReviews. 2009;10(12):e590-9.
124. Onwuneme C, Martin F, McCarthy R, Carroll A, Segurado R, Murphy J, et al. The association of vitamin $D$ status with acute respiratory morbidity in preterm infants. J Pediatr. 2015;166(5):1175-80. e1

125. Agostoni C, Buonocore G, Carnielli VP, De Curtis M, Darmaun D, Decsi T, et al. Enteral nutrient supply for preterm infants: commentary from the European Society of Paediatric Gastroenterology, Hepatology and nutrition committee on nutrition. J Pediatr Gastroenterol Nutr. 2010;50(1):85-91.

126. Rigo J, Pieltain C, Salle B, Senterre J. Enteral calcium, phosphate and vitamin $D$ requirements and bone mineralization in preterm infants. Acta Paediatr. 2007;96(7):969-74.

127. Christmann V, de Grauw AM, Visser R, Matthijsse RP, van Goudoever JB, van Heijst AF. Early postnatal calcium and phosphorus metabolism in preterm infants. J Pediatr Gastroenterol Nutr. 2014;58(4):398-403.

128. Monangi N, Slaughter JL, Dawodu A, Smith C, Akinbi HT. Vitamin D status of early preterm infants and the effects of vitamin $D$ intake during hospital stay. Arch Dis Child Fetal Neonatal Ed. 2014;99(2):F166-8.

129. McCarthy RA, McKenna MJ, Oyefeso O, Uduma O, Murray BF, Brady JJ, et al. Vitamin $D$ nutritional status in preterm infants and response to supplementation. Br J Nutr. 2013;110(1):156-63.

130. Henriksen C, Helland IB, Rønnestad A, Grønn M, Iversen PO, Drevon CA. Fat-soluble vitamins in breast-fed preterm and term infants. Eur J Clin Nutr. 2006;60(6):756-62

131. Hanson C, Armas L, Lyden E, Anderson-Berry A. Vitamin D status and associations in newborn formula-fed infants during initial hospitalization. J Am Diet Assoc. 2011;111(12):1836-43.

132. Pinto K, Collins CT, Gibson RA, Andersen CC. Vitamin D in preterm infants: a prospective observational study. J Paediatr Child Health. 2015;51(7):679-81.

133. Salle BL, Delvin E, Claris O, Hascoet JM, Levy E. Is it justifiable to administrate vitamin $a, E$ and $D$ for 6 months in the premature infants? Arch Pediatr. 2007;14(12):1408-12.

134. Alizadeh Taheri P, Sajjadian N, Beyrami B, Shariat M. Prophylactic effect of low dose vitamin $D$ in osteopenia of prematurity: a clinical trial study. Acta Med Iran. 2014;52(9):671-4.

135. Backström MC, Mäki R, Kuusela AL, Sievänen H, Koivisto AM, Ikonen RS, et al. Randomised controlled trial of vitamin D supplementation on bone density and biochemical indices in preterm infants. Arch Dis Child Fetal Neonatal Ed. 1999;80(3):F161-6.

136. Kislal FM, Dilmen U. Effect of different doses of vitamin D on osteocalcin and deoxypyridinoline in preterm infants. Pediatr Int. 2008;50(2):204-7.

137. Natarajan CK, Sankar MJ, Agarwal R, Pratap OT, Jain V, Gupta N, et al. Trial of daily vitamin D supplementation in preterm infants. Pediatrics. 2014;133(3):e628-34.

138. Tergestina M, Jose A, Sridhar S, Job V, Rebekah G, Kuruvilla KA, Thomas N. Vitamin D status and adequacy of standard supplementation in preterm neonates from South India. J Pediatr Gastroenterol Nutr. 2014;58(5):661-5.

139. Joung KE, Burris HH, Van Marter LJ, McElrath TF, Michael Z, Tabatabai P, et al. Vitamin D and bronchopulmonary dysplasia in preterm infants. J Perinatol. 2016;36(10):878-82

140. Hanson C, Lyden E, Nelson A, Thoene M, Wagner J, Wu A, et al. Response of vitamin $\mathrm{D}$ binding protein and free vitamin $\mathrm{D}$ concentrations to vitamin $\mathrm{D}$ supplementation in hospitalized premature infants. J Pediatr Endocrinol Metab. 2015;28(9-10):1107-14

141. Hanson C, Jones G, Lyden E, Kaufmann M, Armas L, Anderson-Berry A. Vitamin $D$ metabolism in the premature newborn: a randomized trial. Clin Nutr. 2016;35(4):835-41.

142. Cho SY, Park HK, Lee HJ. Efficacy and safety of early supplementation with $800 \mathrm{IU}$ of vitamin D in very preterm infants followed by underlying levels of vitamin D at birth. Ital J Pediatr. 2017;43(1):45.

143. Fort $P$, Salas AA, Nicola T, Craig CM, Carlo WA, Ambalavanan N. A comparison of 3 vitamin $D$ dosing regimens in extremely preterm infants: a randomized controlled trial. J Pediatr. 2016;174:132-8. e1

144. Mathur NB, Saini A, Mishra TK. Assessment of adequacy of supplementation of vitamin $D$ in very low birth weight preterm neonates: a randomized controlled trial. J Trop Pediatr. 2016;62(6):429-35.

145. Tergestina M, Rebekah G, Job V, Simon A, Thomas N. A randomized double-blind controlled trial comparing two regimens of vitamin $D$ supplementation in preterm neonates. J Perinatol. 2016;36(9):763-7.

146. Kołodziejczyk A, Borszewska-Kornacka MK. Monitored supplementation of vitamin D in preterm neonates-a primary report. Dev Period Med. 2015;19(3 Pt 1):313-8.

147. Mølgaard C, Larnkjaer A, Cashman KD, Lamberg-Allardt C, Jakobsen J, Michaelsen KF. Does vitamin D supplementation of healthy Danish 
Caucasian girls affect bone turnover and bone mineralization? Bone. 2010:46(2):432-9.

148. Viljakainen HT, Natri AM, Kärkkäinen M, Huttunen MM, Palssa A, Jakobsen J, et al. A positive dose-response effect of vitamin D supplementation on site-specific bone mineral augmentation in adolescent girls: a doubleblinded randomized placebo-controlled 1-year intervention. J Bone Miner Res. 2006;21(6):836-44.

149. Rajakumar K, Fernstrom JD, Janosky JE, Greenspan SL. Vitamin D insufficiency in preadolescent African-American children. Clin Pediatr (Phila). 2005:44(8):683-92.

150. Cosenza L, Pezzella V, Nocerino R, Di Costanzo M, Coruzzo A, Passariello A, et al. Calcium and vitamin $D$ intakes in children: a randomized controlled trial. BMC Pediatr. 2013;13:86.

151. Dong Y, Stallmann-Jorgensen IS, Pollock NK, Harris RA, Keeton D, Huang $Y$, et al. A 16-week randomized clinical trial of 2000 international units daily vitamin $D_{3}$ supplementation in black youth: 25 -hydroxyvitamin $D$, adiposity, and arterial stiffness. J Clin Endocrinol Metab. 2010;95(10):4584-91.

152. Hower J, Knoll A, Ritzenthaler KL, Steiner C, Berwind R. Vitamin D fortification of growing up milk prevents decrease of serum 25hydroxyvitamin D concentrations during winter: a clinical intervention study in Germany. Eur J Pediatr. 2013;172(12):1597-605.

153. Andersen R, Mølgaard C, Skovgaard LT, Brot C, Cashman KD, Jakobsen J, et al. Effect of vitamin $D$ supplementation on bone and vitamin $D$ status among Pakistani immigrants in Denmark: a randomised double-blinded placebo-controlled intervention study. Br J Nutr. 2008;100(1):197-207.

154. Park CY, Hill KM, Elble AE, Martin BR, DiMeglio LA, Peacock M, et al. Daily supplementation with $25 \mu \mathrm{g}$ cholecalciferol does not increase calcium absorption or skeletal retention in adolescent girls with low serum 25-hydroxyvitamin D. J Nutr. 2010;140(12):2139-44.

155. Shanely RA, Nieman DC, Knab AM, Gillitt ND, Meaney MP, Jin F, et al. Influence of vitamin D mushroom powder supplementation on exerciseinduced muscle damage in vitamin D insufficient high school athletes. J Sports Sci. 2014;32(7):670-9.

156. Abrams SA, Hawthorne KM, Chen Z. Supplementation with 1000 IU vitamin D/d leads to parathyroid hormone suppression, but not increased fractional calcium absorption, in 4-8-y-old children: a double-blind randomized controlled trial. Am J Clin Nutr. 2013;97(1):217-23.

157. Putman MS, Pitts SA, Milliren CE, Feldman HA, Reinold K, Gordon CM. A randomized clinical trial of vitamin $D$ supplementation in healthy adolescents. J Adolesc Health. 2013;52(5):592-8.

158. Lewis RD, Laing EM, Hill Gallant KM, Hall DB, McCabe GP, Hausman DB, et al. A randomized trial of vitamin $D_{3}$ supplementation in children: doseresponse effects on vitamin D metabolites and calcium absorption. J Clin Endocrinol Metab. 2013;98(12):4816-25.

159. Rajakumar K, Moore CG, Yabes J, Olabopo F, Haralam MA, Comer D, et al. Effect of vitamin $D_{3}$ supplementation in black and in white children: a randomized, placebo-controlled trial. J Clin Endocrinol Metab. 2015;100(8):3183-92.

160. Brett NR, Lavery P, Agellon S, Vanstone CA, Maguire JL, Rauch F, Weiler HA. Dietary vitamin $D$ dose-response in healthy children 2 to 8 y of age: a 12-wk randomized controlled trial using fortified foods. Am J Clin Nutr. 2016:103(1):144-52.

161. Mortensen C, Damsgaard CT, Hauger H, Ritz C, Lanham-New SA, Smith TJ, et al. Estimation of the dietary requirement for vitamin $D$ in white children aged 4-8 y: a randomized, controlled, dose-response trial. Am J Clin Nutr. 2016;104(5):1310-7.

162. Smith TJ, Tripkovic L, Damsgaard CT, Mølgaard C, Ritz C, Wilson-Barnes SL, et al. Estimation of the dietary requirement for vitamin $D$ in adolescents aged 14-18 y: a dose-response, double-blind, randomized placebocontrolled trial. Am J Clin Nutr. 2016;104(5):1301-9.

163. Ganmaa D, Stuart JJ, Sumberzul N, Ninjin B, Giovannucci E, Kleinman K, et al. Vitamin D supplementation and growth in urban Mongol school children: results from two randomized clinical trials. PLoS One. 2017;12(5):e0175237.

164. Ferira AJ, Laing EM, Hausman DB, Hall DB, McCabe GP, Martin BR, et al. Vitamin $D$ supplementation does not impact insulin resistance in black and white children. J Clin Endocrinol Metab. 2016;101(4):1710-8.

165. Hirschler V, Maccallini G, Sanchez MS, Castaño L, Molinari C. Improvement in high-density lipoprotein cholesterol levels in argentine Indian school children after vitamin D supplementation. Horm Res Paediatr. 2013;80(5):335-42.

166. El-Haij Fuleihan G, Nabulsi M, Tamim H, Maalouf J, Salamoun M, Khalife H, et al. Effect of vitamin D replacement on musculoskeletal parameters in school children: a randomized controlled trial. J Clin Endocrinol Metab. 2006;91(2): 405-12.

167. Al-Shaar L, Mneimneh R, Nabulsi, Maalouf J, Fuleihan G-H. Vitamin $D_{3}$ dose requirement to raise 25 -hydroxyvitamin $D$ to desirable levels in adolescents: results from a randomized controlled trial. J Bone Miner Res. 2014;29(4):944-51.

168. Ekbote VH, Khadilkar AV, Chiplonkar SA, Hanumante NM, Khadilkar W, Mughal MZ. A pilot randomized controlled trial of oral calcium and vitamin D supplementation using fortified laddoos in underprivileged Indian toddlers. Eur J Clin Nutr. 2011;65(4):440-6.

169. Hirschler V, Maccallini G, Tamborenea MI, Gonzalez C, Sanchez M, Molinari C, et al. Improvement in lipid profile after vitamin D supplementation in indigenous argentine school children. Cardiovasc Hematol Agents Med Chem. 2014;12(1):42-9.

170. Ghazi AA, Hosseinpanah F, M Ardakani E, Ghazi S, Hedayati M, Azizi F. Effects of different doses of oral cholecalciferol on serum 25(OH)D, PTH, calcium and bone markers during fall and winter in schoolchildren. Eur J Clin Nutr. 2010;64(12):1415-22.

171. Kuchay MS, Jevalikar GS, Mithal A, Mishra SK, Dang N. Efficacy and safety of a single monthly dose of cholecalciferol in healthy school children. J Pediatr Endocrinol Metab. 2016;29(4):413-6.

172. Marwaha RK, Tandon N, Agarwal N, Puri S, Agarwal R, Singh S, Mani K. Impact of two regimens of vitamin $D$ supplementation on calcium - vitamin D - PTH axis of schoolgirls of Delhi. Indian Pediatr. 2010;47(9):761-9.

173. Marwaha RK, Yenamandra VK, Ganie MA, Sethuraman G, Sreenivas V, Ramakrishnan $L$, et al. Efficacy of micellized vs. fat-soluble vitamin $D_{3}$ supplementation in healthy school children from northern India. J Pediatr Endocrinol Metab. 2016:29(12):1373-7.

174. Carnes J, Quinn S, Nelson M, Jones G, Winzenberg T. Intermittent high-dose vitamin D corrects vitamin D deficiency in adolescents: a pilot study. Eur J Clin Nutr. 2012;66(4):530-2.

175. Tau C, Ciriani V, Scaiola E, Acuña M. Twice single doses of 100,000 IU of vitamin $D$ in winter is adequate and safe for prevention of vitamin $D$ deficiency in healthy children from Ushuaia, Tierra Del Fuego. Argentina J Steroid Biochem Mol Biol. 2007;103(3-5):651-4.

176. Corsello G, Ferrara P, Chiamenti G, Nigri L, Campanozzi A, PettoelloMantovani M. The child health care system in Italy. J Pediatr. 2016;177S: S116-26.

177. Kimlin MG. Geographic location and vitamin D synthesis. Mol Asp Med. 2008:29:453-61.

178. Mithal A, Wahl DA, Bonjour JP, Burckhardt P, Dawson-Hughes B, Eisman JA, et al. Global vitamin D status and determinants of hypovitaminosis D. Osteoporos Int. 2009:20:1807-20.

179. Saggese G, Baroncelli Gl, Bertelloni S, Webb AR, Holick MF. Effetto delle stagioni sulla sintesi della vitamina $D_{3}$ a $43^{\circ}$ latitudine nord. Riv Ital Pediatr. 1992;18:30-6.

180. Arabi A, El Rassi R, El-Hajj Fuleihan G. Hypovitaminosis D in developing countries-prevalence, risk factors and outcomes. Nat Rev Endocrinol. 2010;6:550-61.

181. Rice SA, Carpenter M, Fityan A, Vearncombe LM, Ardern-Jones M, Jackson $\mathrm{AA}$, et al. Limited exposure to ambient ultraviolet radiation and 25-hydroxyvitamin D levels: a systematic review. Br J Dermatol. 2015;172(3):652-61.

182. Chiappini E, Vierucci F, Ghetti F, de Martino M, Galli L. Vitamin D status and predictors of hypovitaminosis $D$ in internationally adopted children. PLoS One. 2016;11(9):e0158469.

183. Elder CJ, Bishop NJ. Rickets. Lancet. 2014;383(9929):1665-76.

184. Zhang M, Shen F, Petryk A, Tang J, Chen X, Sergi C. "English Disease": historical notes on rickets, the bone-lung link and child neglect issues. Nutrients. 2016:8(11):E722.

185. Goldacre M, Hall N, Yeates DG. Hospitalisation for children with rickets in England: a historical perspective. Lancet. 2014;383(9917):597-8.

186. Creo AL, Thacher TD, Pettifor JM, Strand MA, Fischer PR. Nutritional rickets around the world: an update. Paediatr Int Child Health. 2017;37(2):84-98

187. Vierucci F, Del Pistoia M, Randazzo E, Massart F, Federico G. The spectrum of vitamin D deficiency: description of a family. Exp Clin Endocrinol Diabetes. 2017;125(7):478-84.

188. Allgrove J, Shaw NJ. A practical approach to vitamin D deficiency and rickets. Endocr Dev. 2015;28:119-33.

189. Narchi H, El Jamil M, Kulaylat N. Symptomatic rickets in adolescence. Arch Dis Child. 2001;84(6):501-3. 
190. Shore RM, Chesney RW. Rickets: part II. Pediatr Radiol. 2013;43(2):152-72.

191. Bothra M, Gupta N, Jain V. Effect of intramuscular cholecalciferol megadose in children with nutritional rickets. J Pediatr Endocrinol Metab. 2016;29(6):687-92

192. Mondal K, Seth A, Marwaha RK, Dhanwal D, Aneja S, Singh R, Sonkar P. A randomized controlled trial on safety and efficacy of single intramuscular versus staggered oral dose of $600000 \mathrm{IU}$ vitamin D in treatment of nutritional rickets. J Trop Pediatr. 2014;60(3):203-10.

193. Mittal H, Rai S, Shah D, Madhu SV, Mehrotra G, Malhotra RK, Gupta P. 300,000 IU or 600,000 IU of oral vitamin $D_{3}$ for treatment of nutritional rickets: a randomized controlled trial. Indian Pediatr. 2014;51(4):265-72.

194. McNally JD, Iliriani K, Pojsupap S, Sampson M, O'Hearn K, Mclntyre L, et al. Rapid normalization of vitamin D levels: a meta-analysis. Pediatrics. 2015; 135(1):e152-66.

195. Harnot J, Verma S, Singhi S, Sankhyan N, Sachdeva N, Bharti B. Comparison of 300,000 and 600,000 IU oral vitamin-D bolus for vitamin-d deficiency in young children. Indian J Pediatr. 2017;84(2):111-6.

196. Frost HM, Schönau $E$. The "muscle-bone unit" in children and adolescents: a 2000 overview. J Pediatr Endocrinol Metab. 2000;13(6):571-90.

197. Wintermeyer E, Ihle C, Ehnert S, Stöckle U, Ochs G, de Zwart P, et al. Crucial role of vitamin D in the musculoskeletal system. Nutrients. 2016;8(6):E319.

198. Bhattoa HP, Konstantynowicz J, Laszcz N, Wojcik M, Pludowski P. Vitamin D: musculoskeletal health. Rev Endocr Metab Disord. 2017;18(3):363-71.

199. Gordon CM, Zemel BS, Wren TA, Leonard MB, Bachrach LK, Rauch F, et al. The determinants of peak bone mass. J Pediatr. 2017;180:261-9.

200. Wren TA, Kalkwarf HJ, Zemel BS, Lappe JM, Oberfield S, Shepherd JA, et al. Longitudinal tracking of dual-energy $X$-ray absorptiometry bone measures over 6 years in children and adolescents: persistence of low bone mass to maturity. J Pediatr. 2014;164(6):1280-5.

201. Savino F, Viola S, Tarasco V, Lupica MM, Castagno E, Oggero R, Miniero R. Bone mineral status in breast-fed infants: influence of vitamin D supplementation. Eur J Clin Nutr. 2011;65(3):335-9.

202. Savino F, Viola S, Benetti S, Ceratto S, Tarasco V, Lupica MM, Cordero di Montezemolo L. Quantitative ultrasound applied to metacarpal bone in infants. PeerJ. 2013;1:e141.

203. Bagnoli F, Casucci M, Toti S, Cecchi S, lurato C, Coriolani G, et al. Is vitamin $\mathrm{D}$ supplementation necessary in healthy full-term breastfed infants? A follow-up study of bone mineralization in healthy full-term infants with and without supplemental vitamin D. Minerva Pediatr. 2013;65(3):253-60.

204. Gallo S, Hazell T, Vanstone CA, Agellon S, Jones G, L'Abbé M, et al. Vitamin D supplementation in breastfed infants from Montréal, Canada: 25-hydroxyvitamin D and bone health effects from a follow-up study at 3 years of age. Osteoporos Int. 2016;27(8):2459-66.

205. Hazell TJ, Gallo S, Vanstone CA, Agellon S, Rodd C, Weiler HA. Vitamin D supplementation trial in infancy: body composition effects at 3 years of age in a prospective follow-up study from Montréal. Pediatr Obes. 2017;12(1):38-47.

206. Al-Ghamdi MA, Lanham-New SA, Kahn JA. Differences in vitamin D status and calcium metabolism in Saudi Arabian boys and girls aged 6 to 18 years: effects of age, gender, extent of veiling and physical activity with concomitant implications for bone health. Public Health Nutr. 2012;15(10):1845-53.

207. Pekkinen M, Viljakainen H, Saarnio E, Lamberg-Allardt C, Mäkitie O. Vitamin $D$ is a major determinant of bone mineral density at school age. PLoS One. 2012;7(7):e40090.

208. Hazell TJ, Pham TT, Jean-Philippe S, Finch SL, El Hayek J, Vanstone CA, et al. Vitamin $\mathrm{D}$ status is associated with bone mineral density and bone mineral content in preschool-aged children. J Clin Densitom. 2015;18(1):60-7.

209. Marwaha RK, Tandon N, Reddy DR, Aggarwal R, Singh R, Sawhney RC, et al. Vitamin $\mathrm{D}$ and bone mineral density status of healthy schoolchildren in northern India. Am J Clin Nutr. 2005;82(2):477-82.

210. Talwar SA, Swedler J, Yeh J, Pollack S, Aloia JF. Vitamin-D nutrition and bone mass in adolescent black girls. J Natl Med Assoc. 2007;99(6):650-7.

211. Kremer R, Campbell PP, Reinhardt T, Gilsanz V. Vitamin D status and its relationship to body fat, final height, and peak bone mass in young women. J Clin Endocrinol Metab. 2009;94(1):67-73.

212. Gawlik A, Gepstein V, Rozen N, Dahan A, Ben-Yosef D, Wildbaum G, et al. Duodenal expression of 25 hydroxyvitamin $D_{3}$-1a-hydroxylase is higher in adolescents than in children and adults. J Clin Endocrinol Metab. 2015;100(10):3668-75.

213. Cheung TF, Cheuk KY, Yu FW, Hung WW, Ho CS, Zhu TY, et al. Prevalence of vitamin $\mathrm{D}$ insufficiency among adolescents and its correlation with bone parameters using high-resolution peripheral quantitative computed tomography. Osteoporos Int. 2016;27(8):2477-88.

214. Välimäki W, Alfthan H, Lehmuskallio E, Löyttyniemi E, Sahi T, Stenman UH, et al. Vitamin D status as a determinant of peak bone mass in young Finnish men. J Clin Endocrinol Metab. 2004;89(1):76-80.

215. Boot AM, Krenning EP, de Muinck Keizer-Schrama SM. The relation between 25-hydroxyvitamin $\mathrm{D}$ with peak bone mineral density and body composition in healthy young adults. J Pediatr Endocrinol Metab. 2011;24(5-6):355-60.

216. Du X, Zhu K, Trube A, Zhang Q, Ma G, Hu X, et al. School-milk intervention trial enhances growth and bone mineral accretion in Chinese girls aged 10-12 years in Beijing. Br J Nutr. 2004;92(1):159-68.

217. Cheng S, Lyytikäinen A, Kröger H, Lamberg-Allardt C, Alén M, Koistinen A, et al. Effects of calcium, dairy product, and vitamin D supplementation on bone mass accrual and body composition in 10-12 year old girls: a 2 year randomized trial. Am J Clin Nutr. 2005;82(5):1115-26.

218. El-Hajj Fuleihan G, Vieth R. Vitamin D insufficiency and musculoskeletal health in children and adolescents. In: Burckhardt P, Heaney R, DawsonHughes B, editors. Nutritional aspects of osteoporosis 2006, proceedings of the international symposium on nutritional aspects of osteoporosis, 4-6 may 2006. Lausanne: Elsevier; 2007.

219. Winzenberg TM, Powell S, Shaw KA, Jones G. Vitamin D supplementation for improving bone mineral density in children. Cochrane Database Syst Rev. 2010;10:CD006944.

220. Weaver CM, Gordon CM, Janz KF, Kalkwarf HJ, Lappe JM, Lewis R, et al. The National Osteoporosis Foundation's position statement on peak bone mass development and lifestyle factors: a systematic review and implementation recommendations. Osteoporos Int. 2016;27(4):1281-386.

221. Breen ME, Laing EM, Hall DB, Hausman DB, Taylor RG, Isales CM, et al. 25hydroxyvitamin $D$, insulin-like growth factor-l, and bone mineral accrual during growth. J Clin Endocrinol Metab. 2011;96(1):E89-98.

222. Foo LH, Zhang Q, Zhu K, Ma G, Hu X, Greenfield H, Fraser DR. Low vitamin $D$ status has an adverse influence on bone mass, bone turnover, and muscle strength in Chinese adolescent girls. J Nutr. 2009;139(5):1002-7.

223. Lee YA, Kim JY, Kang MJ, Chung SJ, Shin CH, Yang SW. Adequate vitamin D status and adiposity contribute to bone health in peripubertal nonobese children. J Bone Miner Metab. 2013;31(3):337-45.

224. Khadilkar AV, Sayyad MG, Sanwalka NJ, Bhandari DR, Naik S, Khadilkar W, Mughal MZ. Vitamin D supplementation and bone mass accrual in underprivileged adolescent Indian girls. Asia Pac J Clin Nutr. 2010;19(4):465-72.

225. Ward KA, Das G, Roberts SA, Berry JL, Adams JE, Rawer R, Mughal MZ. A randomized, controlled trial of vitamin D supplementation upon musculoskeletal health in postmenarchal females. J Clin Endocrinol Metab. 2010;95(10):4643-51.

226. Ghazal N, Al-Shaar L, Maalouf J, Nabulsi M, Arabi A, Choucair M, et al. Persistent effect of vitamin D supplementation on musculoskeletal parameters in adolescents one year after trial completion. J Bone Miner Res. 2016;31(7):1473-80.

227. Lewis RD, Laing EM. Conflicting reports on vitamin D supplementation: evidence from randomized controlled trials. Mol Cell Endocrinol. 2015;410:11-8.

228. Young BE, McNanley TJ, Cooper EM, McIntyre AW, Witter F, Harris ZL, O'Brien KO. Maternal vitamin D status and calcium intake interact to affect fetal skeletal growth in utero in pregnant adolescents. Am J Clin Nutr. 2012;95(5):1103-12.

229. Ioannou C, Javaid MK, Mahon P, Yaqub MK, Harvey NC, Godfrey KM, et al. The effect of maternal vitamin D concentration on fetal bone. J Clin Endocrinol Metab. 2012;97(11):E2070-7.

230. Viljakainen HT, Saarnio E, Hytinantti T, Miettinen $M$, Surcel $H$, Mäkitie $O$, et al. Maternal vitamin D status determines bone variables in the newborn. J Clin Endocrinol Metab. 2010;95(4):1749-57.

231. Viljakainen HT, Korhonen T, Hytinantti T, Laitinen EK, Andersson S, Mäkitie O, Lamberg-Allardt C. Maternal vitamin D status affects bone growth in early childhood-a prospective cohort study. Osteoporos Int. 2011;22(3):883-91.

232. Cooper C, Harvey NC, Bishop NJ, Kennedy S, Papageorghiou AT, Schoenmakers I, et al. Maternal gestational vitamin D supplementation and offspring bone health (MAVIDOS): a multicentre, double-blind, randomised placebo-controlled trial. Lancet Diabetes Endocrinol. 2016;4(5):393-402.

233. Reid IR. Towards a trial-based definition of vitamin D deficiency. Lancet Diabetes Endocrinol. 2016;4(5):376-7.

234. Vaziri F, Dabbaghmanesh MH, Samsami A, Nasiri S, Shirazi PT. Vitamin D supplementation during pregnancy on infant anthropometric 
measurements and bone mass of mother-infant pairs: a randomized placebo clinical trial. Early Hum Dev. 2016;103:61-8.

235. Javaid MK, Crozier SR, Harvey NC, Gale CR, Dennison EM, Boucher BJ, et al. Maternal vitamin D status during pregnancy and childhood bone mass at age 9 years: a longitudinal study. Lancet. 2006;367(9504):36-43.

236. Sahoo SK, Katam KK, Das V, Agarwal A, Bhatia V. Maternal vitamin D supplementation in pregnancy and offspring outcomes: a double-blind randomized placebo-controlled trial. J Bone Miner Metab. 2017;35(4):464-71.

237. Garcia AH, Erler NS, Jaddoe WW, Tiemeier $H$, van den Hooven EH, Franco $\mathrm{OH}$, et al. 25-hydroxyvitamin D concentrations during fetal life and bone health in children aged 6 years: a population-based prospective cohort study. Lancet Diabetes Endocrinol. 2017:5(5):367-76.

238. Lawlor DA, Wills AK, Fraser A, Sayers A, Fraser WD, Tobias JH. Association of maternal vitamin D status during pregnancy with bone-mineral content in offspring: a prospective cohort study. Lancet. 2013;381(9884):2176-83.

239. Zhu K, Whitehouse AJ, Hart PH, Kusel M, Mountain J, Lye S, et al. Maternal vitamin D status during pregnancy and bone mass in offspring at 20 years of age: a prospective cohort study. J Bone Miner Res. 2014;29(5):1088-95.

240. Bozzetto S, Carraro S, Giordano G, Boner A, Baraldi E. Asthma, allergy and respiratory infections: the vitamin D hypothesis. Allergy. 2012;67(1):10-7.

241. Larkin A, Lassetter J. Vitamin D deficiency and acute lower respiratory infections in children younger than 5 years: identification and treatment. J Pediatr Health Care. 2014;28(6):572-82.

242. Esposito S, Lelii M. Vitamin D and respiratory tract infections in childhood. BMC Infect Dis. 2015;15:487.

243. Najada AS, Habashneh MS, Khader M. The frequency of nutritional rickets among hospitalized infants and its relation to respiratory diseases. J Trop Pediatr. 2004;50(6):364-8.

244. Banajeh SM. Nutritional rickets and vitamin D deficiency-association with the outcomes of childhood very severe pneumonia: a prospective cohort study. Pediatr Pulmonol. 2009;44(12):1207-15.

245. Muhe L, Lulseged S, Mason KE, Simoes EA. Case-control study of the role of nutritional rickets in the risk of developing pneumonia in Ethiopian children. Lancet. 1997;349(9068):1801-4.

246. Science M, Maguire $J$, Russell ML, Smieja M, Walter SD, Loeb M. Low serum 25-hydroxyvitamin D level and risk of upper respiratory tract infection in children and adolescents. Clin Infect Dis. 2013;57(3):392-7.

247. Aydın S, Aslan I, Yıldız I, Ağaçhan B, Toptass B, Toprak S, et al. Vitamin D levels in children with recurrent tonsillitis. J Pediatr Otorhinolaryngol. 2011;75(3):364-7.

248. Cayir A, Turan Ml, Ozkan O, Cayir Y, Kaya A, Davutoglu S, Ozkan B. Serum vitamin D levels in children with recurrent otitis media. Eur Arch Otorhinolaryngol. 2014;271(4):689-93.

249. Belderbos ME, Houben ML, Wilbrink B, Lentjes E, Bloemen EM, Kimpen JL, et al. Cord blood vitamin D deficiency is associated with respiratory syncytial virus bronchiolitis. Pediatrics. 2011;127(6):e1513-20.

250. Jartti T, Ruuskanen O, Mansbach JM, Vuorinen T, Camargo CA Jr. Low serum 25-hydroxyvitamin D levels are associated with increased risk of viral coinfections in wheezing children. J Allergy Clin Immunol. 2010;126(5):1074-6.

251. Cannell JJ, Vieth R, Umhau JC, Holick MF, Grant WB, Madronich S, et al. Epidemic influenza and vitamin D. Epidemiol Infect. 2006;134(6):1129-40.

252. Camargo CA Jr, Ingham T, Wickens K, Thadhani R, Silvers KM, Epton MJ, et al. Cord-blood 25-hydroxyvitamin D levels and risk of respiratory infection, wheezing, and asthma. Pediatrics. 2011;127(1):e180-7.

253. Magnus MC, Stene LC, Håberg SE, Nafstad P, Stigum H, London SJ, Nystad W. Prospective study of maternal mid-pregnancy 25-hydroxyvitamin $\mathrm{D}$ level and early childhood respiratory disorders. Paediatr Perinat Epidemiol. 2013;27(6):532-41.

254. Dinlen N, Zenciroglu A, Beken S, Dursun A, Dilli D, Okumus N. Association of vitamin $D$ deficiency with acute lower respiratory tract infections in newborns. J Matern Fetal Neonatal Med. 2016;29(6):928-32.

255. de Jongh RT, Crozier SR, D'Angelo S, Pike KC, Roberts G, Lucas JS, et al. Maternal 25-hydroxyvitamin D levels in relation to offspring respiratory symptoms and infections. Eur Respir J. 2014;43(4):1181-3.

256. Xu C, Fang VJ, Perera RA, Kam AM, Ng S, Chan YH, et al. Serum 25-Hydroxyvitamin D was not associated with influenza virus infection in children and adults in Hong Kong, 2009-2010. J Nutr. 2016;146(12):2506-12.

257. Roth $D E$, Jones $A B$, Prosser C, Robinson JL, Vohra S. Vitamin D receptor polymorphisms and the risk of acute lower respiratory tract infection in early childhood. J Infect Dis. 2008;197(5):676-80.
258. Sheen YH, Lee E, Kang MJ, Yu HS, Ahn K, Kim KW, et al. Interaction between 25-hydroxyvitamin D and variants at 17q12-21 on respiratory infections. Pediatr Pulmonol. 2016;51(9):958-67.

259. Charan J, Goyal JP, Saxena D, Yadav P. Vitamin D for prevention of respiratory tract infections: a systematic review and meta-analysis. J Pharmacol Pharmacother. 2012;3(4):300-3.

260. Jolliffe DA, Griffiths CJ, Martineau AR. Vitamin D in the prevention of acute respiratory infection: systematic review of clinical studies. J Steroid Biochem Mol Biol. 2013;136:321-9.

261. Bergman $P$, Lindh AU, Björkhem-Bergman L, Lindh JD. Vitamin D and respiratory tract infections: a systematic review and meta-analysis of randomized controlled trials. PLoS One. 2013;8(6):e65835.

262. Mao S, Huang S. Vitamin D supplementation and risk of respiratory tract infections. Scand J Infect Dis. 2013;45(9):696-702.

263. Ali SR, McDevitt H. Question 1: does vitamin D supplementation prevent acute lower respiratory tract infections in children? Arch Dis Child. 2015;100(9):892-5.

264. Xiao L, Xing C, Yang Z, Xu S, Wang M, Du H, et al. Vitamin D supplementation for the prevention of childhood acute respiratory infections: a systematic review of randomised controlled trials. Br J Nutr. 2015;114(7):1026-34

265. Vuichard Gysin D, Dao D, Gysin CM, Lytvyn L, Loeb M. Effect of vitamin $D_{3}$ supplementation on respiratory tract infections in healthy individuals: a systematic review and meta-analysis of randomized controlled trials. PLoS One. 2016;11(9):e0162996.

266. Yakoob MY, Salam RA, Khan FR, Bhutta ZA. Vitamin D supplementation for preventing infections in children under five years of age. Cochrane Database Syst Rev. 2016;11:CD008824.

267. Marchisio P, Consonni D, Baggi E, Zampiero A, Bianchini S, Terranova L, et al. Vitamin D supplementation reduces the risk of acute otitis media in otitis-prone children. Pediatr Infect Dis J. 2013;32(10):1055-60.

268. Martineau AR, Jolliffe DA, Hooper RL, Greenberg L, Aloia JF, Bergman P, et al. Vitamin $D$ supplementation to prevent acute respiratory tract infections: systematic review and meta-analysis of individual participant data. BMJ. 2017;356:16583.

269. Bolland MJ, Avenell A. Do vitamin D supplements help prevent respiratory tract infections? BMJ. 2017;356:j456.

270. lacobucci G. Vitamin D supplementation does cut respiratory infections, new study suggests. BMJ. 2017;356:j847.

271. Aglipay M, Birken CS, Parkin PC, Loeb MB, Thorpe K, Chen Y, et al. Effect of high-dose vs standard-dose wintertime vitamin D supplementation on viral upper respiratory tract infections in young healthy children. JAMA. 2017:318(3):245-54.

272. Morris SK, Pell LG, Rahman MZ, Dimitris MC, Mahmud A, Islam MM, et al. Maternal vitamin D supplementation during pregnancy and lactation to prevent acute respiratory infections in infancy in Dhaka, Bangladesh (MDARI trial): protocol for a prospective cohort study nested within a randomized controlled trial. BMC Pregnancy Childbirth. 2016;16(1):309.

273. Christensen N, Søndergaard J, Fisker N, Christesen HT. Infant respiratory tract infections or wheeze and maternal vitamin D in pregnancy: a systematic review. Pediatr Infect Dis J. 2017;36(4):384-91.

274. Tekin M, Konca C, Celik V, Almis H, Kahramaner Z, Erdemir A, et al. The association between vitamin $\mathrm{D}$ levels and urinary tract infection in children. Horm Res Paediatr. 2015;83(3):198-203.

275. Aslan S, Akil I, Aslan G, Onay H, Ozyurt BC, Ozkinay F. Vitamin D receptor gene polymorphism in children with urinary tract infection. Pediatr Nephrol. 2012;27(3):417-21.

276. Wang JW, Hogan PG, Hunstad DA, Fritz SA. Vitamin D sufficiency and Staphylococcus aureus infection in children. Pediatr Infect Dis J. 2015;34(5):544-5.

277. Thornton KA, Marín C, Mora-Plazas M, Villamor E. Vitamin D deficiency associated with increased incidence of gastrointestinal and ear infections in school-age children. Pediatr Infect Dis J. 2013;32(6):585-93.

278. Bucak IH, Ozturk AB, Almis H, Cevik MÖ, Tekin M, Konca Ç, et al. Is there a relationship between low vitamin $\mathrm{D}$ and rotaviral diarrhea? Pediatr Int. 2016;58(4):270-3.

279. Cusick SE, Opoka RO, Lund TC, John CC, Polgreen LE. Vitamin D insufficiency is common in Ugandan children and is associated with severe malaria. PLoS One. 2014:9(12):e113185.

280. Diro E, Lynen L, Gebregziabiher B, Assefa A, Lakew W, Belew Z, et al. Clinical aspects of paediatric visceral leishmaniasis in north-West Ethiopia. Tropical Med Int Health. 2015;20(1):8-16. 
281. Eltayeb AA, Abdou MA, Abdel-aal AM, Othman MH. Vitamin D status and viral response to therapy in hepatitis $C$ infected children. World J Gastroenterol. 2015;21(4):1284-91.

282. Aydemir G, Cekmez F, Kalkan G, Fidanci MK, Kaya G, Karaoglu A, et al. High serum 25-hydroxyvitamin D levels are associated with pediatric sepsis. Tohoku J Exp Med. 2014;234(4):295-8.

283. Aluisio AR, Maroof Z, Chandramohan D, Bruce J, Mughal MZ, Bhutta Z, et al. Vitamin $D_{3}$ supplementation and childhood diarrhea: a randomized controlled trial. Pediatrics. 2013;132(4):e832-40.

284. Moodley A, Qin M, Singh KK, Spector SA. Vitamin D-related host genetic variants alter HIV disease progression in children. Pediatr Infect Dis J. 2013;32(11):1230-6.

285. Mehta S, Hunter DJ, Mugusi FM, Spiegelman D, Manji KP, Giovannucci EL, et al. Perinatal outcomes, including mother-to-child transmission of HIV, and child mortality and their association with maternal vitamin D status in Tanzania. J Infect Dis. 2009;200(7):1022-30.

286. Meyzer C, Frange P, Chappuy H, Desse B, Veber F, Le Clésiau H, et al. Vitamin D deficiency and insufficiency in HIV-infected children and young adults. Pediatr Infect Dis J. 2013;32(11):1240-4.

287. Rutstein R, Downes A, Zemel B, Schall J, Stallings V. Vitamin D status in children and young adults with perinatally acquired HIV infection. Clin Nutr. 2011;30(5):624-8.

288. Giacomet V, Vigano A, Manfredini V, Cerini C, Bedogni G, Mora S, et al. Cholecalciferol supplementation in HIV-infected youth with vitamin D insufficiency: effects on vitamin D status and T-cell phenotype: a randomized controlled trial. HIV Clin Trials. 2013;14(2):51-60.

289. Steenhoff AP, Schall JI, Samuel J, Seme B, Marape M, Ratshaa B, et al. Vitamin $\mathrm{D}_{3}$ supplementation in Batswana children and adults with HIV: a pilot double blind randomized controlled trial. PLoS One. 2015;10(2):e0117123.

290. Dougherty KA, Schall JI, Zemel BS, Tuluc F, Hou X, Rutstein RM, Stallings VA. Safety and efficacy of high-dose daily vitamin $D_{3}$ supplementation in children and young adults infected with human immunodeficiency virus. J Pediatric Infect Dis Soc. 2014;3(4):294-303.

291. Daley $P$, Jagannathan $V$, John KR, Sarojini J, Latha A, Vieth $R$, et al. Adjunctive vitamin D for treatment of active tuberculosis in India: a randomised, double-blind, placebo-controlled trial. Lancet Infect Dis. 2015;15(5):528-34

292. Ganmaa D, Giovannucci E, Bloom BR, Fawzi W, Burr W, Batbaatar D, et al. Vitamin D, tuberculin skin test conversion, and latent tuberculosis in Mongolian school-age children: a randomized, double-blind, placebocontrolled feasibility trial. Am J Clin Nutr. 2012;96(2):391-6.

293. Keflie TS, Nölle N, Lambert C, Nohr D, Biesalski HK. Vitamin D deficiencies among tuberculosis patients in Africa: a systematic review. Nutrition. 2015:31(10):1204-12

294. Turnbull ER, Drobniewski F. Vitamin D supplementation: a comprehensive review on supplementation for tuberculosis prophylaxis. Expert Rev Respir Med. 2015;9(3):269-75.

295. Facchini L, Venturini E, Galli L, de Martino M, Chiappini E. Vitamin D and tuberculosis: a review on a hot topic. J Chemother. 2015;27(3):128-38.

296. Gray K, Wood N, Gunasekera H, Sheikh M, Hazelton B, Barzi F, Isaacs D. Vitamin D and tuberculosis status in refugee children. Pediatr Infect Dis J. 2012;31(5):521-3.

297. Williams B, Williams AJ, Anderson ST. Vitamin D deficiency and insufficiency in children with tuberculosis. Ped Infect Dis J. 2008;27(10):941-2.

298. Zeng J, Wu G, Yang W, Gu X, Liang W, Yao Y, Song Y. A serum vitamin D level $<25 \mathrm{nmol} / /$ pose high tuberculosis risk: a meta-analysis. PLoS One. 2015;10(5):e0126014

299. Jubulis J, Kinikar A, Ithape M, Khandave M, Dixit S, Hotalkar S, et al. Modifiable risk factors associated with tuberculosis disease in children in Pune, India. Int J Tuberc Lung Dis. 2014;18(2):198-204.

300. Xia J, Shi L, Zhao L, Xu F. Impact of vitamin D supplementation on the outcome of tuberculosis treatment: a systematic review and meta-analysis of randomized controlled trials. Chin Med J. 2014;127(17):3127-34.

301. Venturini E, Facchini L, Martinez-Alier N, Novelli V, Galli L, de Martino M, Chiappini E. Vitamin D and tuberculosis: a multicenter study in children. BMC Infect Dis. 2014;14:652.

302. Grobler L, Nagpal S, Sudarsanam TD, Sinclair D. Nutritional supplements for people being treated for active tuberculosis. Cochrane Database Syst Rev. 2016;6:CD006086.

303. Wacker M, Holick MF. Vitamin D - effects on skeletal and extraskeletal health and the need for supplementation. Nutrients. 2013;5(1):111-48.
304. Litonjua AA. Vitamin D deficiency as a risk factor for childhood allergic disease and asthma. Curr Opin Allergy Clin Immunol. 2012;12(2):179-85.

305. Muehleisen B, Gallo RL. Vitamin D in allergic disease: shedding light on a complex problem. J Allergy Clin Immunol. 2013;131(2):324-9.

306. Prietl B, Treiber G, Pieber TR, Amrein K. Vitamin D and immune function. Nutrients. 2013;5(7):2502-21.

307. Kamen DL, Tangpricha V. Vitamin D and molecular actions on the immune system: modulation of innate and autoimmunity. J Mol Med (Berl). 2010;88(5):441-50

308. Rolf $L$, Muris AH, Hupperts R, Damoiseaux J. Vitamin D effects on $B$ cell function in autoimmunity. Ann N Y Acad Sci. 2014;1317:84-91.

309. Baker KE, Bonvini SJ, Donovan C, Foong RE, Han B, Jha A, et al. Novel drug targets for asthma and COPD: lessons learned from in vitro and in vivo models. Pulm Pharmacol Ther. 2014;29(2):181-98.

310. Lange NE, Litonjua A, Hawrylowicz CM, Weiss S. Vitamin D, the immune system and asthma. Expert Rev Clin Immunol. 2009;5(6):693-702.

311. Agrawal T, Gupta GK, Agrawal DK. Vitamin D supplementation reduces airway hyperresponsiveness and allergic airway inflammation in a murine model. Clin Exp Allergy. 2013;43(6):672-83.

312. Lai G, Wu C, Hong J, Song Y. 1,25-Dihydroxyvitamin $\mathrm{D}(3)(1,25-(\mathrm{OH})(2) \mathrm{D}(3))$ attenuates airway remodeling in a murine model of chronic asthma. J Asthma. 2013;50(2):133-40.

313. Nanzer AM, Chambers ES, Ryanna K, Richards DF, Black C, Timms PM, et al. Enhanced production of IL-17A in patients with severe asthma is inhibited by $1 a, 25$-dihydroxyvitamin $D_{3}$ in a glucocorticoid-independent fashion. J Allergy Clin Immunol. 2013;132(2):297-304.

314. Irvin C, Zafar I, Good J, Rollins D, Christianson C, Gorska MM, et al. Increased frequency of dual-positive $\mathrm{TH} 2 / \mathrm{TH} 17$ cells in bronchoalveolar lavage fluid characterizes a population of patients with severe asthma. J Allergy Clin Immunol. 2014;134(5):1175-86.

315. Xystrakis E, Kusumakar S, Boswell S, Peek E, Urry Z, Richards DF, et al. Reversing the defective induction of IL-10-secreting regulatory $T$ cells in glucocorticoid-resistant asthma patients. J Clin Invest. 2006;116(1):146-55.

316. White JH. Vitamin D as an inducer of cathelicidin antimicrobial peptide expression: past, present and future. J Steroid Biochem Mol Biol. 2010;121(1-2):234-8.

317. Roby KD, Nardo AD. Innate immunity and the role of the antimicrobial peptide cathelicidin in inflammatory skin disease. Drug Discov Today Dis Mech. 2013;10(3-4):e79-82.

318. Tromp II, Franco OH, van den Hooven EH, Heijboer AC, Jaddoe WW Duijts $L$, et al. 25-Hydroxyvitamin D concentrations, asthma and eczema in childhood: the generation R study. Clin Nutr. 2016;37:169-76.

319. Gazibara T, den Dekker HT, de Jongste JC, McGrath JJ, Eyles DW, Burne TH, et al. Associations of maternal and fetal 25-hydroxyvitamin D levels with childhood lung function and asthma: the generation R study. Clin Exp Allergy. 2016;46(2):337-46.

320. Morales E, Romieu I, Guerra S, Ballester F, Rebagliato M, Vioque J, et al. Maternal vitamin D status in pregnancy and risk of lower respiratory tract infections, wheezing, and asthma in offspring. Epidemiology. 2012;23(1):64-71.

321. Wills AK, Shaheen SO, Granell R, Henderson AJ, Fraser WD, Lawlor DA. Maternal 25-hydroxyvitamin D and its association with childhood atopic outcomes and lung function. Clin Exp Allergy. 2013:43(10):1180-8.

322. Pike KC, Inskip HM, Robinson S, Lucas JS, Cooper C, Harvey NC, et al. Maternal late-pregnancy serum 25-hydroxyvitamin $\mathrm{D}$ in relation to childhood wheeze and atopic outcomes. Thorax. 2012;67(11):950-6.

323. Gale CR, Robinson SM, Harvey NC, Javaid MK, Jiang B, Martyn CN, et al. Maternal vitamin D status during pregnancy and child outcomes. Eur J Clin Nutr. 2008;62(1):68-77.

324. Rothers J, Wright AL, Stern DA, Halonen M, Camargo CA Jr. Cord blood 25-hydroxyvitamin D levels are associated with aeroallergen sensitization in children from Tucson, Arizona. J Allergy Clin Immunol. 2011;128(5):1093-9. e1-5

325. Chawes BL, Bønnelykke K, Stokholm J, Vissing NH, Bjarnadóttir E, Schoos AM, et al. Effect of vitamin $D_{3}$ supplementation during pregnancy on risk of persistent wheeze in the offspring: a randomized clinical trial. JAMA. 2016;315(4):353-61.

326. Litonjua AA, Carey VJ, Laranjo N, Harshfield BJ, McElrath TF, O'Connor GT, et al. Effect of prenatal supplementation with vitamin D on asthma or recurrent wheezing in offspring by age 3 years: the VDAART randomized clinical trial. JAMA. 2016;315(4):362-70. 
327. Bener A, Ehlayel MS, Tulic MK, Hamid Q. Vitamin D deficiency as a strong predictor of asthma in children. Int Arch Allergy Immunol. 2012;157(2):168-75.

328. Gupta A, Sjoukes A, Richards D, Banya W, Hawrylowicz C, Bush A, Saglani S. Relationship between serum vitamin D, disease severity, and airway remodeling in children with asthma. Am J Respir Crit Care Med. 2011;184(12):1342-9

329. Chinellato I, Piazza M, Sandri M, Peroni D, Piacentini G, Boner AL. Vitamin D serum levels and markers of asthma control in Italian children. J Pediatr. 2011;158(3):437-41.

330. Gergen PJ, Teach SJ, Mitchell HE, Freishtat RF, Calatroni A, Matsui E, et al. Lack of a relation between serum 25-hydroxyvitamin D concentrations and asthma in adolescents. Am J Clin Nutr. 2013;97(6):1228-34.

331. Brehm JM, Acosta-Pérez E, Klei L, Roeder K, Barmada M, Boutaoui N, et al. Vitamin D insufficiency and severe asthma exacerbations in Puerto Rican children. Am J Respir Crit Care Med. 2012;186(2):140-6.

332. Gupta A, Dimeloe S, Richards DF, Chambers ES, Black C, Urry Z, et al. Defective IL-10 expression and in vitro steroid-induced IL-17A in paediatric severe therapy-resistant asthma. Thorax. 2014;69(6):508-15.

333. Beigelman A, Zeiger RS, Mauger D, Strunk RC, Jackson DJ, Martinez FD, et al. The association between vitamin $\mathrm{D}$ status and the rate of exacerbations requiring oral corticosteroids in preschool children with recurrent wheezing. J Allergy Clin Immunol. 2014;133(5):1489-92.

334. Fares MM, Alkhaled LH, Mroueh SM, Akl EA. Vitamin D supplementation in children with asthma: a systematic review and meta-analysis. BMC Res Notes. 2015;8:23.

335. Majak P, Rychlik B, Stelmach I. The effect of oral steroids with and without vitamin $D_{3}$ on early efficacy of immunotherapy in asthmatic children. Clin Exp Allergy. 2009;39(12):1830-41.

336. Schou AJ, Heuck C, Wolthers OD. Does vitamin D administered to children with asthma treated with inhaled glucocorticoids affect short-term growth or bone turnover? Pediatr Pulmonol. 2003;36(5):399-404.

337. Majak P, Olszowiec-Chlebna M, Smejda K, Stelmach I. Vitamin D supplementation in children may prevent asthma exacerbation triggered by acute respiratory infection. J Allergy Clin Immunol. 2011;127(5):1294-6.

338. Riverin BD, Maguire JL, Li P. Vitamin D supplementation for childhood asthma: a systematic review and meta-analysis. PLoS One. 2015;10(8):e0136841

339. Pojsupap S, Iliriani K, Sampaio TZ, O'Hearn K, Kovesi T, Menon K, McNally JD. Efficacy of high-dose vitamin D in pediatric asthma: a systematic review and meta-analysis. J Asthma. 2015;52(4):382-90.

340. Lewis E, Fernandez C, Nella A, Hopp R, Gallagher JC, Casale TB. Relationship of 25-hydroxyvitamin D and asthma control in children. Ann Allergy Asthma Immunol. 2012;108(4):281-2.

341. Arshi S, Fallahpour M, Nabavi M, Bemanian MH, Javad-Mousavi SA Nojomi $M$, et al. The effects of vitamin D supplementation on airway functions in mild to moderate persistent asthma. Ann Allergy Asthma Immunol. 2014;113(4):404-9.

342. Bar Yoseph R, Livnat G, Schnapp Z, Hakim F, Dabbah H, Goldbart A, Bentur $L$. The effect of vitamin $D$ on airway reactivity and inflammation in asthmatic children: a double-blind placebo-controlled trial. Pediatr Pulmonol. 2015;50(8):747-53.

343. Zhang Y, Leung DY, Goleva E. Anti-inflammatory and corticosteroidenhancing actions of vitamin $D$ in monocytes of patients with steroidresistant and those with steroid-sensitive asthma. J Allergy Clin Immunol. 2014;133(6):1744-52

344. Searing DA, Zhang Y, Murphy JR, Hauk PJ, Goleva E, Leung DY. Decreased serum vitamin $D$ levels in children with asthma are associated with increased corticosteroid use. J Allergy Clin Immunol. 2010;125(5):995-1000.

345. Sutherland ER, Goleva E, Jackson LP, Stevens AD, Leung DY. Vitamin D levels, lung function, and steroid response in adult asthma. Am J Respir Crit Care Med. 2010;181(7):699-704

346. Vestita M, Filoni A, Congedo M, Foti C, Bonamonte D. Vitamin D and atopic dermatitis in childhood. J Immunol Res. 2015;2015:257879.

347. Baïz N, Dargent-Molina P. Cord serum 25-hydroxyvitamin D and risk of early childhood transient wheezing and atopic dermatitis. J Allergy Clin Immunol. 2014;133(1):147-53.

348. Blomberg M, Rifas-Shiman SL, Camargo CA Jr, Gold DR, Asgari MM, Thyssen JP, et al. Low maternal prenatal 25-hydroxy vitamin D blood levels are associated with childhood atopic dermatitis. J Invest Dermatol. 2017;137:1380
349. Manousaki D, Paternoster L, Standl M, Moffatt MF, Farrall M, Bouzigon E, et al. Vitamin D levels and susceptibility to asthma, elevated immunoglobulin E levels, and atopic dermatitis: a Mendelian randomization study. PLoS Med. 2017;14(5):e1002294.

350. Kim G, Bae JH. Vitamin D and atopic dermatitis: a systematic review and meta-analysis. Nutrition. 2016;32(9):913-20.

351. Kim MJ, Kim SN, Lee YW, Choe YB, Ahn KJ. Vitamin D status and efficacy of vitamin D supplementation in atopic dermatitis: a systematic review and meta-analysis. Nutrients. 2016;8(12):E789.

352. Camargo CA Jr, Ganmaa D, Sidbury R, Erdenedelger K, Radnaakhand N, Khandsuren B. Randomized trial of vitamin D supplementation for winter-related atopic dermatitis in children. J Allergy Clin Immunol. 2014;134(4):831-5. e1

353. Yepes-Nuñez JJ, Fiocchi A, Pawankar R, Cuello-Garcia CA, Zhang Y, Morgano GP, et al. World allergy organization-McMaster University guidelines for allergic disease prevention (GLAD-P): vitamin D. World Allergy Organ J. 2016;9:17.

354. Hyppönen E, Berry DJ, Wjst M, Power C. Serum 25-hydroxyvitamin D and lgE - a significant but nonlinear relationship. Allergy. 2009;64(4):613-20.

355. Willits EK, Wang Z, Jin J, Patel B, Motosue M, Bhagia A, et al. Vitamin D and food allergies in children: a systematic review and meta-analysis. Allergy Asthma Proc. 2017;38(3):238.

356. Suaini NH, Zhang Y, Vuillermin PJ, Allen KJ, Harrison LC. Immune modulation by vitamin $D$ and its relevance to food allergy. Nutrients. 2015;7(8):6088-108.

357. Molloy J, Koplin JJ, Allen KJ, Tang ML, Collier F, Carlin JB, et al. Vitamin D insufficiency in the first 6 months of infancy and challenge-proven IgE-mediated food allergy at 1 year of age: a case-cohort study. Allergy. 2017;72(8):1222-31.

358. Feng R, Li Y, Li G, Li Z, Zhang Y, Li Q, Sun C. Lower serum $25(\mathrm{OH}) \mathrm{D}$ concentrations in type 1 diabetes: a meta-analysis. Diabetes Res Clin Pract. 2015;108(3):e71-5.

359. Greer RM, Rogers MA, Bowling FG, Buntain HM, Harris M, Leong GM, Cotterill AM. Australian children and adolescents with type 1 diabetes have low vitamin D levels. Med J Aust. 2007;187(1):59-60.

360. Littorin B, Blom P, Schölin A, Arnqvist HJ, Blohmé G, Bolinder J, et al. Lower levels of plasma 25-hydroxyvitamin D among young adults at diagnosis of autoimmune type 1 diabetes compared with control subjects: results from the nationwide diabetes incidence study in Sweden (DISS). Diabetologia. 2006;49(12):2847-52

361. Huynh T, Greer RM, Nyunt O, Bowling F, Cowley D, Leong GM, et al. The association between ketoacidosis and $25(\mathrm{OH})$-vitamin D levels at presentation in children with type 1 diabetes mellitus. Pediatr Diabetes. 2009;10(1):38-43.

362. Svoren BM, Volkening LK, Wood JR, Laffel LM. Significant vitamin D deficiency in youth with type 1 diabetes mellitus. J Pediatr. 2009;154(1):132-4.

363. Greer RM, Portelli SL, Hung BS, Cleghorn GJ, McMahon SK, Batch JA, Conwell LS. Serum vitamin D levels are lower in Australian children and adolescents with type 1 diabetes than in children without diabetes. Pediatr Diabetes. 2013;14(1):31-41

364. Cadario F, Prodam F, Savastio S, Monzani A, Balafrej A, Bellomo G, Bona G. Vitamin D status and type 1 diabetes in children: evaluation according to latitude and skin color. Minerva Pediatr. 2015;67(3):263-7.

365. The NS, Crandell JL, Lawrence JM, King IB, Dabelea D, Marcovina SM, et al. Vitamin D in youth with type 1 diabetes: prevalence of insufficiency and association with insulin resistance in the SEARCH nutrition ancillary study. Diabet Med. 2013;30(11):1324-32.

366. Savastio S, Cadario F, Genoni G, Bellomo G, Bagnati M, Secco G, et al. Vitamin D deficiency and glycemic status in children and adolescents with type 1 diabetes mellitus. PLoS One. 2016;11(9):e0162554.

367. Thorsen SU, Mortensen HB, Carstensen B, Fenger M, Thuesen BH, Husemoen $\mathrm{LL}$, et al. No difference in vitamin $\mathrm{D}$ levels between children newly diagnosed with type 1 diabetes and their healthy siblings: a 13-year nationwide Danish study. Diabetes Care. 2013;36(9):e157-8.

368. Raab J, Giannopoulou EZ, Schneider S, Warncke K, Krasmann M, Winkler C, Ziegler AG. Prevalence of vitamin D deficiency in pre-type 1 diabetes and its association with disease progression. Diabetologia. 2014;57(5):902-8.

369. Wang Q, Xi B, Reilly KH, Liu M, Fu M. Quantitative assessment of the associations between four polymorphisms (Fokl, Apal, Bsml, Taql) of vitamin D receptor gene and risk of diabetes mellitus. Mol Biol Rep. 2012;39(10):9405-14. 
370. Zhang J, Li W, Liu J, Wu W, Ouyang H, Zhang Q, et al. Polymorphisms in the vitamin $\mathrm{D}$ receptor gene and type 1 diabetes mellitus risk: an update by meta-analysis. Mol Cell Endocrinol. 2012;355(1):135-42.

371. Wang G, Zhang Q, Xu N, Xu K, Wang J, He W, Yang T. Associations between two polymorphisms (Fokl and Bsml) of vitamin D receptor gene and type 1 diabetes mellitus in Asian population: a meta-analysis. PLoS One. 2014;9(3):e89325.

372. Sahin OA, Goksen D, Ozpinar A, Serdar M, Onay H. Association of vitamin D receptor polymorphisms and type 1 diabetes susceptibility in children: a meta-analysis. Endocr Connect. 2017;6(3):159-71.

373. Bailey R, Cooper JD, Zeitels L, Smyth DJ, Yang JH, Walker NM, et al. Association of the vitamin D metabolism gene CYP27B1 with type 1 diabetes. Diabetes. 2007;56(10):2616-21.

374. Frederiksen BN, Kroehl M, Fingerlin TE, Wong R, Steck AK, Rewers M, Norris JM. Association between vitamin D metabolism gene polymorphisms and risk of islet autoimmunity and progression to type 1 diabetes: the diabetes autoimmunity study in the young (DAISY). J Clin Endocrinol Metab. 2013;98(11):E1845-51.

375. Frederiksen B, Liu E, Romanos J, Steck AK, Yin X, Kroehl M, et al. Investigation of the vitamin D receptor gene (VDR) and its interaction with protein tyrosine phosphatase, non-receptor type 2 gene (PTPN2) on risk of islet autoimmunity and type 1 diabetes: the diabetes autoimmunity study in the young (DAISY). J Steroid Biochem Mol Biol. 2013;133:51-7.

376. Cooper JD, Smyth DJ, Walker NM, Stevens H, Burren OS, Wallace C, et al. Inherited variation in vitamin $D$ genes is associated with predisposition to autoimmune disease type 1 diabetes. Diabetes. 2011;60(5):1624-31.

377. Hyppönen $E$, Läärä E, Reunanen A, Järvelin MR, Virtanen SM. Intake of vitamin D and risk of type 1 diabetes: a birth-cohort study. Lancet. 2001; 358(9292):1500-3.

378. Stene LC, Joner G. Norwegian childhood diabetes study group. Use of cod liver oil during the first year of life is associated with lower risk of childhood-onset type 1 diabetes: a large, population-based, case-control study. Am J Clin Nutr. 2003;78(6):1128-34.

379. Dong JY, Zhang WG, Chen JJ, Zhang ZL, Han SF, Qin LQ. Vitamin D intake and risk of type 1 diabetes: a meta-analysis of observational studies. Nutrients. 2013;5(9):3551-62.

380. Harvey NC, Holroyd C, Ntani G, Javaid K, Cooper P, Moon R, et al. Vitamin D supplementation in pregnancy: a systematic review. Health Technol Assess. 2014;18(45):1-190.

381. Simpson M, Brady H, Yin X, Seifert J, Barriga K, Hoffman M, et al. No association of vitamin D intake or 25-hydroxyvitamin D levels in childhood with risk of islet autoimmunity and type 1 diabetes: the diabetes autoimmunity study in the young (DAISY). Diabetologia. 2011;54(11):2779-88.

382. Cadario F, Savastio S, Pagliardini V, Bagnati M, Vidali M, Cerutti F, et al. Vitamin D levels at birth and risk of type 1 diabetes in childhood: a case-control study. Acta Diabetol. 2015;52(6):1077-81.

383. Jacobsen R, Thorsen SU, Cohen AS, Lundqvist M, Frederiksen P, Pipper CB, et al. Neonatal vitamin D status is not associated with later risk of type 1 diabetes: results from two large Danish population-based studies. Diabetologia. 2016;59(9):1871-81.

384. Pitocco D, Crinò A, Di Stasio E, Manfrini S, Guglielmi C, Spera S, et al. The effects of calcitriol and nicotinamide on residual pancreatic beta-cell function in patients with recent-onset type 1 diabetes (IMDIAB XI). Diabet Med. 2006;23(8):920-3

385. Bizzarri C, Pitocco D, Napoli N, Di Stasio E, Maggi D, Manfrini S, et al. No protective effect of calcitriol on beta-cell function in recent-onset type 1 diabetes: the IMDIAB XIII trial. Diabetes Care. 2010;33(9):1962-3.

386. Bock G, Prietl B, Mader JK, Höller E, Wolf M, Pilz S, et al. The effect of vitamin $D$ supplementation on peripheral regulatory $T$ cells and $\beta$ cell function in healthy humans: a randomized controlled trial. Diabetes Metab Res Rev. 2011;27(8):942-5.

387. Gabbay MA, Sato MN, Finazzo C, Duarte AJ, Dib SA. Effect of cholecalciferol as adjunctive therapy with insulin on protective immunologic profile and decline of residual $\beta$-cell function in new-onset type 1 diabetes mellitus. Arch Pediatr Adolesc Med. 2012;166(7):601-7.

388. Treiber G, Prietl B, Fröhlich-Reiterer E, Lechner E, Ribitsch A, Fritsch M, et al. Cholecalciferol supplementation improves suppressive capacity of regulatory T-cells in young patients with new-onset type 1 diabetes mellitus - a randomized clinical trial. Clin Immunol. 2015;161(2):217-24.

389. Bogdanou D, Penna-Martinez M, Filmann N, Chung TL, Moran-Auth Y, Wehrle J, et al. T-lymphocyte and glycemic status after vitamin D treatment in type 1 diabetes: a randomized controlled trial with sequential crossover. Diabetes Metab Res Rev. 2017;33(3)

390. Papadimitriou DT, Marakaki C, Fretzayas A, Nicolaidou P, Papadimitriou A. Negativation of type 1 diabetes-associated autoantibodies to glutamic acid decarboxylase and insulin in children treated with oral calcitriol. J Diabetes. 2013;5(3):344-8.

391. Federico G, Focosi D, Marchi B, Randazzo E, De Donno M, Vierucci F, et al. Administering 25 -hydroxyvitamin $D_{3}$ in vitamin D-deficient young type $1 \mathrm{~A}$ diabetic patients reduces reactivity against islet autoantigens. Clin Nutr. 2014;33(6):1153-6.

392. Hardenberg G, Steiner TS, Levings MK. Environmental influences on T regulatory cells in inflammatory bowel disease. Semin Immunol. 2011;23(2):130-8.

393. Narula N, Marshall JK. Management of inflammatory bowel disease with vitamin D: beyond bone health. J Crohns Colitis. 2012;6(4):397-404.

394. Kosmowska-Miśków A. The role of vitamin $D_{3}$ in inflammatory bowel diseases. Adv Clin Exp Med. 2014;23(4):497-504.

395. Wu S, Zhang YG, Lu R, Xia Y, Zhou D, Petrof EO, et al. Intestinal epithelial vitamin $\mathrm{D}$ receptor deletion leads to defective autophagy in colitis. Gut. 2015;64(7):1082-94.

396. Holmes EA, Xiang F, Lucas RM. Variation in incidence of pediatric Crohn's disease in relation to latitude and ambient ultraviolet radiation: a systematic review and analysis. Inflamm Bowel Dis. 2015;21(4):809-17.

397. Levin AD, Wadhera V, Leach ST, Woodhead HJ, Lemberg DA, Mendoza-Cruz AC, Day AS. Vitamin D deficiency in children with inflammatory bowel disease. Dig Dis Sci. 2011;56(3):830-6.

398. Pappa HM, Langereis EJ, Grand RJ, Gordon CM. Prevalence and risk factors for hypovitaminosis $D$ in young patients with inflammatory bowel disease. J Pediatr Gastroenterol Nutr. 2011;53(4):361-4.

399. Sadeghian M, Saneei P, Siassi F, Esmaillzadeh A. Vitamin D status in relation to Crohn's disease: meta-analysis of observational studies. Nutrition. 2016:32(5):505-14

400. Pappa HM, Gordon CM, Saslowsky TM, Zholudev A, Horr B, Shih MC, Grand RJ. Vitamin D status in children and young adults with inflammatory bowel disease. Pediatrics. 2006;118(5):1950-61.

401. O'Malley T, Heuberger R. Vitamin D status and supplementation in pediatric gastrointestinal disease. J Spec Pediatr Nurs. 2011;16(2):140-50.

402. Veit $L E$, Maranda $L$, Nwosu BU. The nondietary determinants of vitamin D status in pediatric inflammatory bowel disease. Nutrition. 2015;31(7-8):994-9.

403. Pappa H, Thayu M, Sylvester F, Leonard M, Zemel B, Gordon C. Skeletal health of children and adolescents with inflammatory bowel disease. J Pediatr Gastroenterol Nutr. 2011;53(1):11-25.

404. Rufo PA, Denson LA, Sylvester FA, Szigethy E, Sathya P, Lu Y, et al. Health supervision in the management of children and adolescents with IBD: NASPGHAN recommendations. J Pediatr Gastroenterol Nutr. 2012;55(1):93-108.

405. Scott Fl, Lichtenstein GR. Approach to the patient with mild Crohn's disease: a 2016 update. Curr Gastroenterol Rep. 2016;18(9):50.

406. Ahlawat R, Weinstein T, Pettei MJ. Vitamin D in pediatric gastrointestinal disease. Curr Opin Pediatr. 2017;29(1):122-7.

407. Pappa HM, Mitchell PD, Jiang H, Kassiff S, Filip-Dhima R, DiFabio D, et al. Maintenance of optimal vitamin D status in children and adolescents with inflammatory bowel disease: a randomized clinical trial comparing two regimens. J Clin Endocrinol Metab. 2014;99(9):3408-17.

408. Wingate KE, Jacobson $K$, Issenman R, Carroll M, Barker C, Israel D, et al. 25-Hydroxyvitamin D concentrations in children with Crohn's disease supplemented with either 2000 or 400 IU daily for 6 months: a randomized controlled study. J Pediatr. 2014;164(4):860-5.

409. Hradsky O, Soucek O, Maratova K, Matyskova J, Copova I, Zarubova K, et al. Supplementation with $2000 \mathrm{IU}$ of cholecalciferol is associated with improvement of trabecular bone mineral density and muscle power in pediatric patients with IBD. Inflamm Bowel Dis. 2017;23(4):514-23.

410. Pappa HM, Mitchell PD, Jiang H, Kassiff S, Filip-Dhima R, DiFabio D, et al. Treatment of vitamin D insufficiency in children and adolescents with inflammatory bowel disease: a randomized clinical trial comparing three regimens. J Clin Endocrinol Metab. 2012;97(6):2134-42.

411. Simek RZ, Prince J, Syed S, Sauer CG, Martineau B, Hofmekler T, et al. Pilot study evaluating efficacy of 2 regimens for hypovitaminosis $D$ repletion in pediatric inflammatory bowel disease. J Pediatr Gastroenterol Nutr. 2016;62(2):252-8.

412. Shepherd D, Day AS, Leach ST, Lopez R, Messenger R, Woodhead HJ, et al. Single high-dose oral vitamin $D_{3}$ therapy (stoss): a solution to vitamin $D$ 
deficiency in children with inflammatory bowel disease? J Pediatr Gastroenterol Nutr. 2015;61(4):411-4.

413. Tanpowpong P, Camargo CA. Early-life vitamin D deficiency and childhoodonset coeliac disease. Public Health Nutr. 2014;17(4):823-6.

414. Unalp-Arida A, Ruhl CE, Choung RS, Brantner TL, Murray JA. Lower prevalence of celiac disease and gluten-related disorders in persons living in southern vs northern latitudes of the United States. Gastroenterology. 2017;152(8):1922-32. e2

415. Yang J, Tamura RN, Aronsson CA, Uusitalo UM, Lernmark $\AA$, Rewers M, et al. Maternal use of dietary supplements during pregnancy is not associated with coeliac disease in the offspring: the environmental determinants of diabetes in the young (TEDDY) study. Br J Nutr. 2017;117(3):466-72.

416. Mårild K, Tapia G, Haugen M, Dahl SR, Cohen AS, Lundqvist M, et al. Maternal and neonatal vitamin D status, genotype and childhood celiac disease. PLoS One. 2017;12(7):e0179080.

417. Zanchi C, Di Leo G, Ronfani L, Martelossi S, Not T, Ventura A. Bone metabolism in celiac disease. J Pediatr. 2008;153(2):262-5.

418. Lerner A, Shapira Y, Agmon-Levin N, Pacht A, Ben-Ami Shor D, López HM, et al. The clinical significance of $25 \mathrm{OH}$-vitamin D status in celiac disease. Clin Rev Allergy Immunol. 2012;42(3):322-30.

419. Margoni D, Chouliaras G, Duscas G, Voskaki I, Voutsas N, Papadopoulou A, et al. Bone health in children with celiac disease assessed by dual $x$-ray absorptiometry: effect of gluten-free diet and predictive value of serum biochemical indices. J Pediatr Gastroenterol Nutr. 2012;54(5):680-4.

420. Erdem T, Ferat Ç, Nurdan YA, Halime E, Muhammed Selçuk S, Hamza K, Mukadder Ayşe S. Vitamin and mineral deficiency in children newly diagnosed with celiac disease. Turk J Med Sci. 2015;45(4):833-6.

421. Wessels MM, van Veen II, Vriezinga SL, Putter H, Rings EH, Mearin ML. Complementary serologic investigations in children with celiac disease is unnecessary during follow-up. J Pediatr. 2016;169:55-60.

422. Kamycheva E, Goto T, Camargo CA Jr. Celiac disease is associated with reduced bone mineral density and increased FRAX scores in the US National Health and nutrition examination survey. Osteoporos Int. 2017;28(3):781-90.

423. Zanchetta MB, Longobardi V, Bai JC. Bone and celiac disease. Curr Osteoporos Rep. 2016;14(2):43-8.

424. Bianchi ML, Bardella MT. Bone in celiac disease. Osteoporos Int. 2008;19(12):1705-16.

425. Tau C, Mautalen C, De Rosa S, Roca A, Valenzuela X. Bone mineral density in children with celiac disease. Effect of a gluten-free diet. Eur J Clin Nutr. 2006;60(3):358-63.

426. Grace-Farfaglia P. Bones of contention: bone mineral density recovery in celiac disease-a systematic review. Nutrients. 2015;7(5):3347-69.

427. Rubio-Tapia A, Hill ID, Kelly CP, Calderwood AH, Murray JA, American College of Gastroenterology. ACG clinical guidelines: diagnosis and management of celiac disease. Am J Gastroenterol. 2013;108(5):656-76.

428. Ludvigsson JF, Bai JC, Biagi F, Card TR, Ciacci C, Ciclitira PJ, et al. Diagnosis and management of adult coeliac disease: guidelines from the British Society of Gastroenterology. Gut. 2014;63(8):1210-28.

429. Hill ID, Fasano A, Guandalini S, Hoffenberg E, Levy J, Reilly N, Verma R. NASPGHAN clinical report on the diagnosis and treatment of gluten-related disorders. J Pediatr Gastroenterol Nutr. 2016;63(1):156-65.

430. Snyder J, Butzner JD, DeFelice AR, Fasano A, Guandalini S, Liu E, Newton KP. Evidence-informed expert recommendations for the management of celiac disease in children. Pediatrics. 2016;138(3):e20153147.

431. Ohlund K, Olsson C, Hernell O, Ohlund I. Dietary shortcomings in children on a gluten-free diet. J Hum Nutr Diet. 2010;23(3):294-300.

432. Blazina S, Bratanic N, Campa AS, Blagus R, Orel R. Bone mineral density and importance of strict gluten-free diet in children and adolescents with celiac disease. Bone. 2010;47(3):598-603.

433. Downey L, Houten R, Murch S, Longson D, Guideline Development Group. Recognition, assessment, and management of coeliac disease: summary of updated NICE guidance. BMJ. 2015;351:h4513.

434. Dong Y, Pollock N, Stallmann-Jorgensen IS, Gutin B, Lan L, Chen TC, et al. Low 25-hydroxyvitamin D levels in adolescents: race, season, adiposity, physical activity, and fitness. Pediatrics. 2010;125(6):1104-11.

435. Earthman CP, Beckman LM, Masodkar K, Sibley SD. The link between obesity and low circulating 25-hydroxyvitamin D concentrations: considerations and implications. Int J Obes. 2012;36(3):387-96.

436. Gilbert-Diamond D, Baylin A, Mora-Plazas M, Marin C, Arsenault JE, Hughes MD, et al. Vitamin D deficiency and anthropometric indicators of adiposity in school-age children: a prospective study. Am J Clin Nutr. 2010;92(6):1446-51.
437. Rusconi RE, De Cosmi V, Gianluca G, Giavoli C, Agostoni C, Vitamin D. sufficiency in obese children and relation with lipid profile. Int J Food Sci Nutr. 2015;66(2):132-4.

438. Miraglia del Giudice E, Grandone A, Cirillo G, Capristo C, Marzuillo P, Di Sessa A, et al. Bioavailable vitamin $D$ in obese children: the role of insulin resistance. J Clin Endocrinol Metab. 2015;100(10):3949-55.

439. Pereira-Santos M, Costa PR, Assis AM, Santos CA, Santos DB. Obesity and vitamin $D$ deficiency: a systematic review and meta-analysis. Obes Rev. 2015;16(4):341-9.

440. Yao Y, Zhu L, He L, Duan Y, Liang W, Nie Z, et al. A meta-analysis of the relationship between vitamin D deficiency and obesity. Int J Clin Exp Med. 2015;8(9):14977-84.

441. Vimaleswaran KS, Berry DJ, Lu C, Tikkanen E, Pilz S, Hiraki LT, et al. Causal relationship between obesity and vitamin D status: bi-directional Mendelian randomization analysis of multiple cohorts. PLoS Med. 2013;10(2):e1001383.

442. Reinehr T, de Sousa G, Alexy U, Kersting M, Andler W. Vitamin D status and parathyroid hormone in obese children before and after weight loss. Eur J Endocrinol. 2007;157(2):225-32.

443. Mallard SR, Howe AS, Houghton LA. Vitamin D status and weight loss: a systematic review and meta-analysis of randomized and nonrandomized controlled weight-loss trials. Am J Clin Nutr. 2016;104(4):1151-9.

444. Pathak K, Soares MJ, Calton EK, Zhao Y, Hallett J. Vitamin D supplementation and body weight status: a systematic review and meta-analysis of randomized controlled trials. Obes Rev. 2014;15(6):528-37.

445. Chandler PD, Wang L, Zhang X, Sesso HD, Moorthy MV, Obi O, et al. Effect of vitamin $\mathrm{D}$ supplementation alone or with calcium on adiposity measures: a systematic review and meta-analysis of randomized controlled trials. Nutr Rev. 2015;73(9):577-93.

446. Rosen CJ, Adams JS, Bikle DD, Black DM, Demay MB, Manson JE, et al. The nonskeletal effects of vitamin D: an Endocrine Society scientific statement. Endocr Rev. 2012;33(3):456-92.

447. Zhou QG, Hou FF, Guo ZJ, Liang M, Wang GB, Zhang X. 1,25-Dihydroxyvitamin D improved the free fatty-acid-induced insulin resistance in cultured $\mathrm{C} 2 \mathrm{C} 12$ cells. Diabetes Metab Res Rev. 2008;24(6):459-64.

448. Reis JP, von Mühlen D, Miller ER 3rd, Michos ED, Appel LJ. Vitamin D status and cardiometabolic risk factors in the United States adolescent population Pediatrics. 2009;124(3):e371-9.

449. Roth CL, Elfers C, Kratz M, Hoofnagle AN. Vitamin d deficiency in obese children and its relationship to insulin resistance and adipokines. J Obes. 2011;2011:495101.

450. Erdönmez D, Hatun S, Çizmecioğlu FM, Keser A. No relationship between vitamin $D$ status and insulin resistance in a group of high school students. J Clin Res Pediatr Endocrinol. 2011;3(4):198-201.

451. Nobili V, Giorgio V, Liccardo D, Bedogni G, Morino G, Alisi A, Cianfarani S. Vitamin D levels and liver histological alterations in children with nonalcoholic fatty liver disease. Eur J Endocrinol. 2014;170(4):547-53.

452. Black LJ, Jacoby P, She Ping-Delfos WC, Mori TA, Beilin LJ, Olynyk JK, et al. Low serum 25-hydroxyvitamin D concentrations associate with nonalcoholic fatty liver disease in adolescents independent of adiposity. J Gastroenterol Hepatol. 2014;29(6):1215-22.

453. Hourigan SK, Abrams S, Yates K, Pfeifer K, Torbenson M, Murray K, et al. Relation between vitamin $D$ status and nonalcoholic fatty liver disease in children. J Pediatr Gastroenterol Nutr. 2015;60(3):396-404.

454. Belenchia AM, Tosh AK, Hillman LS, Peterson CA. Correcting vitamin D insufficiency improves insulin sensitivity in obese adolescents: a randomized controlled trial. Am J Clin Nutr. 2013;97(4):774-81.

455. Kelishadi R, Salek S, Salek M, Hashemipour M, Movahedian M. Effects of vitamin D supplementation on insulin resistance and cardiometabolic risk factors in children with metabolic syndrome: a triple-masked controlled trial. J Pediatr. 2014;90(1):28-34.

456. Poomthavorn P, Nantarakchaikul P, Mahachoklertwattana P, Chailurkit LO, Khlairit P. Effects of correction of vitamin D insufficiency on serum osteocalcin and glucose metabolism in obese children. Clin Endocrinol. 2014;80(4):516-23.

457. Nader NS, Aguirre Castaneda R, Wallace J, Singh R, Weaver A, Kumar S. Effect of vitamin $D_{3}$ supplementation on serum $25(\mathrm{OH}) \mathrm{D}$, lipids and markers of insulin resistance in obese adolescents: a prospective, randomized, placebo controlled pilot trial. Horm Res Paediatr. 2014;82(2):107-12.

458. Shah S, Wilson DM, Bachrach LK. Large doses of vitamin D fail to increase 25-hydroxyvitamin D levels or to alter cardiovascular risk factors in obese adolescents: a pilot study. J Adolesc Health. 2015;57(1):19-23. 
459. Javed A, Vella A, Balagopal PB, Fischer PR, Weaver AL, Piccinini F, et al. Cholecalciferol supplementation does not influence $\beta$-cell function and insulin action in obese adolescents: a prospective double-blind randomized trial. J Nutr. 2015;145(2):284-90.

460. Della Corte C, Carpino G, De Vito R, De Stefanis C, Alisi A, Cianfarani S, et al. Docosahexanoic acid plus vitamin D treatment improves features of NAFLD in children with serum vitamin D deficiency: results from a single Centre trial. PLoS One. 2016;11(12):e0168216.

461. Jamka M, Woźniewicz M, Jeszka J, Mardas M, Bogdański P, Stelmach-Mardas M. The effect of vitamin D supplementation on insulin and glucose metabolism in overweight and obese individuals: systematic review with meta-analysis. Sci Rep. 2015;5:16142.

462. Jamka M, Woźniewicz M, Walkowiak J, Bogdański P, Jeszka J, Stelmach-Mardas M. The effect of vitamin D supplementation on selected inflammatory biomarkers in obese and overweight subjects: a systematic review with meta-analysis. Eur J Nutr. 2016;55(6):2163-76.

463. Rajakumar K, Fernstrom JD, Holick MF, Janosky JE, Greenspan SL. Vitamin D status and response to vitamin $\mathrm{D}(3)$ in obese vs. non-obese African American children. Obesity (Silver Spring). 2008;16(1):90-5.

464. Aguirre Castaneda R, Nader N, Weaver A, Singh R, Kumar S. Response to vitamin $D_{3}$ supplementation in obese and non-obese Caucasian adolescents. Horm Res Paediatr. 2012;78(4):226-31.

465. Radhakishun NN, van Vliet M, Poland DC, Weijer O, Beijnen JH, Brandjes DP, et al. Efficacy and tolerability of a high loading dose (25,000 IU weekly) vitamin $D_{3}$ supplementation in obese children with vitamin D insufficiency/ deficiency. Horm Res Paediatr. 2014;82(2):103-6.

466. Motlaghzadeh Y, Sayarifard F, Allahverdi B, Rabbani A, Setoodeh A, Sayarifard $A$, et al. Assessment of vitamin D status and response to vitamin $D_{3}$ in obese and non-obese Iranian children. J Trop Pediatr. 2016;62(4):269-75.

467. Javed A, Kullo IJ, Balagopal PB, Kumar S. Effect of vitamin $D_{3}$ treatment on endothelial function in obese adolescents. Pediatr Obes. 2016;11(4):279-84.

468. Szlagatys-Sidorkiewicz A, Brzeziński M, Jankowska A, Metelska P, Słomińska-Frączek M, Socha P. Long-term effects of vitamin D supplementation in vitamin $\mathrm{D}$ deficient obese children participating in an integrated weight-loss programme (a double-blind placebo-controlled study) - rationale for the study design. BMC Pediatr. 2017;17(1):97.

469. Grant WB, Soles CM. Epidemiologic evidence supporting the role of maternal vitamin $D$ deficiency as a risk factor for the development of infantile autism. Dermatoendocrinol. 2009;1(4):223-8.

470. Grant WB, Cannell JJ. Autism prevalence in the United States with respect to solar UV-B doses: an ecological study. Dermatoendocrinol. 2013;5(1):159-64.

471. Kinney DK, Barch DH, Chayka B, Napoleon S, Munir KM. Environmental risk factors for autism: do they help cause de novo genetic mutations that contribute to the disorder? Med Hypotheses. 2010;74(1):102-6.

472. Cannell JJ, Grant WB. What is the role of vitamin D in autism? Dermatoendocrinol. 2013;5(1):199-204.

473. Cannell JJ. Vitamin D and autism, what's new? Rev Endocr Metab Disord. 2017;18(2):183-93.

474. Mostafa GA, AL-Ayadhi LY. Reduced serum concentrations of 25-hydroxy vitamin $D$ in children with autism: relation to autoimmunity. J Neuroinflammation. 2012;9:201.

475. Anderson G, Maes M. Redox regulation and the autistic spectrum: role of tryptophan catabolites, immuno-inflammation, autoimmunity and the amygdala. Curr Neuropharmacol. 2014;12(2):148-67.

476. Neggers YH. Increasing prevalence, changes in diagnostic criteria, and nutritional risk factors for autism spectrum disorders. ISRN Nutr. 2014;2014:514026.

477. Bener A, Khattab AO, Al-Dabbagh MM. Is high prevalence of vitamin D deficiency evidence for autism disorder?: in a highly endogamous population. J Pediatr Neurosci. 2014;9(3):227-33.

478. Zimmer MH, Hart LC, Manning-Courtney P, Murray DS, Bing NM, Summer S. Food variety as a predictor of nutritional status among children with autism J Autism Dev Disord. 2012;42(4):549-56.

479. Graf-Myles J, Farmer C, Thurm A, Royster C, Kahn P, Soskey L, et al. Dietary adequacy of children with autism compared to controls and the impact of restricted diet. J Dev Behav Pediatr. 2013;34(7):10.

480. Wang T, Shan L, Du L, Feng J, Xu Z, Staal WG, Jia F. Serum concentration of 25-hydroxyvitamin D in autism spectrum disorder: a systematic review and meta-analysis. Eur Child Adolesc Psychiatry. 2016;25(4):341-50.

481. Jia F, Wang B, Shan L, Xu Z, Staal WG, Du L. Core symptoms of autism improved after vitamin D supplementation. Pediatrics. 2015;135(1):e196-8.
482. Saad K, Abdel-Rahman AA, Elserogy YM, Al-Atram AA, Cannell JJ, Bjørklund G, et al. Vitamin D status in autism spectrum disorders and the efficacy of vitamin D supplementation in autistic children. Nutr Neurosci. 2016;19(8):346-51.

483. Saad K, Abdel-Rahman AA, Elserogy YM, Al-Atram AA, El-Houfey AA, Othman HA, et al. Randomized controlled trial of vitamin D supplementation in children with autism spectrum disorder. J Child Psychol Psychiatry. 2016; https://doi.org/10.1111/jcpp.12652.

484. Feng J, Shan L, Du L, Wang B, Li H, Wang W, et al. Clinical improvement following vitamin $D_{3}$ supplementation in autism spectrum disorder. Nutr Neurosci. 2017;20(5):284-90.

485. Kerley CP, Power C, Gallagher L, Coghlan D. Lack of effect of vitamin $D_{3}$ supplementation in autism: a 20-week, placebo-controlled RCT. Arch Dis Child. 2017:102:1030-6.

486. Thapar A, Collishaw S, Potter R, Thapar AK. Managing and preventing depression in adolescents. BMJ. 2010;340:c209.

487. Drevets WC, Price JL, Furey ML. Brain structural and functional abnormalities in mood disorders: implications for neurocircuitry neurocircuitry models of depression. Brain Struct Funct. 2008;213(1-2):93-118.

488. Eyles DW, Smith S, Kinobe R, Hewison M, McGrath JJ. Distribution of the vitamin $\mathrm{D}$ receptor and 1 alpha-hydroxylase in human brain. J Chem Neuroanat. 2005;29(1):21-30.

489. Bertone-Johnson ER. Vitamin D and the occurrence of depression: causal association or circumstantial evidence? Nutr Rev. 2009;67(8):481-92.

490. Tolppanen AM, Sayers A, Fraser WD, Lewis G, Zammit S, Lawlor DA. The association of 25-hydroxyvitamin $D_{3}$ and $D_{2}$ with behavioural problems in childhood. PLoS One. 2012;7(7):e40097.

491. Högberg G, Gustafsson SA, Hällström T, Gustafsson T, Klawitter B, Petersson M. Depressed adolescents in a case-series were low in vitamin D and depression was ameliorated by vitamin D supplementation. Acta Paediatr. 2012;101(7):779-83.

492. Smith BA, Cogswell A, Garcia G. Vitamin D and depressive symptoms in children with cystic fibrosis. Psychosomatics. 2014;55(1):76-81.

493. Fazeli PK, Mendes N, Russell M, Herzog DB, Klibanski A, Misra M. Bone density characteristics and major depressive disorder in adolescents. Psychosom Med. 2013;75(2):117-23.

494. Tolppanen AM, Sayers A, Fraser WD, Lewis G, Zammit S, Lawlor DA. The association of serum 25-hydroxyvitamin $D_{3}$ and $D_{2}$ with depressive symptoms in childhood-a prospective cohort study. J Child Psychol Psychiatry. 2012;53(7):757-66.

495. Spedding S. Vitamin D and depression: a systematic review and metaanalysis comparing studies with and without biological flaws. Nutrients. 2014;6(4):1501-18.

496. Shaffer JA, Edmondson D, Wasson LT, Falzon L, Homma K, Ezeokoli N, et al. Vitamin D supplementation for depressive symptoms: a systematic review and meta-analysis of randomized controlled trials. Psychosom Med. 2014;76(3):190-6.

497. Gowda U, Mutowo MP, Smith BJ, Wluka AE, Renzaho AM. Vitamin D supplementation to reduce depression in adults: meta-analysis of randomized controlled trials. Nutrition. 2015;31(3):421-9.

498. Gaggero M, Mariani L, Guarino R, Patrucco G, Ballardini G, Boscardini L, et al. Vitamin $D$ at term of pregnancy and during lactation in white and black women living in northern Italy. Minerva Ginecol. 2010;62(2):91-6.

499. Kovacs CS. Vitamin D in pregnancy and lactation: maternal, fetal, and neonatal outcomes from human and animal studies. Am J Clin Nutr. 2008;88(2):520S-8S.

500. Black RE, Victora CG, Walker SP, Bhutta ZA, Christian P, et al. Maternal and child undernutrition and overweight in low-income and middle-income countries. Lancet. 2013;382(9890):427-51.

501. Park H, Brannon PM, West AA, Yan J, Jiang X, Perry CA, et al. Maternal vitamin $\mathrm{D}$ biomarkers are associated with maternal and fetal bone turnover among pregnant women consuming controlled amounts of vitamin D, calcium, and phosphorus. Bone. 2017:95:183-91.

502. Zhang H, Huang Z, Xiao L, Jiang X, Chen D, Wei Y. Meta-analysis of the effect of the maternal vitamin $D$ level on the risk of spontaneous pregnancy loss. Int J Gynaecol Obstet. 2017;138(3):242-9.

503. Qin LL, Lu FG, Yang SH, Xu HL, Luo BA. Does maternal vitamin D deficiency increase the risk of preterm birth: a meta-analysis of observational studies. Nutrients. 2016;8(5):E301.

504. Amegah AK, Klevor MK, Wagner CL. Maternal vitamin D insufficiency and risk of adverse pregnancy and birth outcomes: a systematic review and meta-analysis of longitudinal studies. PLoS One. 2017;12(3):e0173605. 
505. Arnold DL, Enquobahrie DA, Qiu C, Huang J, Grote N, VanderStoep A, Williams MA. Early pregnancy maternal vitamin D concentrations and risk of gestational diabetes mellitus. Paediatr Perinat Epidemiol. 2015;29(3):200-10.

506. Lu M, Xu Y, LV L, Zhang M. Association between vitamin D status and the risk of gestational diabetes mellitus: a meta-analysis. Arch Gynecol Obstet. 2016;293(5):959-66.

507. Song H, Yang L, Jia C. Maternal vitamin D status during pregnancy and risk of childhood asthma: a meta-analysis of prospective studies. Mol Nutr Food Res. 2017;61(5)

508. Wei Z, Zhang J, Yu X. Maternal vitamin D status and childhood asthma, wheeze, and eczema: a systematic review and meta-analysis. Pediatr Allergy Immunol. 2016;27(6):612-9.

509. Yang N, Wang L, Li Z, Chen S, Li N, Ye R. Effects of vitamin D supplementation during pregnancy on neonatal vitamin D and calcium concentrations: a systematic review and meta-analysis. Nutr Res. 2015;35(7):547-56.

510. De-Regil LM, Palacios C, Lombardo LK, Peña-Rosas JP. Vitamin D supplementation for women during pregnancy. Cochrane Database Syst Rev. 2016;1:CD008873.

511. Royal College of Obstetricians \& Gynaecoloists. Vitamin D in pregnancy. Sci Impact Pap. 2017:43:1-11. Available at: https://www.rcog.org.uk/ globalassets/documents/guidelines/scientific-impact-papers/vitamin_d_ sip43_june14.pdf. Accessed 1 Sept 2017.

512. Hollis BW, Johnson D, Hulsey TC, Ebeling M, Wagner CL. Vitamin D supplementation during pregnancy: double-blind, randomized clinical trial of safety and effectiveness. J Bone Miner Res. 2011;26(10):2341-57.

513. Wagner CL, Hollis BW, Kotsa K, Fakhoury H, Karras SN. Vitamin D administration during pregnancy as prevention for pregnancy, neonatal and postnatal complications. Rev Endocr Metab Disord. 2017;18(3):307-22.

514. Wagner CL, Baggerly C, McDonnell S, Baggerly KA, French CB, Baggerly L, et al. Post-hoc analysis of vitamin D status and reduced risk of preterm birth in two vitamin D pregnancy cohorts compared with South Carolina March of Dimes 2009-2011 rates. J Steroid Biochem Mol Biol. 2016;155(Pt B):245.

515. Gordon CM, Williams AL, Feldman HA, May J, Sinclair L, Vasquez A, Cox JE. Treatment of hypovitaminosis D in infants and toddlers. J Clin Endocrinol Metab. 2008;93(7):2716-21.

516. Rao YK, Midha T, Singh S, Bajpai A, Tilak A. Increment in vitamin D level and bone mineral accrual in children with vitamin D deficiency. Korean J Pediatr. 2016;59(7):292-7.

517. Talib HJ, Ponnapakkam T, Gensure R, Cohen HW, Coupey SM. Treatment of vitamin D deficiency in predominantly Hispanic and black adolescents: a randomized clinical trial. J Pediatr. 2016;170:266-72. e1

518. Garg MK, Marwaha RK, Khadgawat R, Ramot R, Obroi AK, Mehan N, et al. Efficacy of vitamin D loading doses on serum 25-hydroxy vitamin D levels in school going adolescents: an open label non-randomized prospective trial. J Pediatr Endocrinol Metab. 2013;26(5-6):515-23.

519. Goswami R, Vatsa M, Sreenivas V, Singh U, Gupta N, Lakshmy R, et al. Skeletal muscle strength in young Asian Indian females after vitamin D and calcium supplementation: a double-blind randomized controlled clinical trial. J Clin Endocrinol Metab. 2012;97(12):4709-16.

520. Maalouf J, Nabulsi M, Vieth R, Kimball S, El-Rassi R, Mahfoud Z, El-Hajj Fuleihan G. Short- and long-term safety of weekly high-dose vitamin D3 supplementation in school children. J Clin Endocrinol Metab. 2008;93(7):2693-701.

521. Talaat IM, Kamal NM, Alghamdi HA, Alharthi AA, Alshahrani MA. A randomized clinical trial comparing 3 different replacement regimens of vitamin D in clinically asymptomatic pediatrics and adolescents with vitamin D insufficiency. Ital J Pediatr. 2016;42(1):106.

522. Soliman AT, Adel A, Wagdy M, Alali M, Aziz Bedair EM. Manifestations of severe vitamin $D$ deficiency in adolescents: effects of intramuscular injection of a megadose of cholecalciferol. J Trop Pediatr. 2011;57(4):303-6.

523. Koçyiğit C, Çatlı G, Ince G, Özkan EB, Dündar BN. Can stoss therapy be used in children with vitamin D deficiency or insufficiency without rickets? J Clin Res Pediatr Endocrinol. 2017;9(2):150-5.

524. Kakalia S, Sochett EB, Stephens D, Assor E, Read SE, Bitnun A. Vitamin D supplementation and CD4 count in children infected with human immunodeficiency virus. J Pediatr. 2011;159(6):951-7.

525. Groleau V, Herold RA, Schall Jl, Wagner JL, Dougherty KA, Zemel BS, et al. Blood lead concentration is not altered by high-dose vitamin D supplementation in children and young adults with HIV. J Pediatr Gastroenterol Nutr. 2013;56(3):316-9.

526. Schall II, Hediger ML, Zemel BS, Rutstein RM, Stallings VA. Comprehensive safety monitoring of 12 -month daily $7000-I U$ vitamin $D_{3}$ supplementation in human immunodeficiency virus-infected children and young adults. JPEN J Parenter Enteral Nutr. 2016:40(7):1057-63.

527. Stallings VA, Schall J, Hediger ML, Zemel BS, Tuluc F, Dougherty KA, et al. High-dose vitamin $D_{3}$ supplementation in children and young adults with HIV: a randomized, placebo-controlled trial. Pediatr Infect Dis J. 2015:34(2):e32-40.

528. Havens PL, Mulligan K, Hazra R, Flynn P, Rutledge B, Van Loan MD, et al. Serum 25-hydroxyvitamin $D$ response to vitamin $D_{3}$ supplementation 50,000 IU monthly in youth with HIV-1 infection. J Clin Endocrinol Metab. 2012;97(11):4004-13.

529. Arpadi SM, McMahon D, Abrams EJ, Bamji M, Purswani M, Engelson ES, et al. Effect of bimonthly supplementation with oral cholecalciferol on serum 25-hydroxyvitamin D concentrations in HIV-infected children and adolescents. Pediatrics. 2009;123(1):e121-6.

530. Arpadi SM, McMahon DJ, Abrams EJ, Bamji M, Purswani M, Engelson ES, et al. Effect of supplementation with cholecalciferol and calcium on 2-y bone mass accrual in HIV-infected children and adolescents: a randomized clinical trial. Am J Clin Nutr. 2012;95(3):678-85.

531. Mikati MA, Dib L, Yamout B, Sawaya R, Rahi AC, Fuleihan G-H. Two randomized vitamin $D$ trials in ambulatory patients on anticonvulsants: impact on bone. Neurology. 2006;67(11):2005-14.

\section{Ready to submit your research? Choose BMC and benefit from:}

- fast, convenient online submission

- thorough peer review by experienced researchers in your field

- rapid publication on acceptance

- support for research data, including large and complex data types

- gold Open Access which fosters wider collaboration and increased citations

- maximum visibility for your research: over $100 \mathrm{M}$ website views per year

At BMC, research is always in progress.

Learn more biomedcentral.com/submissions 